OAK RIDGE
NATIONAL LABORATORY

MANAGED BY UT-BATTELLE FOR THE DEPARTMENT OF ENERGY
ORNL/TM-2013/4

\section{High Pressure Response of Siliceous Materials}

A. A. Wereszczak, ${ }^{*}$ T. G. Morrissey, M. K. Ferber, K. P. Bortle, and E. A. Rodgers Ceramic Science and Technology Group Materials Science and Technology Division Oak Ridge National Laboratory

Oak Ridge, TN 37831

G. Tsoi, J. M. Montgomery, and Y. K. Vohra Department of Physics

University of Alabama-Birmingham

Birmingham, AL 35294

\author{
S. Toller \\ LSP Technologies \\ Dublin, OH 43016 \\ * Corresponding Author: \\ wereszczakaa@ornl.gov
}

Publication Date: February 2013

Prepared by the OAK RIDGE NATIONAL LABORATORY

Oak Ridge, Tennessee 37831

managed by

UT-BATTELLE, LLC

for the

U.S. DEPARTMENT OF ENERGY

Under contract DE-AC05-00OR22725

UT-BATTELLE

ORNL-27 (4-00)
US ARMY TARDEC

DISTRIBUTION STATEMENT A.

Approved for public release; distribution unlimited. 


\section{DOCUMENT AVAILABILITY}

Reports produced after January 1, 1996, are generally available free via the U.S. Department of Energy (DOE) Information Bridge:

Web site: $h$ ttp://www.osti.gov/bridge

Reports produced before January 1, 1996, may be purchased by members of the public from the following source:

National Technical Information Service

5285 Port Royal Road

Springfield, VA 22161

Telephone: 703-605-6000 (1-800-553-6847)

TDD: $703-487-4639$

Fax: 703-605-6900

E-mail: info@ntis.fedworld.gov

Web site: http://www.ntis.gov/support/ordernowabout.htm

Reports are available to DOE employees, DOE contractors, Energy Technology Data Exchange (ETDE) representatives, and International Nuclear Information System (INIS) representatives from the following source:

Office of Scientific and Technical Information

P.O. Box 62

Oak Ridge, TN 37831

Telephone: $865-576-8401$

Fax: 865-576-5728

E-mail: reports@osti.gov

Web site: http://www.osti.gov/contact.html

This report was prepared as an account of work sponsored by an agency of the United States Government. Neither the United States government nor any agency thereof, nor any of their employees, makes any warranty, express or implied, or assumes any legal liability or responsibility for the accuracy, completeness, or usefulness of any information, apparatus, product, or process disclosed, or represents that its use would not infringe privately owned rights. Reference herein to any specific commercial product, process, or service by trade name, trademark, manufacturer, or otherwise, does not necessarily constitute or imply its endorsement, recommendation, or favoring by the United States Government or any agency thereof. The views and opinions of authors expressed herein do not necessarily state or reflect those of the United States Government or any agency thereof. 


\section{TABLE OF CONTENTS}

Page

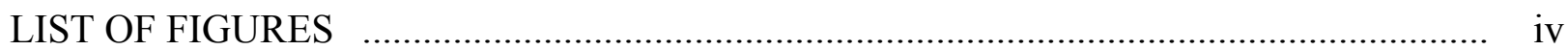

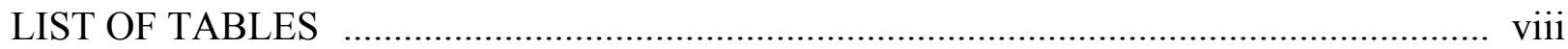

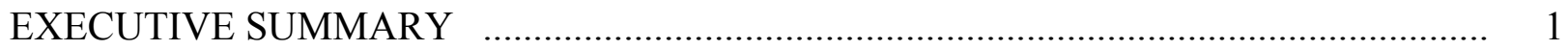

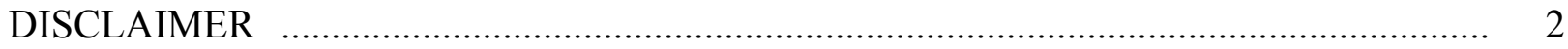

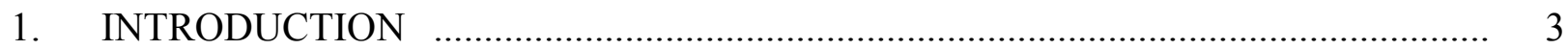

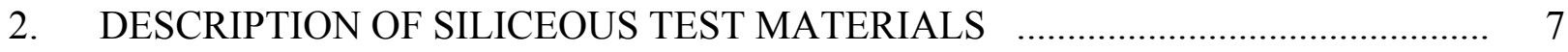

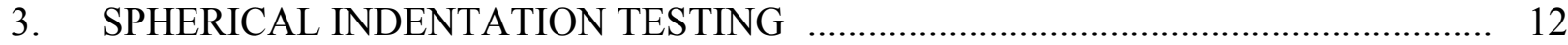

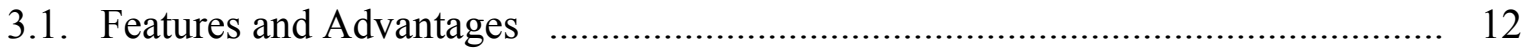

3.2. Indentation Stress Field ............................................................................. 13

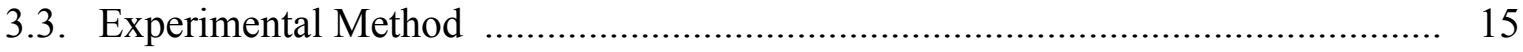

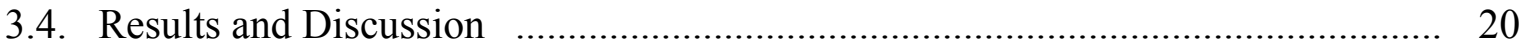

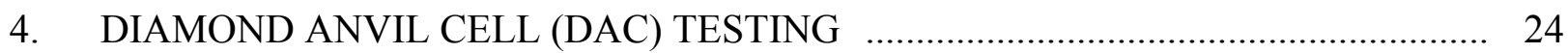

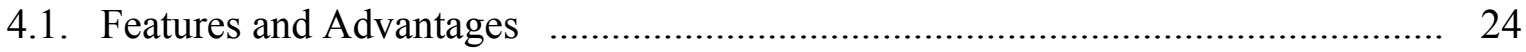

4.2. DAC Stress Field .................................................................................... 26

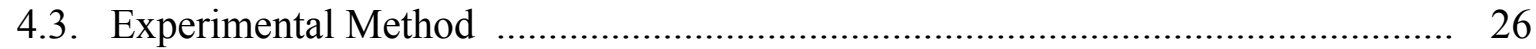

4.4. Results and Discussion ........................................................................ 27

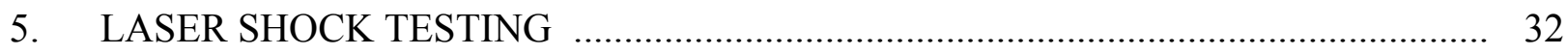

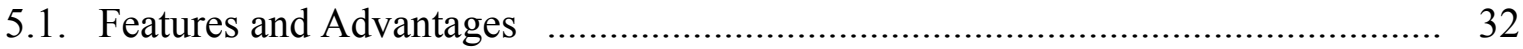

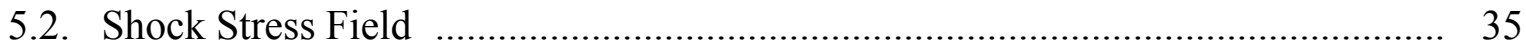

5.3. Experimental Method ................................................................................ 36

5.4. Results and Discussion .................................................................... 38

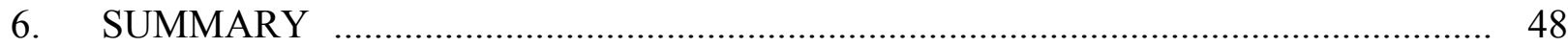

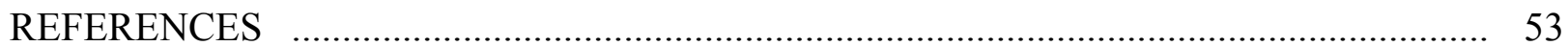

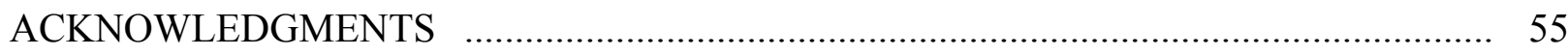

APPENDIX I: List of Spherical Indentation Results ................................................. 56

APPENDIX II: List of Laser Shock Results ....................................................... 57 


\section{LIST OF FIGURES}

Figure

Page

1.1. Silica structure diagram after Sosman [2]. .................................................... 3

1.2. Fused silica densification response as a function of pressure after Bridgman [4]. .... 4

1.3. Densification as a function of temperature at $3 \mathrm{GPa}$ for a number of alkali silicate

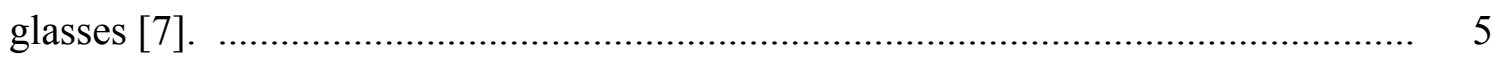

1.4. Densification of various glasses as a function stress [10]. .................................... 5

2.1. Fused silica (or fused quartz) glass. .................................................................. 8

2.2. Starphire soda lime silicate glass. .................................................................. 8

2.3. Hydrated Starphire soda lime silicate glass (white flaked). .................................... 9

2.4. BOROFLOAT borosilicate glass. .................................................................. 9

2.5. Iron-containing soda lime silicate glass. ....................................................... 10

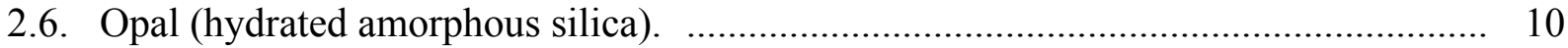

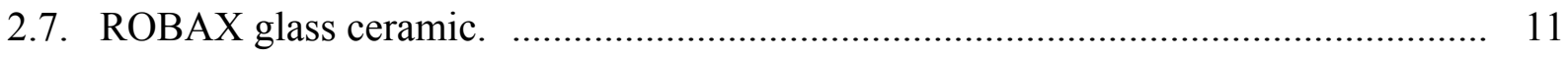

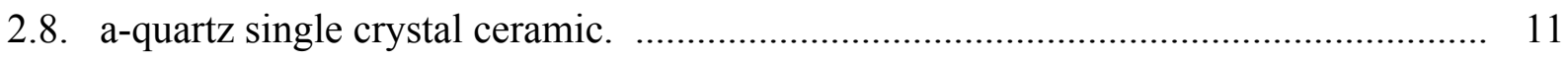

2.9. Coesite polycrystalline ceramic. Coesite is a high pressure phase of quartz. ........... 12

3.1. Stress fields associated with spherical (Hertzian) indentation (right side of schematic).

3.2. Zwick microindentation system (left) was used for the spherical indentation.

Close-up of the indenter depth sensor making contact (right) with sample (indenter not visible).

3.3. Schematic of the indenter and indenter depth of penetration measurement system. .. 16

3.4. Example of a generated load-unload profile from a spherical indentation test. $\ldots . . . . . \quad 17$

3.5. Although the manufacturer reported the indenter radius to be $150 \mu \mathrm{m}$, two different measurement methods showed the actual radius to be smaller. A radius of $110 \mu \mathrm{m}$ was used for all the stress calculations. 


\section{LIST OF FIGURES (Continued)}

Figure

Page

3.6. ORNL-developed software enabled the identification where apparent yielding initiated.

3.7. Enlarged region of load (P) indent depth of penetration $(y)$ where theoretical curve diverges from experimental curve.

3.8. A portrayal of the indenter depth of penetration to load ratio $(\mathrm{y} / \mathrm{P})$ as a function of y sometimes was effective at helping the user identify the divergence.

3.9. Comparison of the average apparent yield stress for all the indented siliceous materials.

3.10. Comparison of the calculated Hugoniot Elastic Limit from apparent yield stress values with literature HEL values. 23

4.1. Schematic of the diamond anvil cell test. 24

4.2. Sample and ruby mounted in the diamond anvil cell. 25

4.3. Peak ships for the ruby are used to determine stress. 25

4.4. Stress state produced by diamond anvil cell testing. 26

4.5. Raman spectrum as a function of stress for fused silica. 28

4.6. Raman spectrum as a function of stress for Starphire soda lime silicate glass. 28

4.7. Raman spectrum as a function of stress for BOROFLOAT borosilicate glass. 29

4.8. Raman spectrum as a function of stress for opal (hydrated silica) glass. 29

4.9. Raman spectrum as a function of stress for hydrated Starphire soda lime silicate glass. 30

4.10. Raman spectrum as a function of stress for ROBAX glass ceramic. 30

4.11. Raman spectrum as a function of stress for a-Quartz. 31

4.12. Raman spectrum as a function of stress for Coesite. 31 


\section{LIST OF FIGURES (Continued)}

Figure

Page

5.1. Setup of laser shock system. 33

5.2. Schematic of laser shock process. 33

5.3. Exceeding the Hugoniot elastic limit (HEL) will deform the target material. 34

5.4. Impact pressure is a function of applied power density. 34

5.5. Stress fields associated with uniform loading of laser shock (left side of schematic).

5.6. One dimensional P-wave propagation curves showing (a) compressive wave just prior to reaching back surface, and the initial interaction of compressive and reflected tensile waves during (b) early, (c) mid, and (d) late stages of reflection. $\mathrm{P}$-wave speeds were $>5500 \mathrm{~m} / \mathrm{s}$ in the tested materials. 36

5.7. Layout of laser shock tests on test tiles.

5.8. Graphical example of onset of impact-side damage as a function of pressure for the tin side of Starphire soda lime silicate glass. Zero represents no damage whereas a value of one means damage occurred.

5.9. Minimum laser shock pressure needed to initiate damage on the contact side.

5.10. Shock damage on fused silica glass. Shown values are the applied pressure in GPa.

5.11. Shock damage on the tin side of Starphire soda lime silicate glass. Shown values are the applied pressure in GPa.

5.12. Shock damage on the tin side of BOROFLOAT borosilicate glass. Shown values are the applied pressure in GPa.

5.13. Example of multiple failure initiation locations on laser shock impacted Starphire soda lime silicate glass.

5.14. Example of multiple failure initiation locations on laser shock impacted BOROFLOAT borosilicate glass. 


\section{LIST OF FIGURES (Continued)}

5.15. Side view of a surface-located damage zone caused by laser shock. 44

5.16. Side view of an interior damage zone caused by laser shock.

5.17. Minimum pressure to initiate shock damage increased with ring crack initiation force measured using spherical indentation in a previous study by the authors [19-21].

5.18. Minimum pressure to initiative shock damage increased with ball impact ring crack initiation force measured in a previous study by the authors [22-24].

5.19. There was no correlation between onset of laser-shock-induced damage on the impact surface and apparent yield stress. 


\section{LIST OF TABLES}

Table

Page

2.1. Material and Test Matrix. …........................................................................ 7

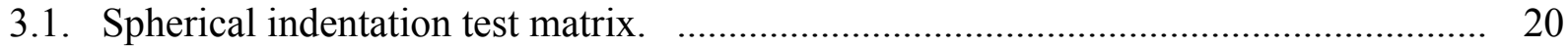

3.2. Summary of spherical indentation results. ...................................................... 22

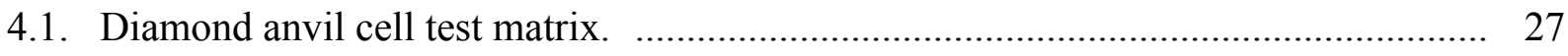

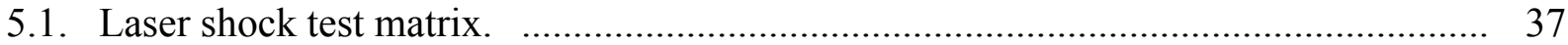

5.2. Estimated crack propagation speeds. ….............................................................. 43 


\section{EXECUTIVE SUMMARY}

Several siliceous (i.e., materials containing, resembling, relating to or consisting of silica or silicon dioxide) materials were examined in this study conducted by Oak Ridge National Laboratory and sponsored by the US Army TARDEC. Some were glasses (fused silica or fused quartz, Starphire soda lime silicate glass, hydrated Starphire, BOROFLOAT borosilicate glass, an iron-containing soda lime silicate glass, opal (a hydrated silicate glass), ROBAX glass ceramic, and others were single crystal ( $\alpha$-quartz) and polycrystalline (Coesite - a high pressure phase of crystalline quartz) ceramics. Some of these materials are presently used in transparent armor systems or are under consideration for such. The testing of these materials allowed for comparisons of glass types, glass versus glass ceramics, effect of water content, and comparison of amorphous versus crystalline materials of the same composition.

The responses of these materials to high pressure loading were studied using spherical indentation testing, diamond anvil cell testing, and laser shock testing. So besides the focus of this study being on the siliceous materials, as much emphasis was placed on the efficacy of these three test methods to exploit high pressure responses. Each test is different and enables the study of different aspects of high pressure response as highlighted below.

1. Spherical indentation, when using small indenter diameters, produces both high pressure and shear, and the loading and unloading histories enabled quantification of apparent yield stress and semi-quantification of energy absorption capability (hysteresis) of the various siliceous materials.

2. Diamond anvil cell testing produces a hydrostatic stress, and when concurrently used with Raman Spectroscopy, enabled the potential identification of changes of state of material as a function of quantified pressure for the various siliceous materials. Permanent densification was also detectable.

3. Laser shock testing produces high pressures but under dynamic conditions (impact event less than $30 \mathrm{~ns}$ ), so this enabled the study of the effect of rate on high pressure. A previously unobserved damage mechanism was revealed with this testing, and the 
ease or difficulty of laser-shock-induced damage initiation was deemed to be relatable to the native surface flaw population that exists on these materials.

\section{DISCLAIMER}

Reference herein to any specific commercial company, product, process, or service by trade name, trademark, manufacturer, or otherwise, does not necessarily constitute or imply its endorsement, recommendation, or favoring by the United States Government or the Department of the Army (DoA). The opinions of the authors expressed herein do not necessarily state or reflect those of the United States Government or the DoA, and shall not be used for advertising or product endorsement purposes.

As the authors are not Government employees, this document was only reviewed for export controls, and improper Army association or emblem usage considerations. All other legal considerations are the responsibility of the authors and their employers. 


\section{INTRODUCTION}

The ballistic impact of transparent armor materials often involve the imposition of very high pressures. Transparent armor materials are almost always silicate (siliceous) based either in the form of glass or glass ceramics, and can exist in many forms and phases if crystalline (see Fig. 1.1).

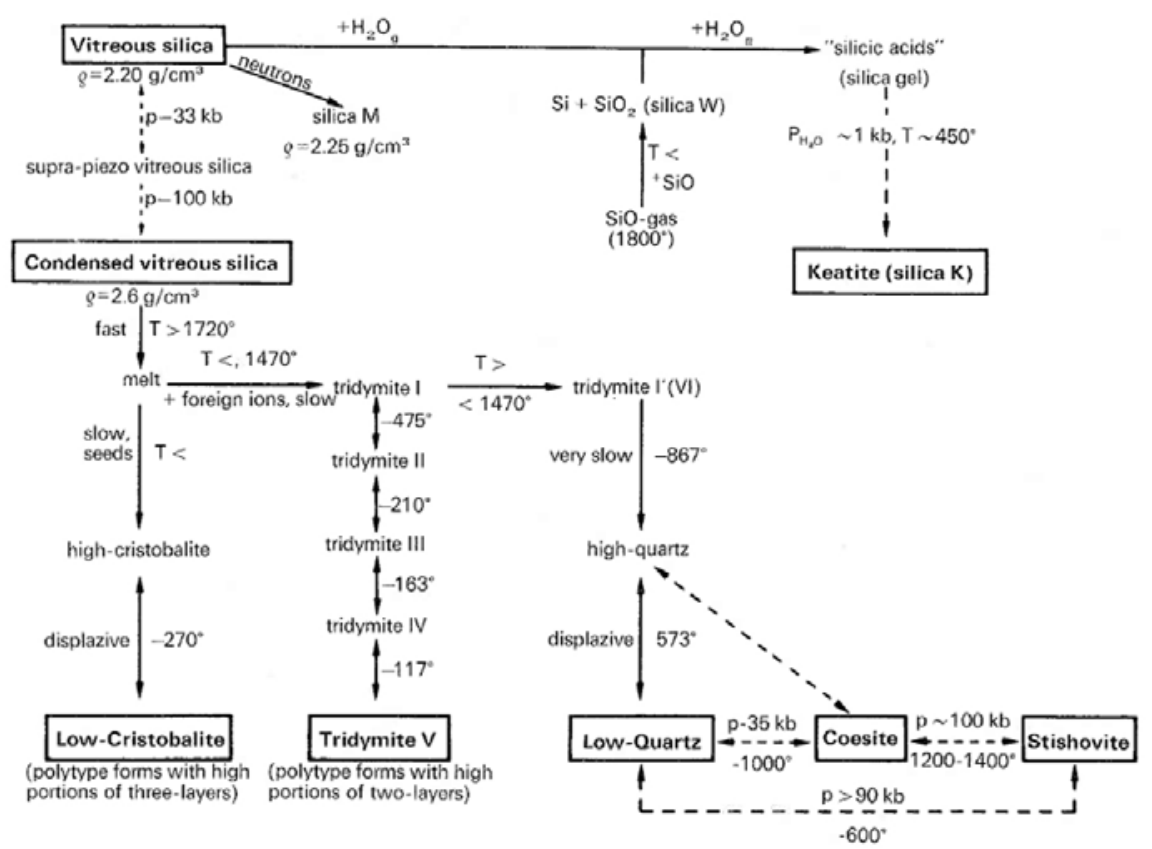

Figure 1.1. Silica structure diagram after Sosman [2].

The discussion and interpretation of high pressure response of siliceous based materials has continued for several decades now and arose from recognized pioneering work by Robert B. Sosman (regarding all things silica) and 1947 Nobel Prize recipient Percy W. Bridgman (high pressure testing). The authors of the present report do not provide a history of this discussion nor of the extensive amount of work that has occurred since then; however, the reader is directed toward selected References [1-10] should interest exist in reviewing some of the more classical literature and useful reviews. 
A statement of stress or pressure units and their conversions is important when surveying the literature in context to the testing completed in this study; namely

$$
1 \mathrm{GPa}=1,000 \mathrm{MPa}=10 \mathrm{kbar} \approx 10,000 \mathrm{~kg} \bullet \mathrm{cm}^{-2} \approx 10,000 \mathrm{~atm} .
$$

The present study's authors use GPa for pressures generated in their testing whereas the other shown units of pressure in Eq. 1 are also often used in the literature.

Relatively large densifications of glass under pressure are known to exist with initiations occurring as low as a few GPa, as shown in Fig. 1.2, and is known to be a strong function of the glass's chemistry (Figs. 1.3-1.4). Additionally, the amount of water in a glass is known to decrease its hardness [11], therefore its role potential densification in a soda lime silicate glass is considerable too.

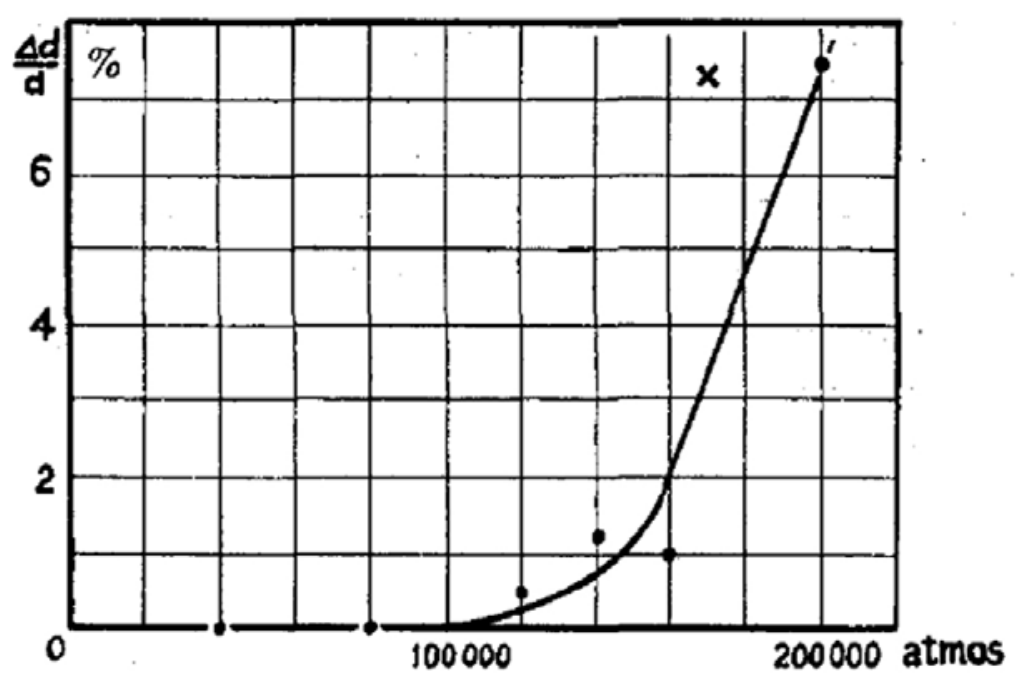

Figure 1.2. Fused silica densification response as a function of pressure after Bridgman [4]. 


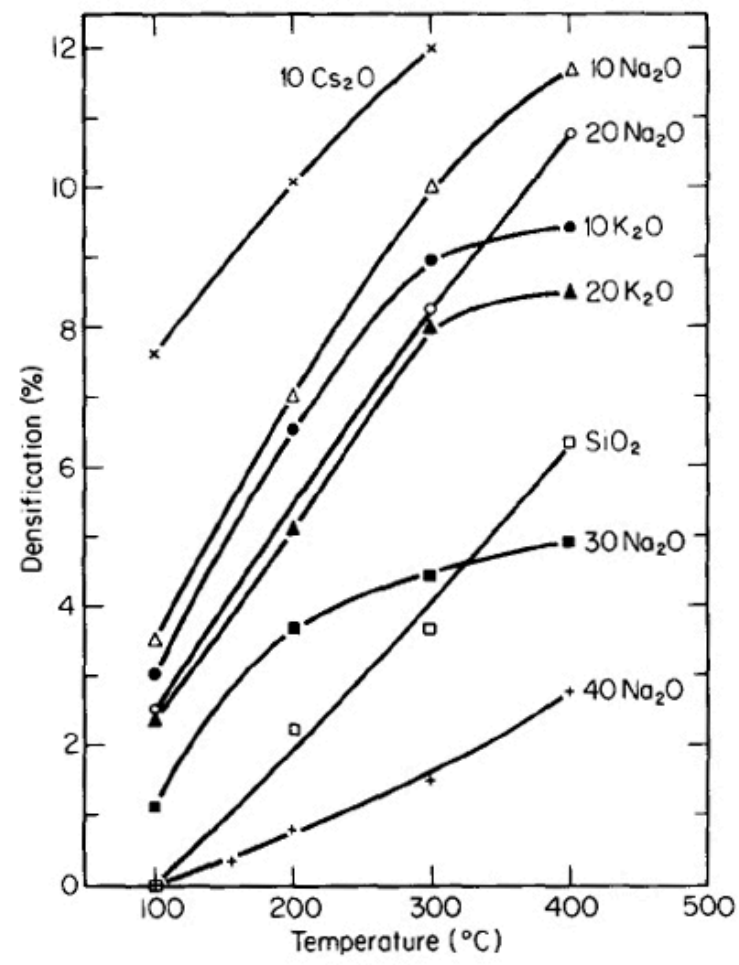

Figure 1.3. Densification as a function of temperature at $3 \mathrm{GPa}$ for a number of alkali silicate glasses [7].

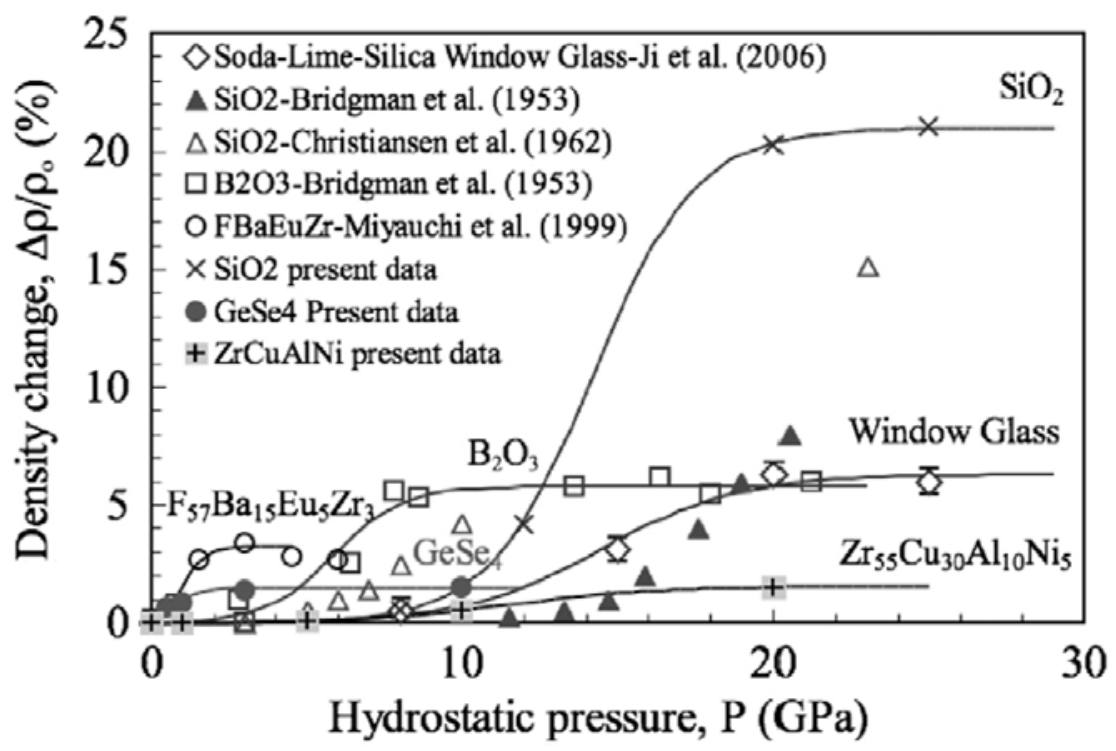

Figure 1.4. Densification of various glasses as a function stress [10]. 
While pressure-induced densification is a sum of reversible and permanent densification, only recently has the latter started to have been accounted for in ballistic modeling [12]. Ballistics testing can produce densification and enable densification's study; however, it is expensive, time consuming, and not always amenable for postmortem material characterization. Consequently ballistic testing as a screening tool is impractical when there are many different potential glass candidates for transparent armor with different compositions. Therefore, three different high-pressure-application test methods were employed in this study to explore the high pressure response of siliceous materials. The methods were:

1. Spherical indentation testing with small indenter diameter. Produces both high pressure and shear, and the loading and unloading histories enables quantification of apparent yield stress and semi-quantification of energy absorption capability (hysteresis). The authors of the present report continue to assert this method is applicable for characterizing high pressure response, and continue to refine its testing protocol and interpretation to satisfy that.

2. Diamond anvil cell testing. Produces a hydrostatic stress, and when concurrently used with Raman Spectroscopy, enables the potential identification of changes of state of material as a function of quantified pressure for the various siliceous materials. Permanent densification is also detectable. Most high pressure studies involve this method.

3. Laser shock testing. Produces high pressures but under dynamic conditions (impact event less than $30 \mathrm{~ns}$ ), so this enables the study of the effect of rate on high pressure. This is a non-standard test; however, the authors of the present report continue to consider its utility because it (1) applies high pressure under dynamic conditions, and (2) does so in the absence of a penetrating projectile thusly enabling the potential deconvolution of shock damage and contact damage.

This study ultimately had two objectives: investigate and compare the response of various siliceous materials to high pressures, and investigate the utility and advantages and disadvantages of these three test methods to impart that high pressure. 


\section{DESCRIPTION OF SILICEOUS TEST MATERIALS}

Several materials were evaluated but not all could be tested using all three test methods (spherical indentation, diamond anvil cell testing, and laser shock testing) owing to specimen size limitations in some cases. A summary of which materials were tested by each test method is listed in Table 2.1. Among all those listed, the responses of four materials (fused silica, Starphire soda lime silicate glass, BOROFLOAT borosilicate glass, and ROBAX glass ceramic) were evaluated by all three test techniques. The air and tin sides of the three float glasses were also tested with all three test methods. The starting material or test coupons for all the listed materials in Table 2.1 are shown in Figs. 2.1-2.9. The physical properties of these materials are disclosed later in Sections 3-5.

Table 2.1. Material and Test Matrix.

\begin{tabular}{|c|c|c|c|c|c|}
\hline $\begin{array}{c}\text { Material } \\
\text { Class } \\
\end{array}$ & $\begin{array}{c}\text { Brand Name } \\
\text { or Description }\end{array}$ & $\begin{array}{c}\text { Manufacturer } \\
\text { or Vendor }\end{array}$ & $\begin{array}{c}\text { Spherical } \\
\text { Indentation } \\
\text { Testing }\end{array}$ & $\begin{array}{c}\text { Diamond } \\
\text { Anvil Cell } \\
\text { Testing } \\
\end{array}$ & $\begin{array}{c}\text { Laser } \\
\text { Shock } \\
\text { Testing }\end{array}$ \\
\hline \multirow{6}{*}{ Glass } & $\begin{array}{l}\text { Fused silica or fused } \\
\text { quartz }\end{array}$ & Quartz Scientific & $\mathrm{X}$ & $\mathrm{X}$ & $\mathrm{X}$ \\
\hline & $\begin{array}{c}\text { Starphire } \\
\text { (soda lime silicate) }\end{array}$ & PPG & $\begin{array}{c}X \\
\text { Air \& Tin } \\
\end{array}$ & $\begin{array}{c}X \\
\text { Air \& Tin } \\
\end{array}$ & $\begin{array}{c}\text { X } \\
\text { Air \& Tin } \\
\end{array}$ \\
\hline & Hydrated Starphire & $\begin{array}{c}\text { PPG } \\
\text { (ORNL modified) }\end{array}$ & & $\mathrm{X}$ & \\
\hline & $\begin{array}{c}\text { BOROFLOAT } \\
\text { (borosilicate) }\end{array}$ & SCHOTT & $\begin{array}{c}X \\
\text { Air \& Tin } \\
\end{array}$ & $\mathrm{X}$ & $\begin{array}{c}\mathrm{X} \\
\text { Air \& Tin } \\
\end{array}$ \\
\hline & $\begin{array}{l}\text { Fe-containing soda } \\
\text { lime silicate }\end{array}$ & $\begin{array}{c}\text { Dulles Glass and } \\
\text { Mirror }\end{array}$ & $\begin{array}{c}\text { X } \\
\text { Air \& Tin } \\
\end{array}$ & & $\begin{array}{c}\mathrm{X} \\
\text { Air \& Tin } \\
\end{array}$ \\
\hline & $\begin{array}{c}\text { Opal } \\
\text { (hydrated silica) }\end{array}$ & $\begin{array}{c}\text { Excalibur Mineral } \\
\text { Corporation }\end{array}$ & $\mathrm{X}$ & $X$ & \\
\hline Glass Ceramic & ROBAX & SCHOTT & $\mathrm{X}$ & $\mathrm{X}$ & $\mathrm{X}$ \\
\hline \multirow{3}{*}{$\begin{array}{l}\text { Single } \\
\text { Crystal } \\
\text { Ceramic }\end{array}$} & $\alpha$-Quartz & \multirow{3}{*}{$\begin{array}{l}\text { Jim Coleman } \\
\text { Crystal Mines }\end{array}$} & & \multirow{3}{*}{$\mathrm{X}$} & \\
\hline & $\begin{array}{c}\alpha-Q u a r t z \\
\{1000\}\end{array}$ & & $\mathrm{X}$ & & \\
\hline & $\begin{array}{c}\alpha-Q u a r t z \\
(0001)\end{array}$ & & $\mathrm{X}$ & & \\
\hline $\begin{array}{c}\text { Polycrystalline } \\
\text { Ceramic }\end{array}$ & Coesite & $\begin{array}{c}\text { Excalibur Mineral } \\
\text { Corporation }\end{array}$ & & $\mathrm{X}$ & \\
\hline
\end{tabular}




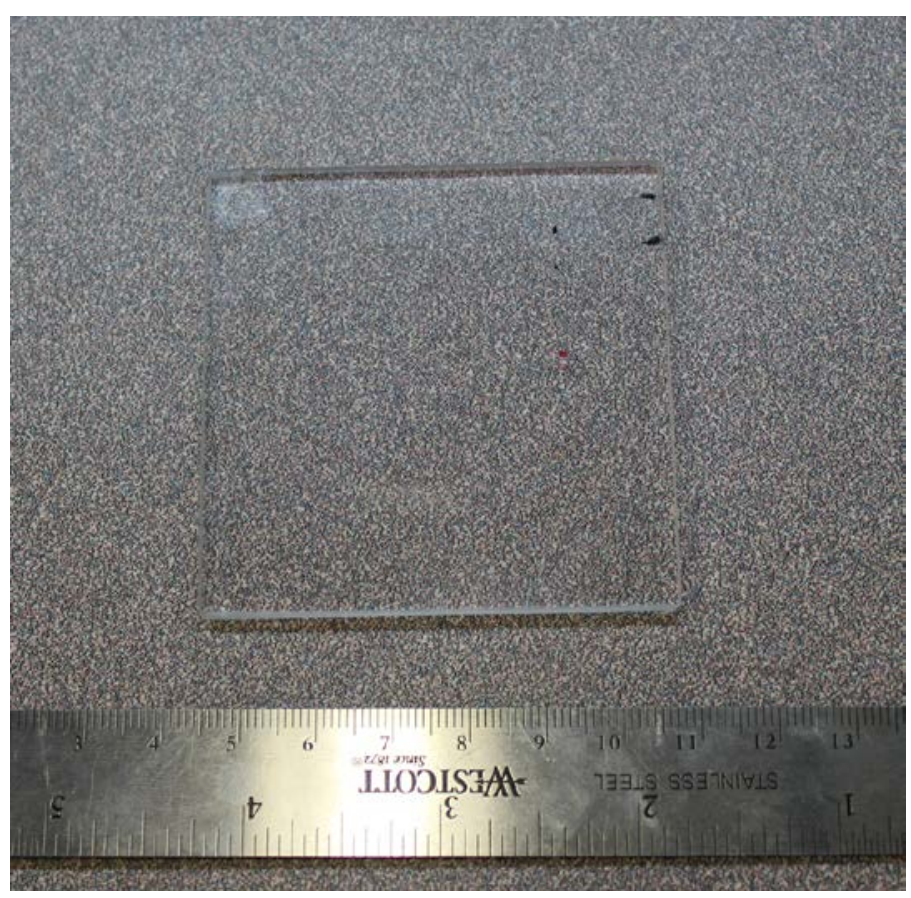

Figure 2.1. Fused silica (or fused quartz) glass.

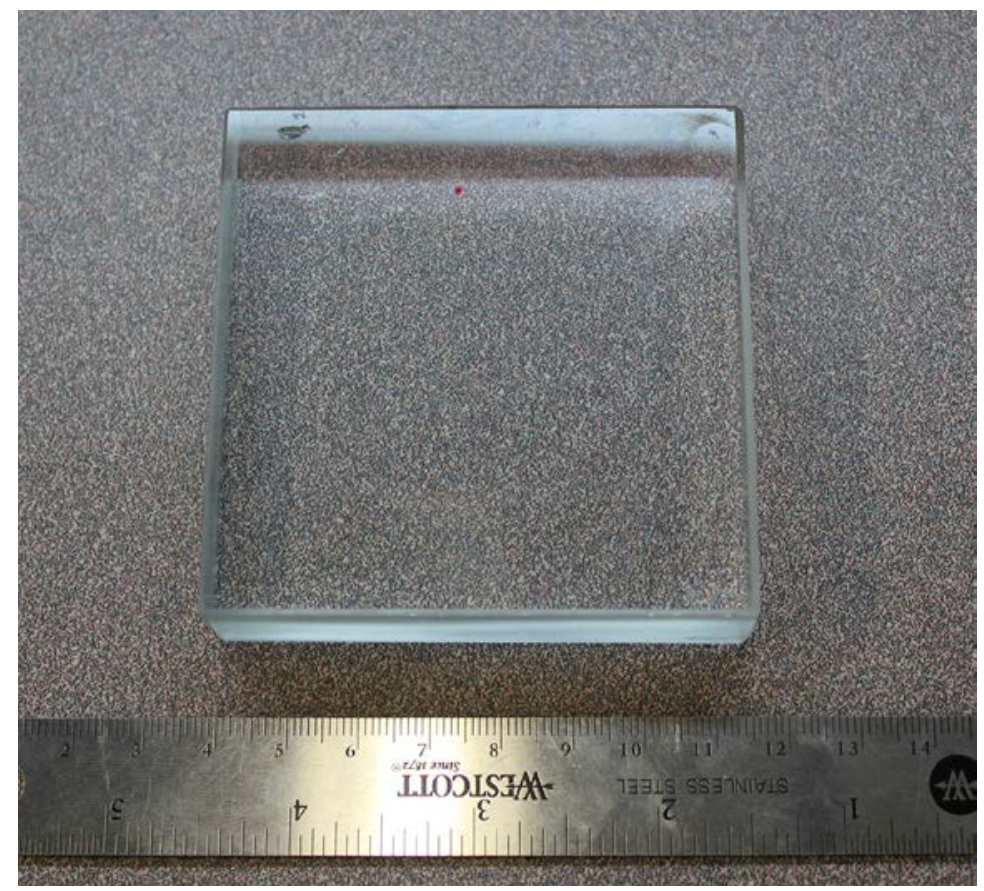

Figure 2.2. Starphire soda lime silicate glass. 


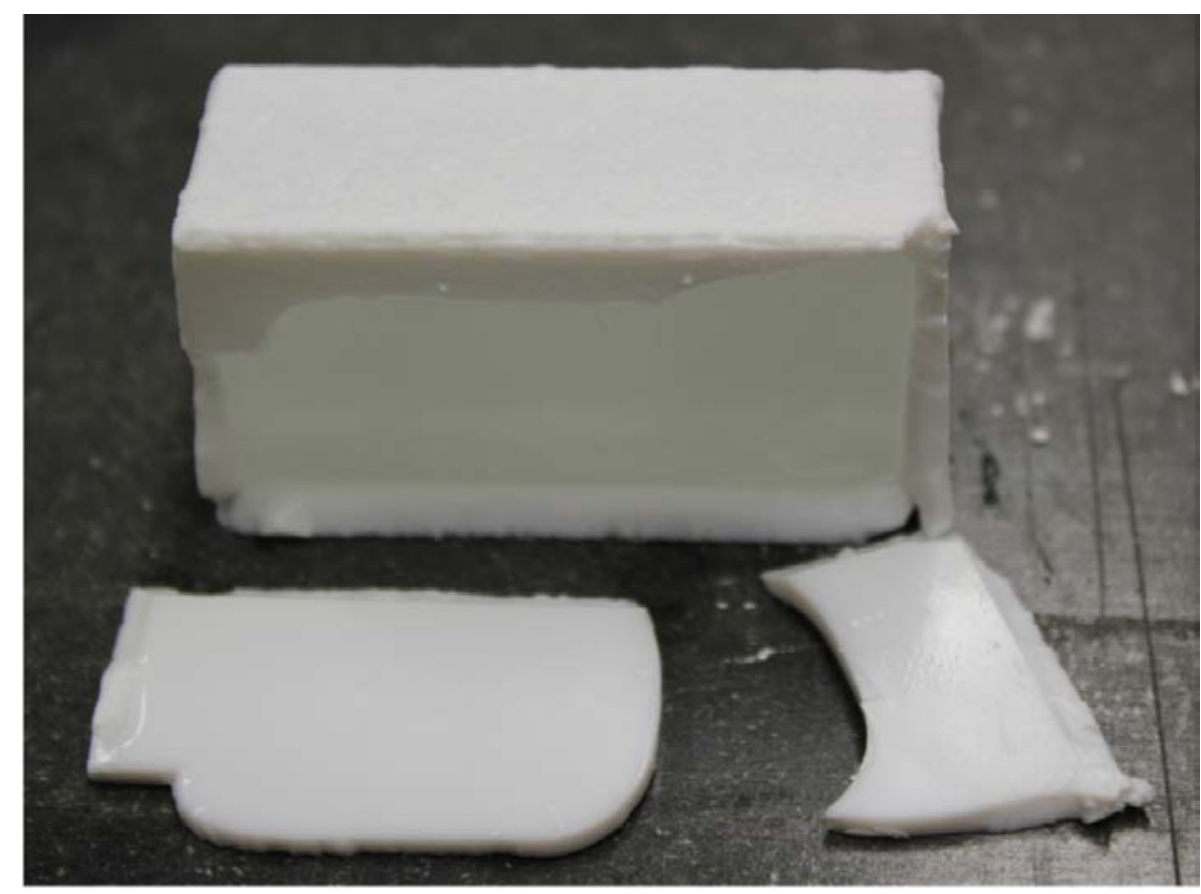

Figure 2.3. Hydrated Starphire soda lime silicate glass (white flaked).

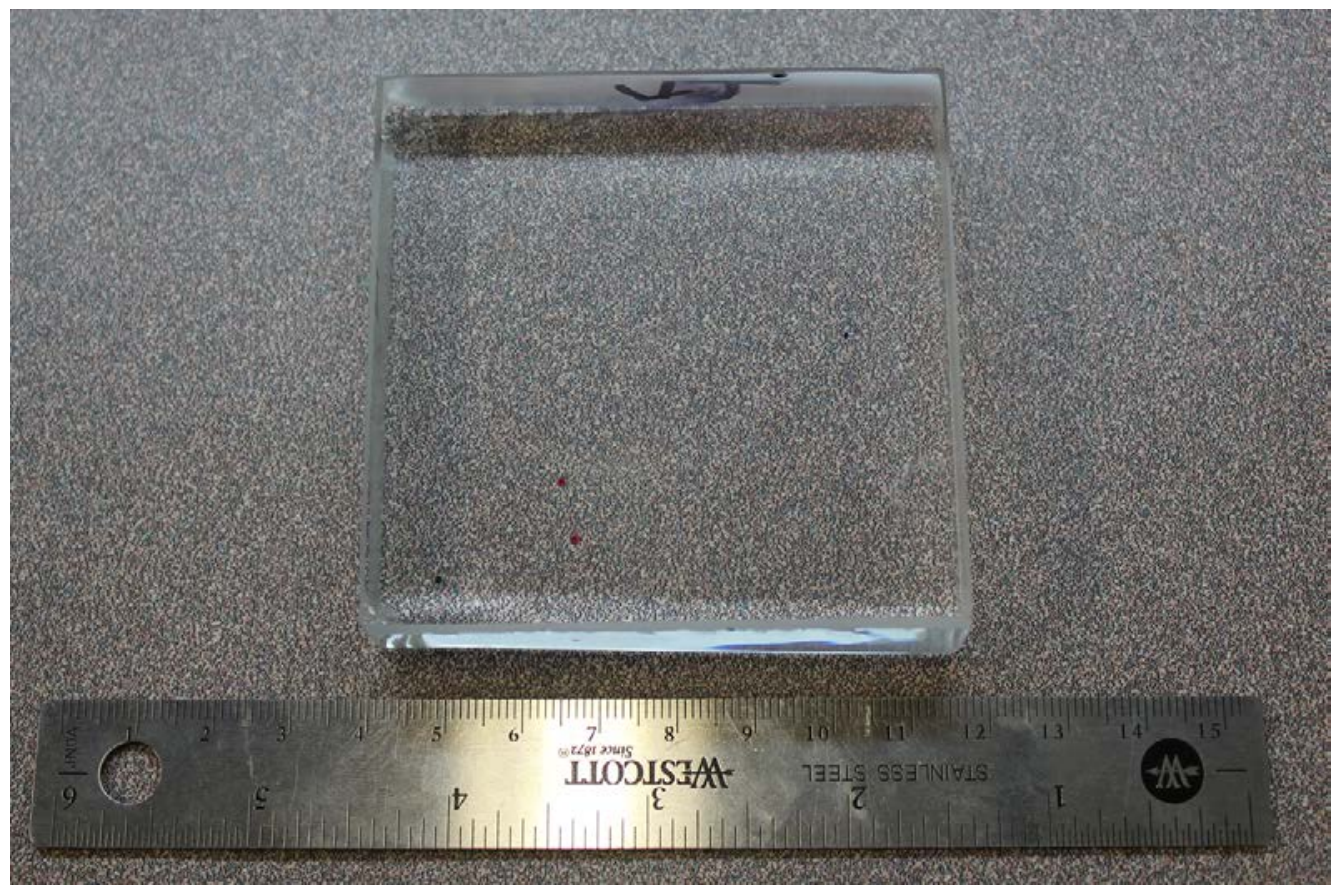

Figure 2.4. BOROFLOAT borosilicate glass. 


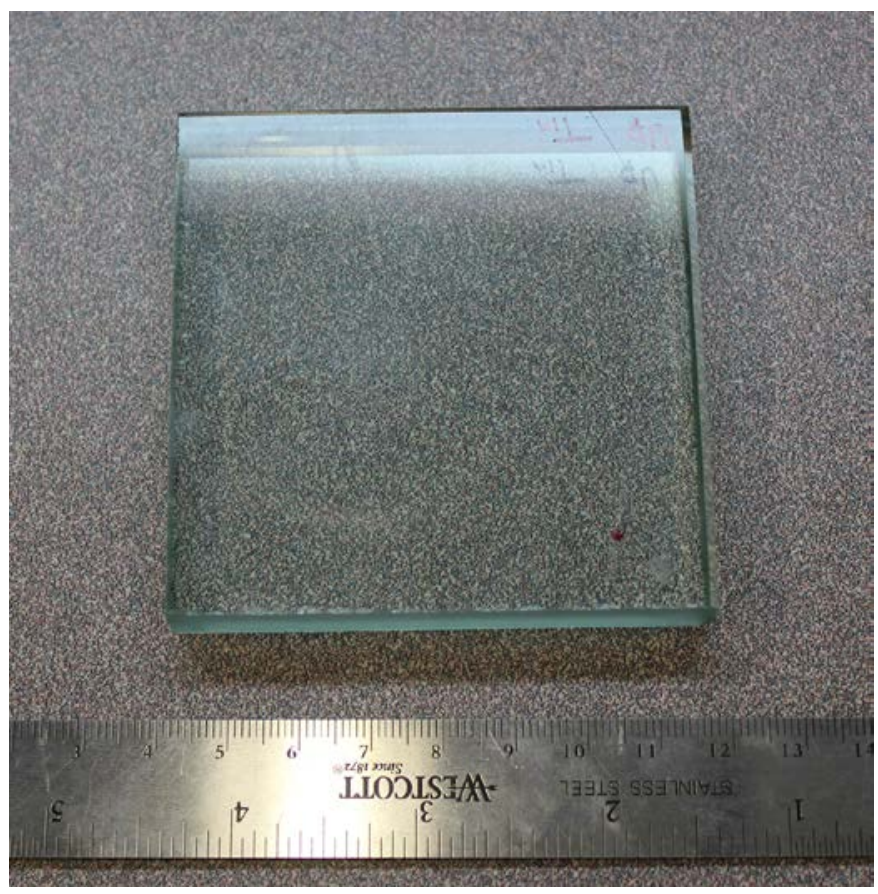

Figure 2.5. Iron-containing soda lime silicate glass.

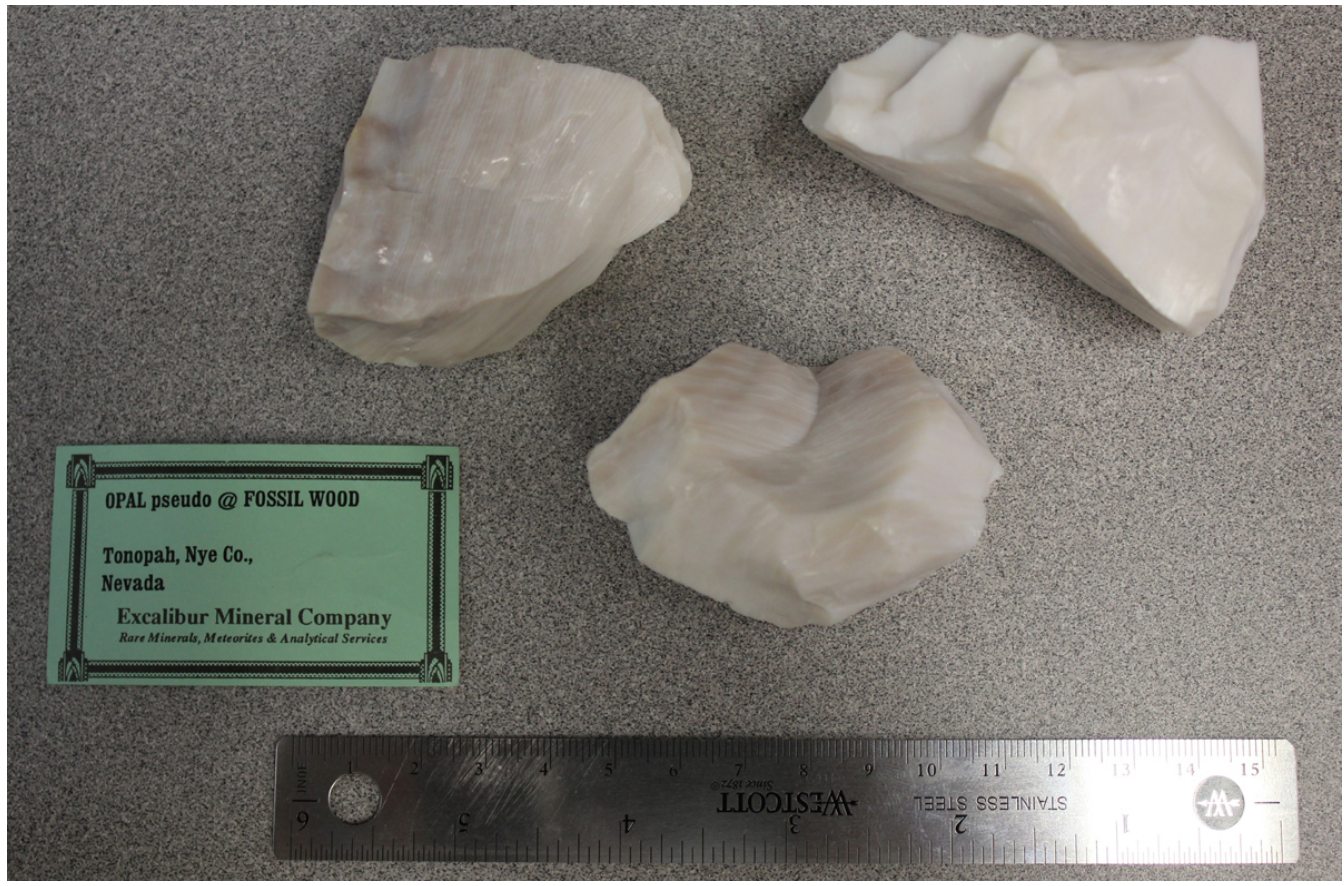

Figure 2.6. Opal (hydrated amorphous silica). 


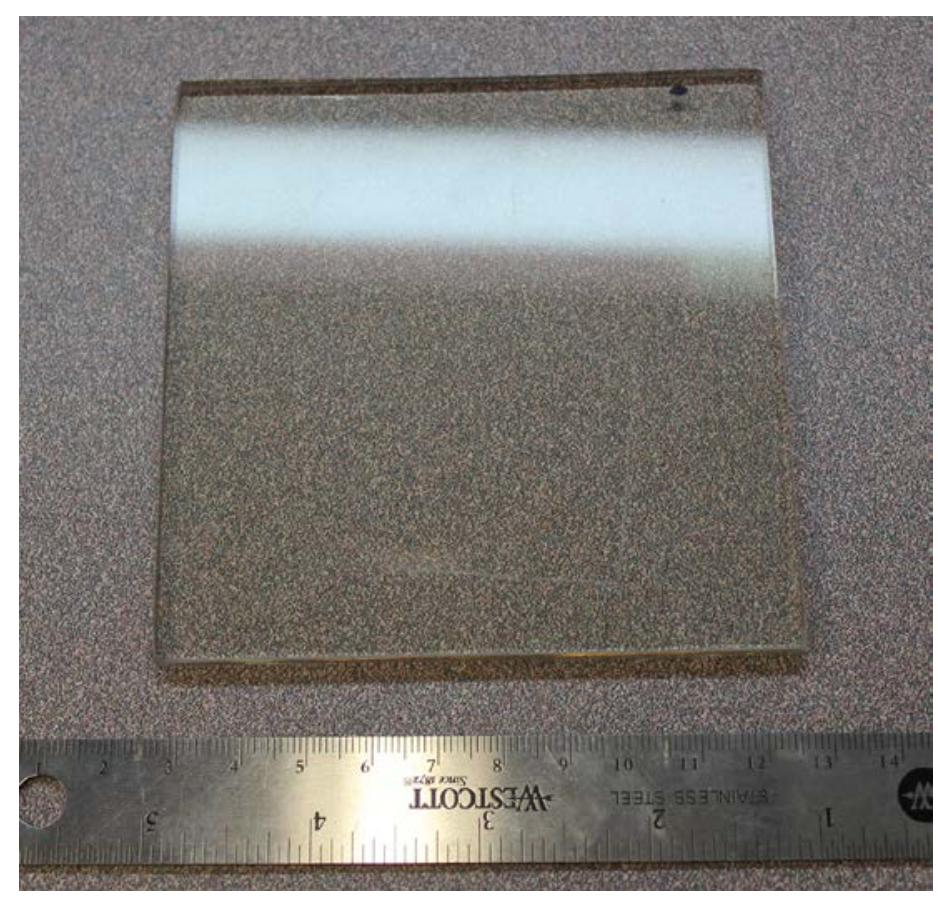

Figure 2.7. ROBAX glass ceramic.

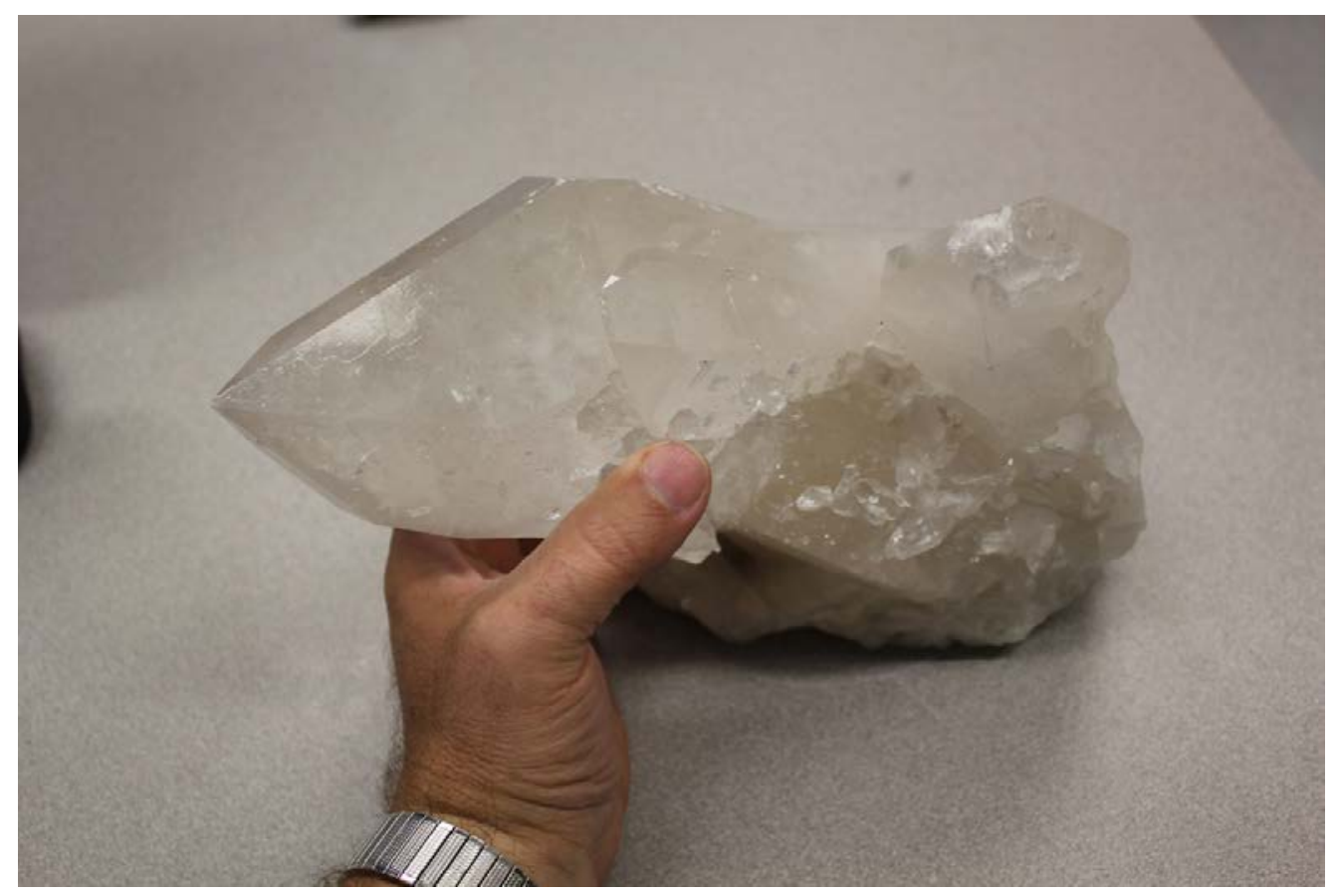

Figure 2.8. $\alpha$-quartz single crystal ceramic. 


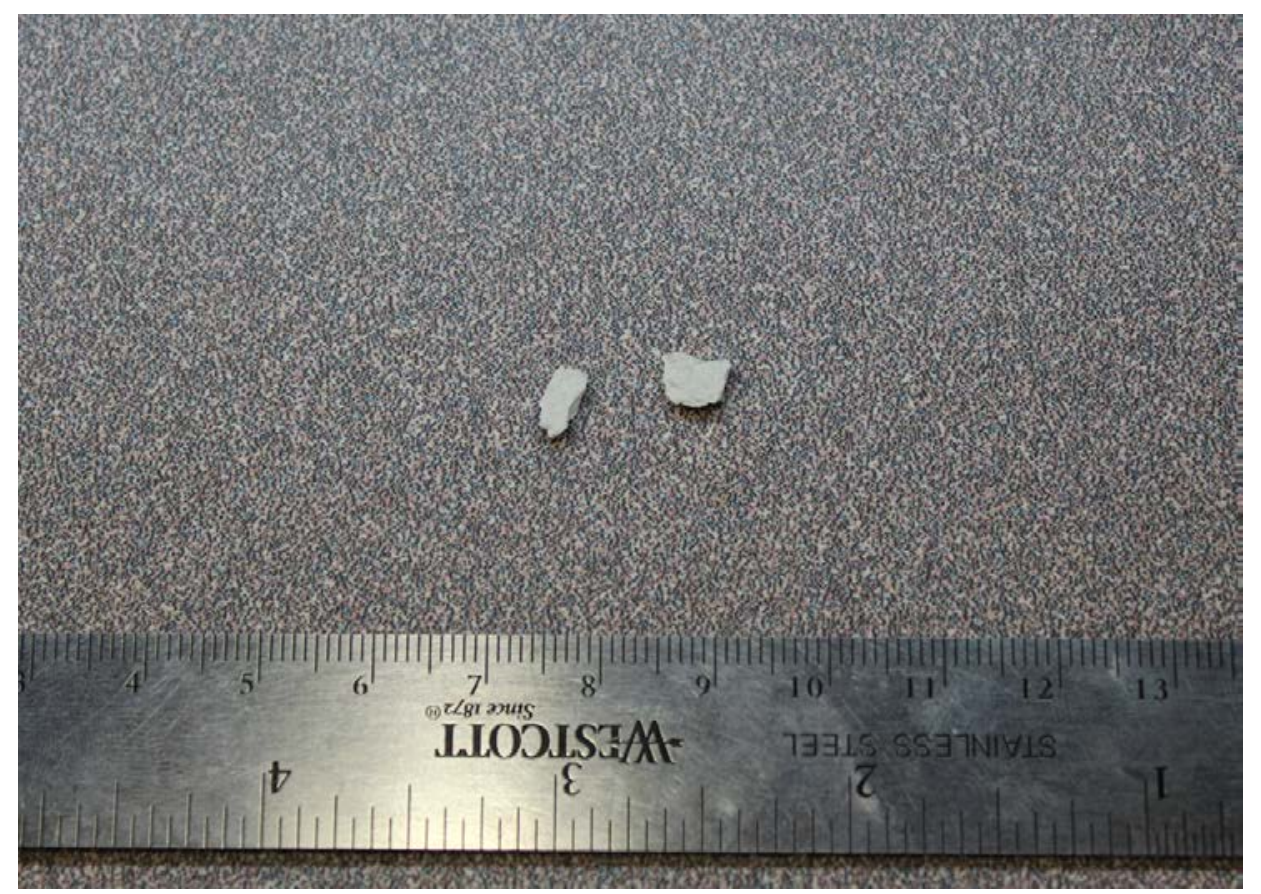

Figure 2.9. Coesite polycrystalline ceramic. Coesite is a high pressure phase of quartz.

\section{SPHERICAL INDENTATION TESTING}

\subsection{Features and Advantages}

Spherical indentation using a sufficiently small diamond indenter can be a very effective way to produce a yield-like response in brittle materials with cracking (i.e., fracture) prematurely halting it. A key issue is the size of that indenter. A diameter that is too large causes sufficiently high radial tensile stresses (e.g., many hundreds of $\mathrm{MPa}$ ) to form on the surface before a sufficiently high contact pressure develops resulting in ring and cone crack formation before yielding. This complicates the situation because once fracture starts, it is much more energetically favorable in brittle materials to promote additional crack propagation with additional load increase than to initiate a yield-like response. But a sufficiently small indenter diameter causes sufficiently high contact pressure to form first (e.g., many GPa), and the brittle material will exhibit a yield-like response first. This enables an estimation of apparent yield stress of the material. For amorphous materials, using a too-small indenter is not as problematic 
as it is with polycrystalline brittle materials. In this case, one should strive to sample as many grains as possible so using too small of an indenter does not satisfy that. The authors of the present study have done many hundreds, if not thousands, of spherical indents during the last 10 years, and an indenter diameter in a range between 250-500 $\mu \mathrm{m}$ has been found to be the most versatile. It is sufficiently small to usually cause plastic-like response before fracture is induced, and its contact diameter patch during indentation is sufficiently large to sample many dozens of grains and a bulk material response.

Lastly, spherical indentation using diamond indenters can be implemented relatively inexpensively, specimen preparation can be very simple, not much material is needed, and many tests can be conducted relatively quickly to produce sufficient statistics. Spherical testing takes a quantum leap in usefulness if the indenter depth of penetration can be concurrently measured during a loading-unloading response. This feature enables repeatable data analysis and ultimate estimation of apparent yield stress.

\subsection{Indentation Stress Field}

The Hertzian contact stress field is well chronicled by Johnson [13] and a multitude of others, and is shown on the right hand side of Fig. 3.1. The maximum pressure in the stress field is not located at the contact surface directly under the indenter; rather, it is located at a depth below the surface of approximately one-fourth the surface contact diameter. If yielding initiates, then it initiates at that location and not at the surface.

This brings in the use of the term "apparent yield stress" in these experiments. A yieldlike response is being detected in this spherical indentation by the use of a (surface located) indent depth of penetration sensor. The indenter depth of penetration sensor will not detect (permanent) penetration until the deformation field from that yield initiation finds its way to the surface. Therefore, the "actual" yielding in spherical indentation occurs at a compressive load slightly lower than what it experimentally determined here. For that reason, our reporting of a value here is not the material's actual yield stress but rather an "apparent yield stress." While it would be ideal to measure the actual yield stress (a material property), the estimation of an 
apparent yield stress is a good compromise because its value indicates that the actual yield stress of a material is no larger than it. It depends on the material of course (i.e., a material's elastic modulus and Poisson's ratio and those properties of the indenter too), but the authors have performed finite element analysis in the past to try to estimate the difference between the two and the actual yield stress was $\sim 8-10 \%$ less than the apparent yield stress.

In contrast to the conventional measurement of hardness, the yield stress of a material is an intrinsic material property. Hardness however is a material characteristic and not a material property because it depends very much on the indenter shape being used and different indenters will produce different measurements of hardness. If spherical indentation can be employed to estimate apparent yield stress, then it is a superior measurement to hardness measurement. A hardness indent can be predicted if a material's yield stress is known; however, going in the opposite direction to calculate yield stress from a hardness number is nearly impossible.

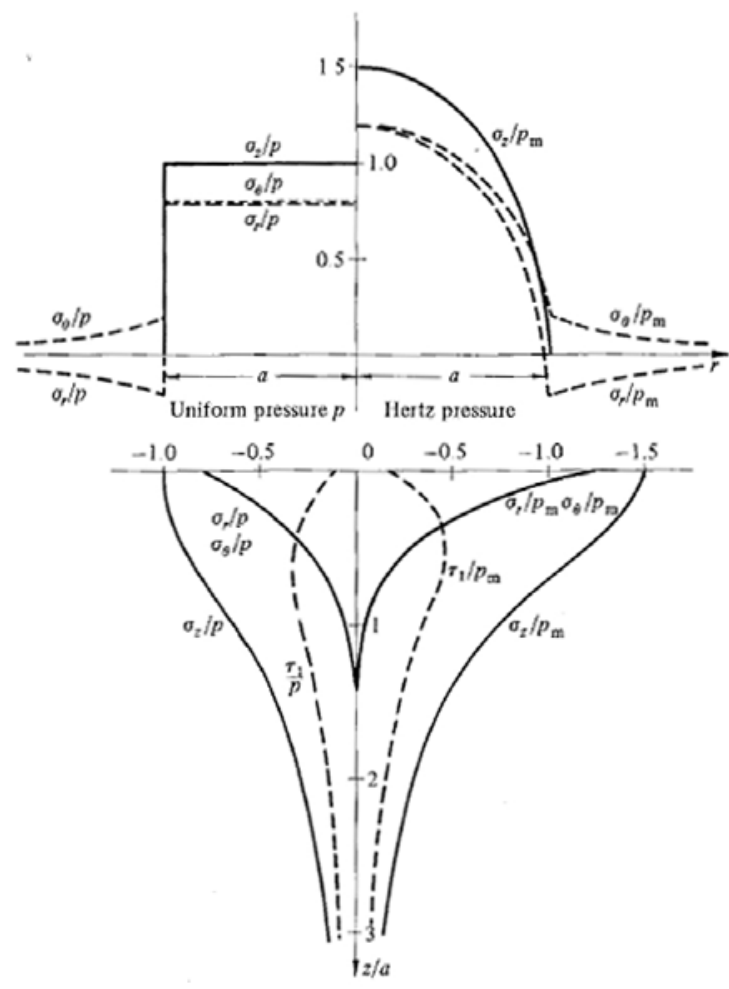

Figure 3.1. Stress fields associated with spherical (Hertzian) indentation (right side of schematic). 


\subsection{Experimental Method}

A Zwick microhardness indenter was used to perform spherical indentation as shown in Fig. 3.2. This indenter independently measures compressive force and indenter depth of penetration during a programmed load-unload test waveform. A schematic of the indenter depth of penetration sensor is shown in Fig. 3.3. Its patented design avoids the sampling of machine compliance giving good fidelity of the measured response.
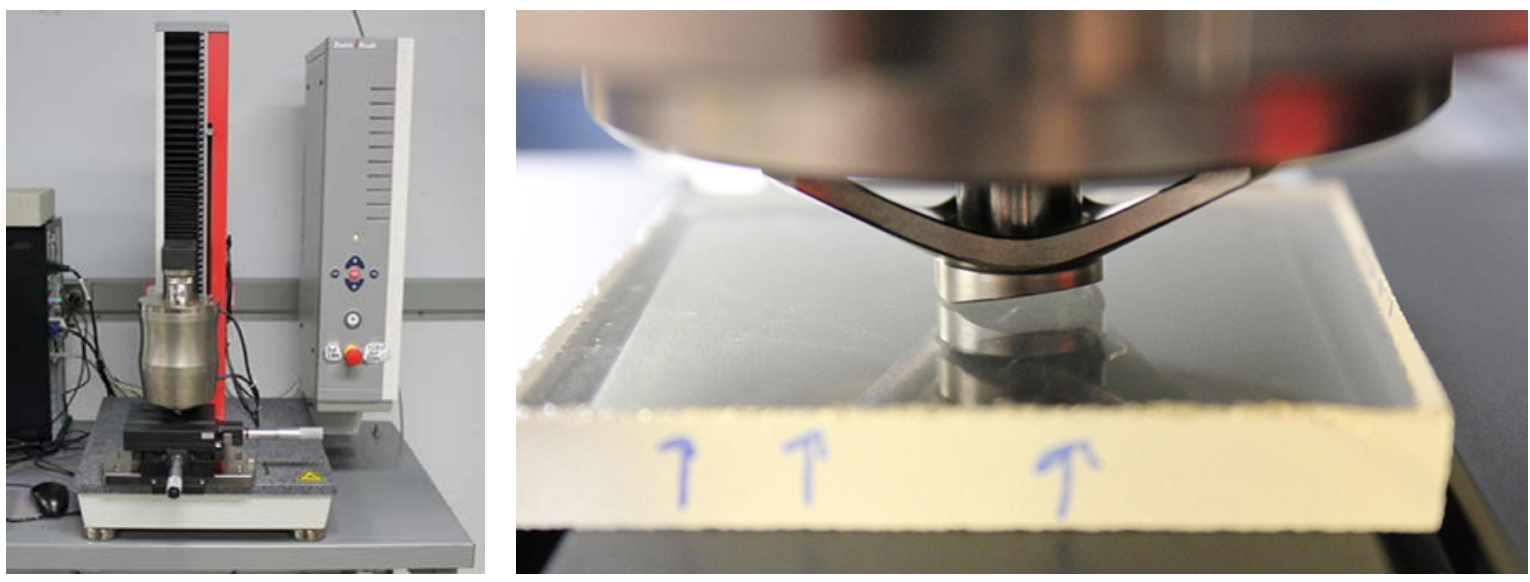

Figure 3.2. Zwick microindentation system (left) was used for the spherical indentation. Close-up of the indenter depth sensor making contact (right) with sample (indenter not visible). 


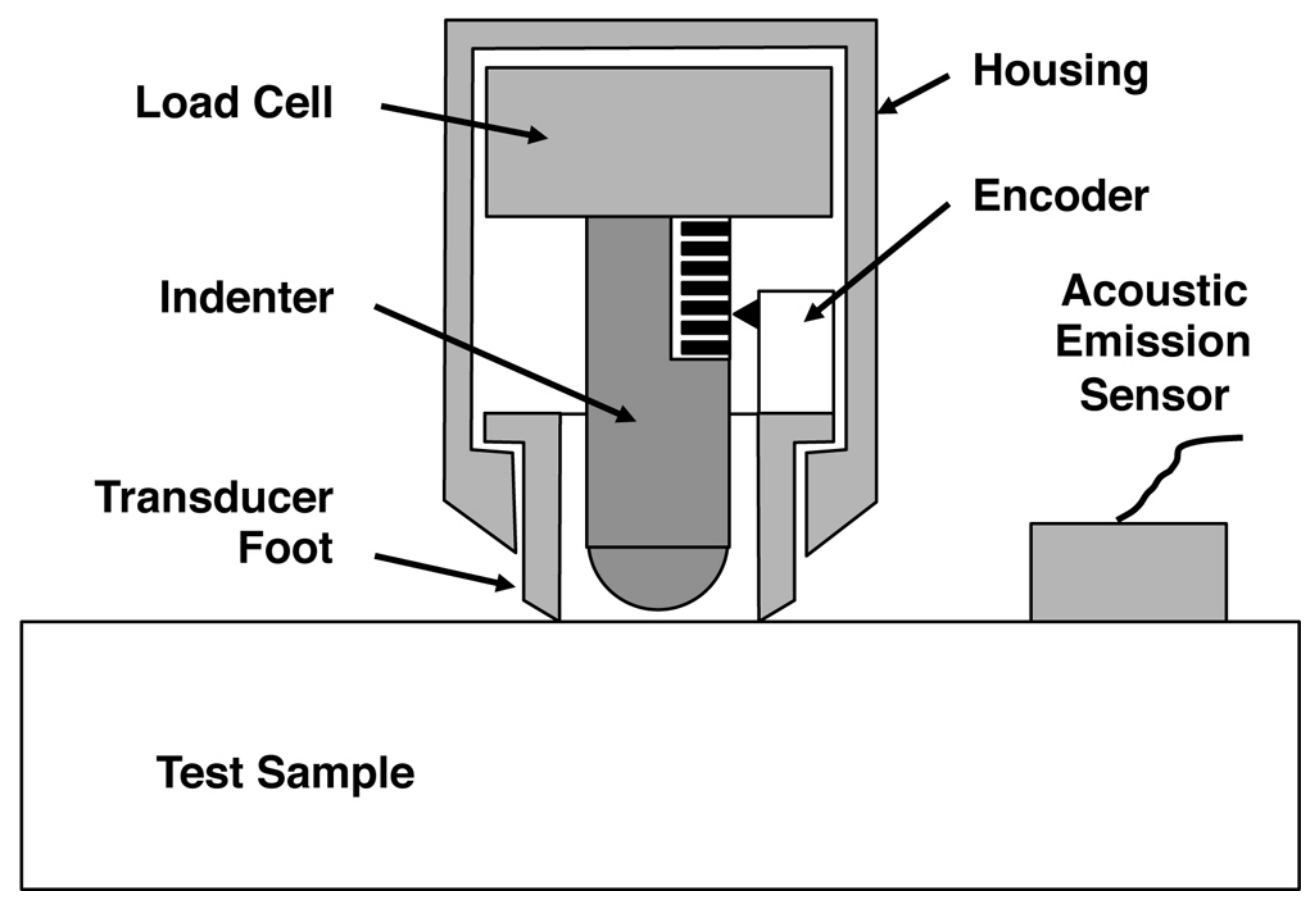

Figure 3.3. Schematic of the indenter and indenter depth of penetration measurement system.

A displacement rate of $10 \mu \mathrm{m} / \mathrm{min}$ was used for the loading, and a diamond indenter diameter of $220 \mu \mathrm{m}$ was used in all the testing. An example of representative load-unload curves for an indentation test is shown in Fig. 3.4. Acoustic emission sensing and analysis was used in all spherical indentation tests to discern where crack initiation occurred. 


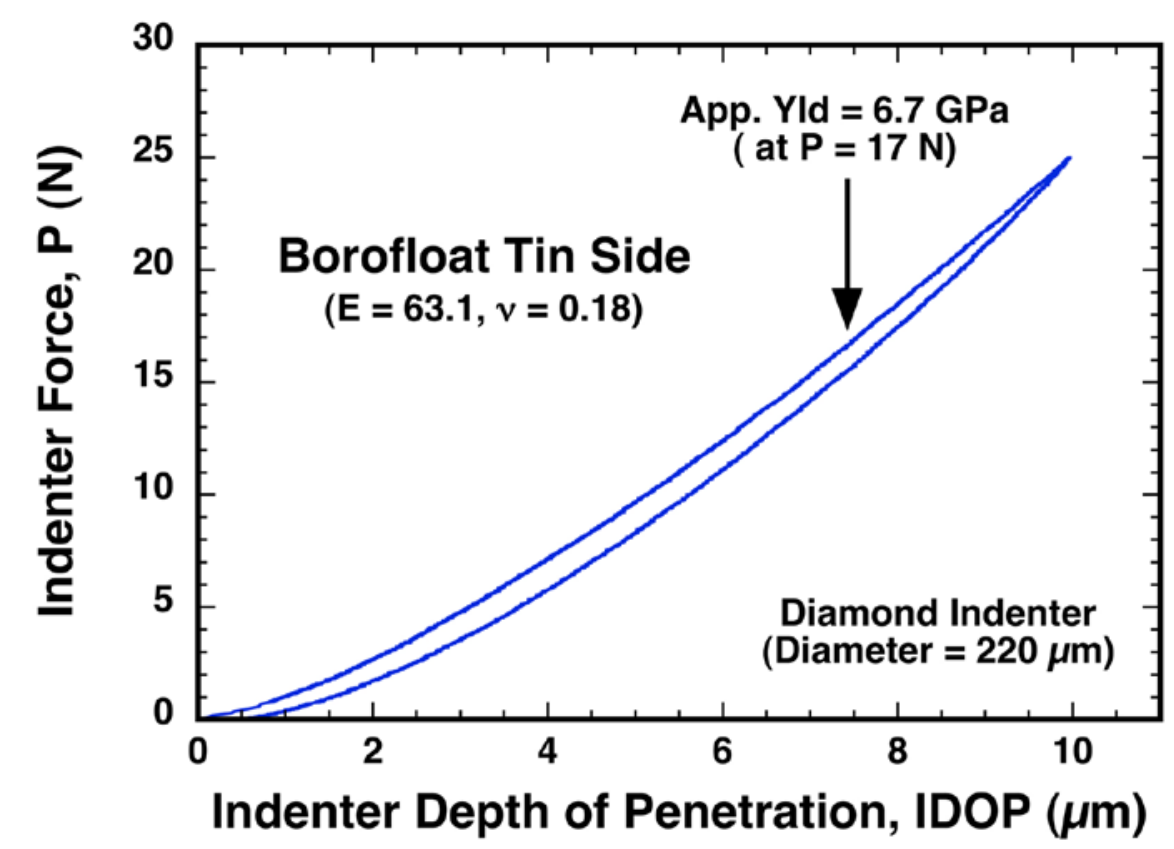

Figure 3.4. Example of a generated load-unload profile from a spherical indentation test.

One lesson learned is to always independently confirm the size of the employed indenter diameter. The indenter diameter was claimed to be $250 \mu \mathrm{m}$ by its manufacturer. However, when using that size with the to-be-described analysis, the elastic portion of the indent loading cycle could not be reconciled with theoretical prediction. The indenter's radius of curvature was then measured using two different methods (see Fig. 3.5), and its size was found to be $\sim 27 \%$ smaller than what the manufacturer reported. Once this correct value of diameter was used in the Hertzian stress analysis, the measured elastic responses of the test materials behaved as expected, and this provided confident analysis for identifying and quantifying the load associated with the onset of a yield-like response. 

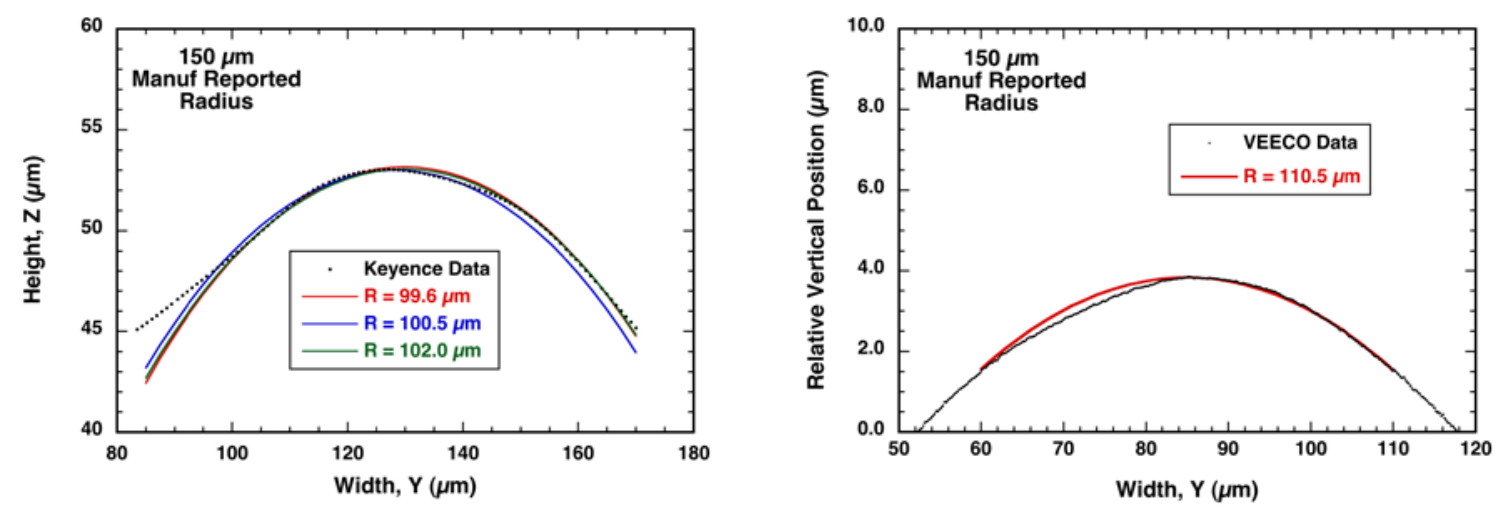

Figure 3.5. Although the manufacturer reported the indenter radius to be $150 \mu \mathrm{m}$, two different measurement methods showed the actual radius to be smaller. A radius of $110 \mu \mathrm{m}$ was used for all the stress calculations.

A computer program previously developed at ORNL was used to estimate the apparent yield stress. It compares the experimentally measured loading curve with an idealized loading curve when the material is linearly elastic. Illustrations of some of its analysis are shown in Figs. 3.6-3.8. The software identifies the load where the two curves diverge, and then this load is used in classical Hertzian theory to estimate the associated apparent yield stress.

Lastly, to employ Hertzian calculations of stresses, the elastic properties of the indented materials needed to be known first. While the above-described software, coupled with the good data generated from the Zwick indenter, allowed for determination of the material's elastic modulus, a resonant ultrasound spectroscope was instead used to independently measure elastic modulus and Poisson's ratio of the indented materials using analysis described elsewhere [14-15]. Those results are listed in Table 3.1 for all the materials that were spherically indented. 


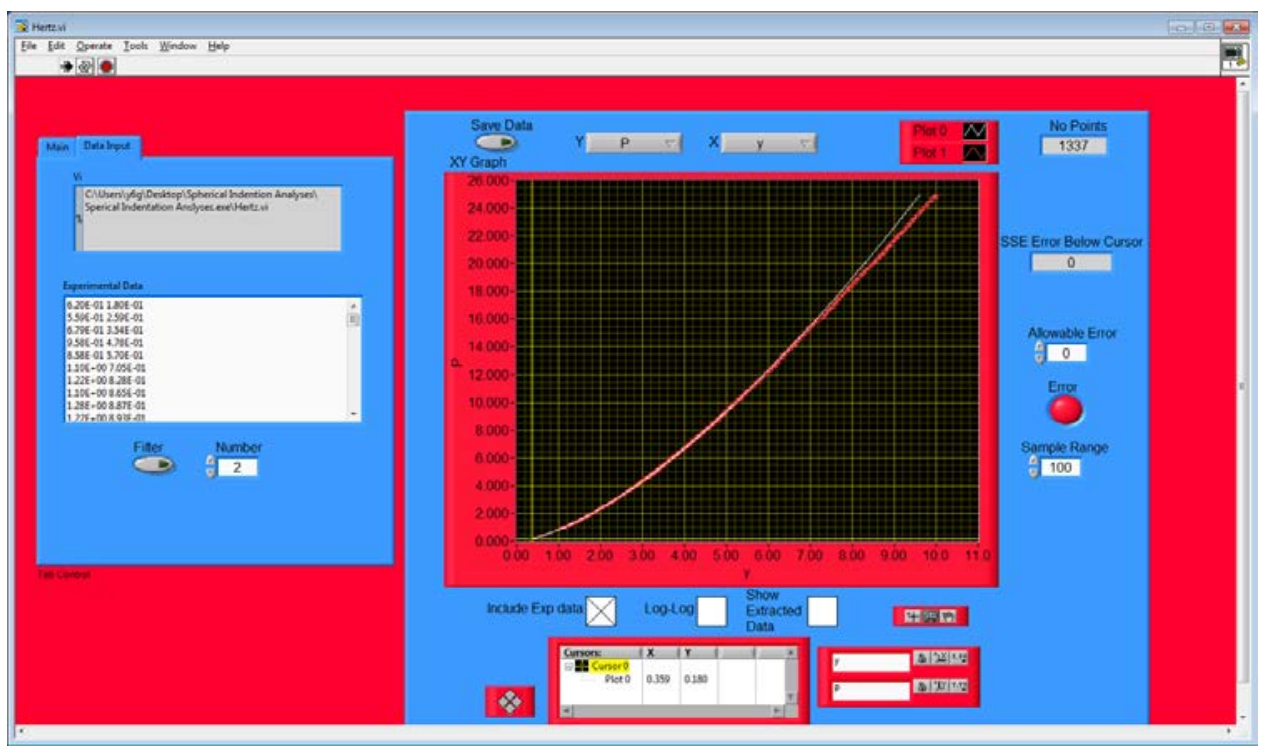

Figure 3.6. ORNL-developed software enabled the identification where apparent yielding initiated.

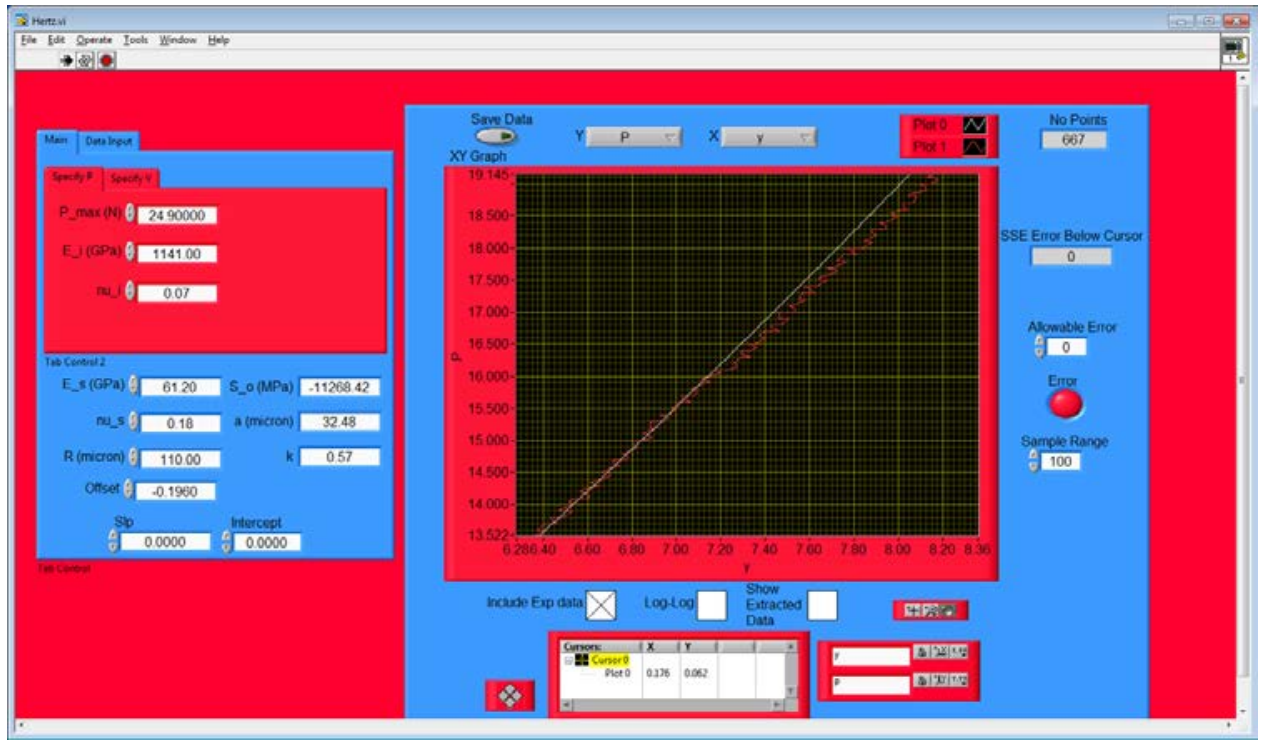

Figure 3.7. Enlarged region of load (P) indent depth of penetration (y) where theoretical curve diverges from experimental curve. 


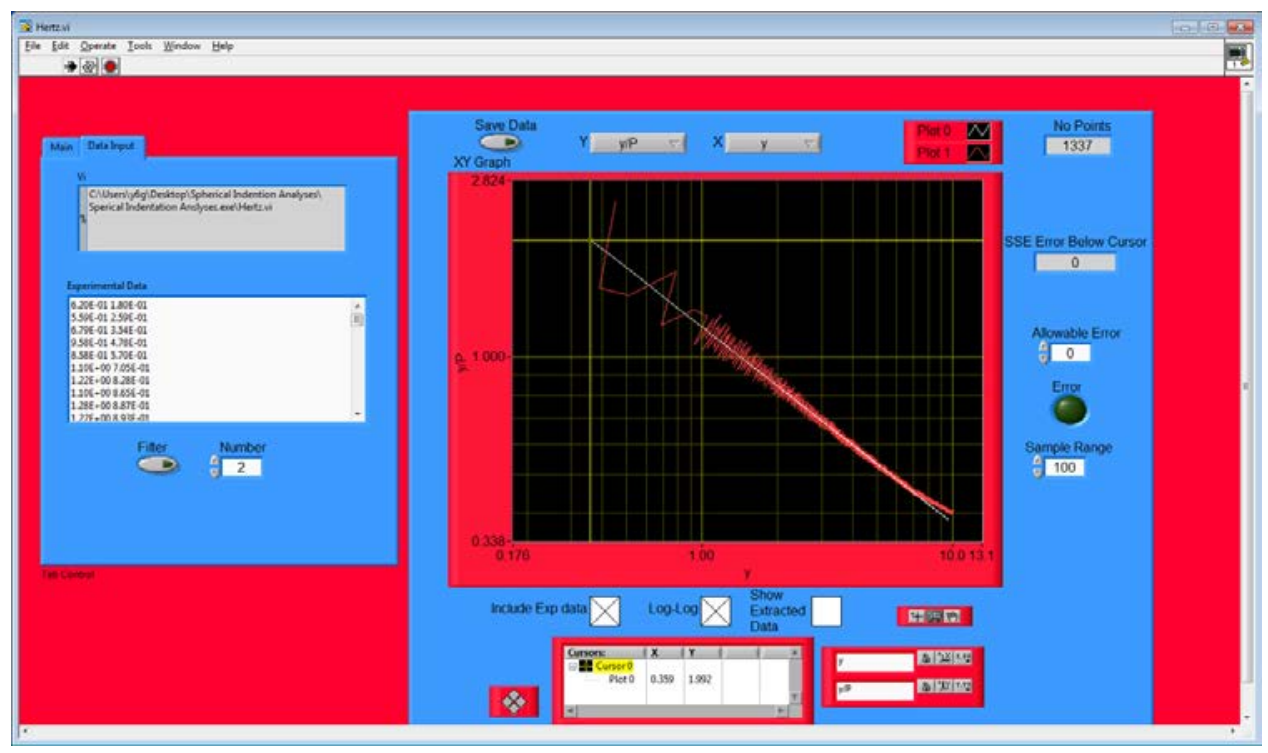

Figure 3.8. A portrayal of the indenter depth of penetration to load ratio $(y / P)$ as a function of $y$ sometimes was effective at helping the user identify the divergence.

Table 3.1. Spherical indentation test matrix.

\begin{tabular}{|c|c|c|c|c|c|c|c|c|c|}
\hline $\begin{array}{c}\text { Material } \\
\text { Structure }\end{array}$ & Brand Name or Type & $\begin{array}{c}\text { Density } \\
\rho \\
\left(\mathrm{g} / \mathrm{cm}^{\wedge} 3\right)\end{array}$ & $\begin{array}{c}\text { Youngs } \\
\text { Modulus } \\
\text { E } \\
\text { (GPa) }\end{array}$ & $\begin{array}{c}\text { Poissons } \\
\text { Ratio } \\
\text { v }\end{array}$ & $\begin{array}{l}\text { Shear } \\
\text { Modulus } \\
\text { G } \\
\text { (GPa) }\end{array}$ & $\begin{array}{c}\text { Bulk } \\
\text { Modulus } \\
\text { K } \\
\text { (GPa) }\end{array}$ & $\begin{array}{c}\text { P-Wave or } \\
\text { Compressive } \\
\text { Wave } \\
\text { Speed of } \\
\text { Sound } \\
\text { VL } \\
(\mathrm{m} / \mathrm{s})\end{array}$ & $\begin{array}{l}\text { S-Wave or } \\
\text { Shear } \\
\text { Wave } \\
\text { Speed of } \\
\text { Sound } \\
\text { VS } \\
(\mathrm{m} / \mathrm{s})\end{array}$ & $\begin{array}{c}\text { Estimated } \\
\text { Crack Propagation } \\
\text { Speed } \\
\text { VC } \\
(\mathrm{m} / \mathrm{s})\end{array}$ \\
\hline Glass & Fused Silica & 2.18 & 72.8 & 0.159 & 31.4 & 35.6 & 5957 & 3793 & 1896 \\
\hline Glass & Starphire - Air & 2.50 & 73.1 & 0.203 & 30.4 & 41.0 & 5714 & 3488 & 1744 \\
\hline Glass & Starphire - Tin & 2.50 & 73.1 & 0.203 & 30.4 & 41.0 & 5714 & 3488 & 1744 \\
\hline Glass & BOROFLOAT - Air & 2.22 & 63.1 & 0.180 & 26.7 & 32.9 & 5560 & 3474 & 1737 \\
\hline Glass & BOROFLOAT - Tin & 2.22 & 63.1 & 0.180 & 26.7 & 32.9 & 5560 & 3474 & 1737 \\
\hline Glass & Fe soda-lime silicate - Air & 2.51 & 75.5 & 0.231 & 30.7 & 46.8 & 5910 & 3495 & 1748 \\
\hline Glass & Fe soda-lime silicate - Tin & 2.51 & 75.5 & 0.231 & 30.7 & 46.8 & 5910 & 3495 & 1748 \\
\hline Glass & Opal (Hydrated silica) & 1.97 & 75.5 & 0.231 & 30.7 & 46.8 & 6671 & 3945 & 1973 \\
\hline Glass Ceramic & ROBAX & 2.51 & 99.7 & 0.269 & 39.3 & 71.9 & 7043 & 3959 & 1980 \\
\hline Single Crystal & a-Quartz $\{1000\}$ & 2.64 & 78 & 0.147 & 34.0 & 36.8 & 5579 & 3589 & 1794 \\
\hline Single Crystal & a-Quartz (0001) & 2.65 & 100 & 0.047 & 47.8 & 36.8 & 6157 & 4245 & 2123 \\
\hline
\end{tabular}

3.4. Results and Discussion

The results from the spherical indentation are listed in Table 3.2 for $25 \mathrm{~N}$ loading and a comparison of the estimated apparent yield stresses are shown in Fig. 3.9. A listing of all the indentation tests is shown in Appendix I. The BOROFLOAT's apparent yield stress ( $5.5 \mathrm{GPa})$ was about $25 \%$ lower than that of Starphire ( $7.5 \mathrm{GPa}$ and taken here to be a reference value). The apparent yield stress of the iron-containing soda lime silicate was equivalent, that of 
ROBAX was about $10 \%$ lower, and that of opal was about $80 \%$ lower than that of Starphire. Two different directions of loading were applied for alpha quartz testing due to anisotropy and the respective apparent yield stress values measured were about 15\% lower than that of Starphire.

Hugoniot elastic limit $\left(H E L_{c a l c}\right)$ was calculated using each materials apparent yield stress $\left(S_{\text {app }}\right)$ and Poisson's ratio $(v)$ according to

$$
H E L_{\text {calc }}=\left(\frac{1-v}{1-2 v}\right) S_{a p p}
$$

Their values are compared against literature values for three of the glasses (fused silica [16], Starphire soda lime silicate glass [17], and BOROFLOAT borosilicate glass [18]), and this is shown in Fig. 3.10. The $H E L_{\text {calc }}$ values are somewhat larger than literature values, and this could be attributed to $S_{a p p}$ being larger valued than the material's actual yield stress.

While BOROFLOAT had a lower apparent yield stress than both Starphire and the ironcontaining soda lime silicate glass, its total amount of hysteresis was $~ 35 \%$ lower when indented to the same maximum load. However, the amount of applied stress is higher in the Starphire and iron-containing soda lime silicate than the BOROFLOAT (for the same indentation force) because the elastic modulus of both of them is about $15 \%$ higher than that of BOROFLOAT. The glass ceramics had equivalent amounts of hysteresis as BOROFLOAT, but the elastic modulus of all of them is $\sim 50 \%$ higher than that of BOROFLOAT. If the product of the amount of hysteresis and elastic modulus is related to total absorbed energy, then the glass ceramics absorb more energy than the BOROFLOAT. 
Table 3.2. Summary of spherical indentation results.

\begin{tabular}{|c|c|c|c|c|c|c|c|c|c|c|c|c|c|}
\hline Material Class & Material & $\begin{array}{l}\text { Max } \\
\text { Force } \\
\text { (N) }\end{array}$ & $\begin{array}{c}\text { Max Hertz } \\
\text { Contact } \\
\text { Stress } \\
(\mathrm{GPa})\end{array}$ & $\begin{array}{c}\text { Max Indent } \\
\text { Depth of } \\
\text { Penetration } \\
(\mu \mathrm{m})\end{array}$ & $\begin{array}{c}\text { Residual } \\
\text { Depth } \\
(\mu \mathrm{m})\end{array}$ & $\begin{array}{c}\text { Hysteresis } \\
(\text { N. } \mu \mathrm{m})\end{array}$ & $\begin{array}{c}\text { Load at } \\
\text { 1st } \\
\text { Inflection } \\
(\mathrm{N})\end{array}$ & $\begin{array}{c}\text { Load at } \\
\text { First } \\
\text { Acoustic } \\
\text { Event (N) }\end{array}$ & $\begin{array}{c}\text { Estimated } \\
\text { Load of } \\
\text { Apparent } \\
\text { Yielding (N) }\end{array}$ & $\begin{array}{l}\text { Calculated } \\
\text { Apparent } \\
\text { Yield } \\
\text { Stress } \\
\text { (GPa) }\end{array}$ & $\begin{array}{c}\text { Ring } \\
\text { Cracking }\end{array}$ & $\begin{array}{c}\text { Ring } \\
\text { Crack } \\
\text { Diameter } \\
(\mu \mathrm{m})\end{array}$ & $\begin{array}{c}\text { Radial } \\
\text { Cracking }\end{array}$ \\
\hline Glass & Fused Silica & 25 & 12.53 & 8.8 & 0.13 & 1.8 & 17.91 & None & 15.7 & 7.3 & Yes & 61.7 & No \\
\hline Glass & Starphire Air & 25 & 12.69 & 7.7 & 1.03 & 14.0 & None & None & 18.6 & 7.9 & Yes & No data & Yes \\
\hline Glass & Starphire Tin & 25 & 12.69 & 8.2 & 1.08 & 14.0 & 15.12 & None & 14.9 & 7.0 & Yes & No data & Yes \\
\hline Glass & Borofloat Air & 25 & 11.50 & 9.6 & 0.71 & 9.3 & None & None & 10.8 & 5.5 & Yes & No data & No \\
\hline Glass & Borofloat Tin & 25 & 11.50 & 9.4 & 0.73 & 8.8 & None & None & 11.3 & 5.4 & Yes & No data & No \\
\hline Glass & Fe-SLS Air & 25 & 10.62 & 8.5 & 0.96 & 13.6 & None & 18.3 & 18.0 & 7.6 & Yes & 57.5 & No \\
\hline Glass & $\mathrm{Fe}$-SLS Tin & 25 & 10.61 & 8.6 & 1.09 & 15.3 & None & 23.8 & 17.0 & 7.7 & Yes & 67.0 & No \\
\hline Glass & Opal (Hydrated Glass) & 25 & 10.62 & 25.0 & 8.25 & 87.0 & None & 2.47 & 3.2 & 1.4 & Yes & 42.3 & Yes \\
\hline Glass Ceramic & ROBAX & 25 & 12.77 & 8.5 & 0.35 & 7.6 & 11.6 & 11.6 & 12.0 & 6.6 & Yes & 65.7 & No \\
\hline Single Crystal & alpha Quartz $\{0001\}$ & 25 & 12.90 & 49.8 & 7.92 & 320.6 & None & 14.4 & 4.9 & 5.4 & Yes & 56.2 & Yes \\
\hline Single Crystal & alpha Quartz (1000) & 25 & 10.61 & 8.5 & 0.39 & 7.7 & 14.19 & 14.55 & 7.2 & 6.1 & Yes & 72.1 & No \\
\hline
\end{tabular}

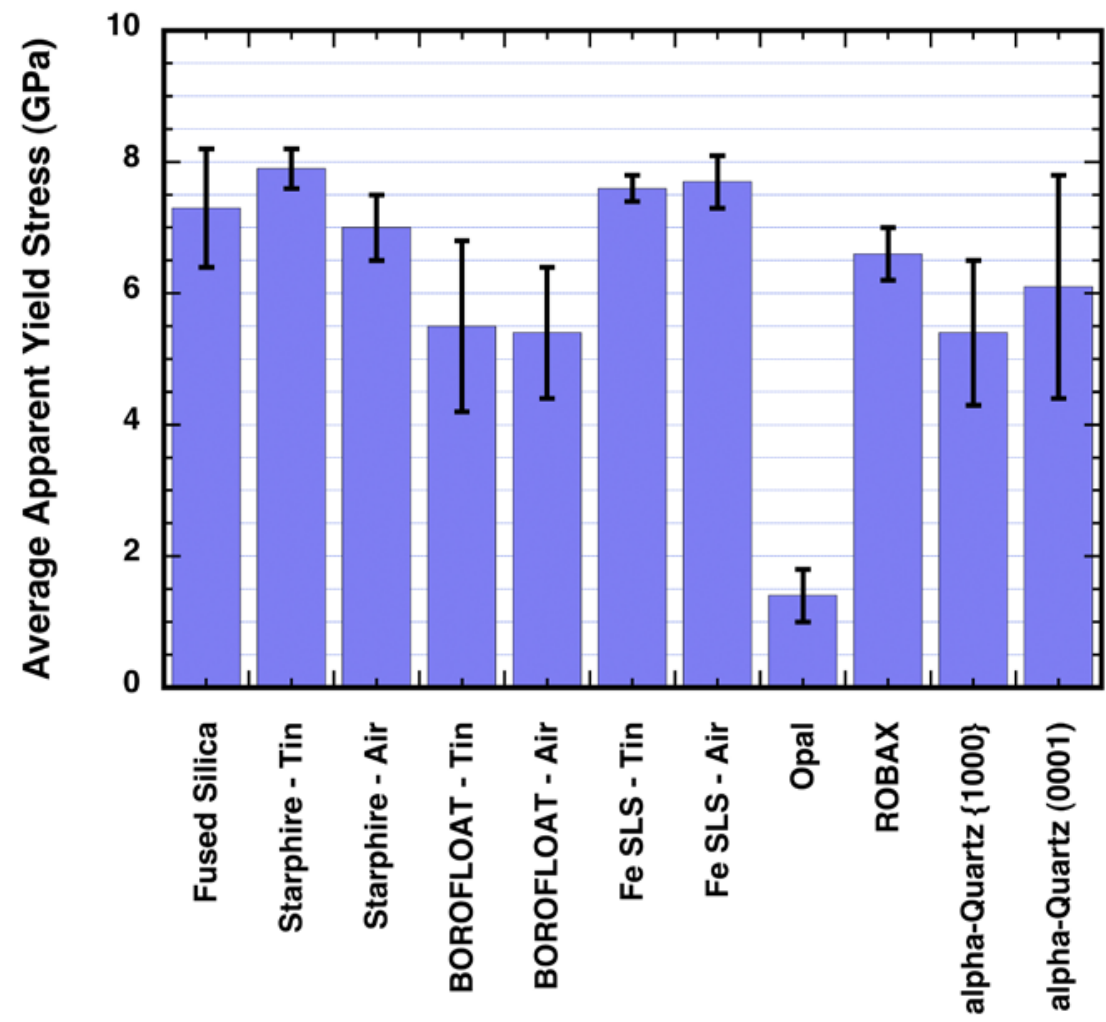

Test Materials

Figure 3.9. Comparison of the average apparent yield stress for all the indented siliceous materials. 


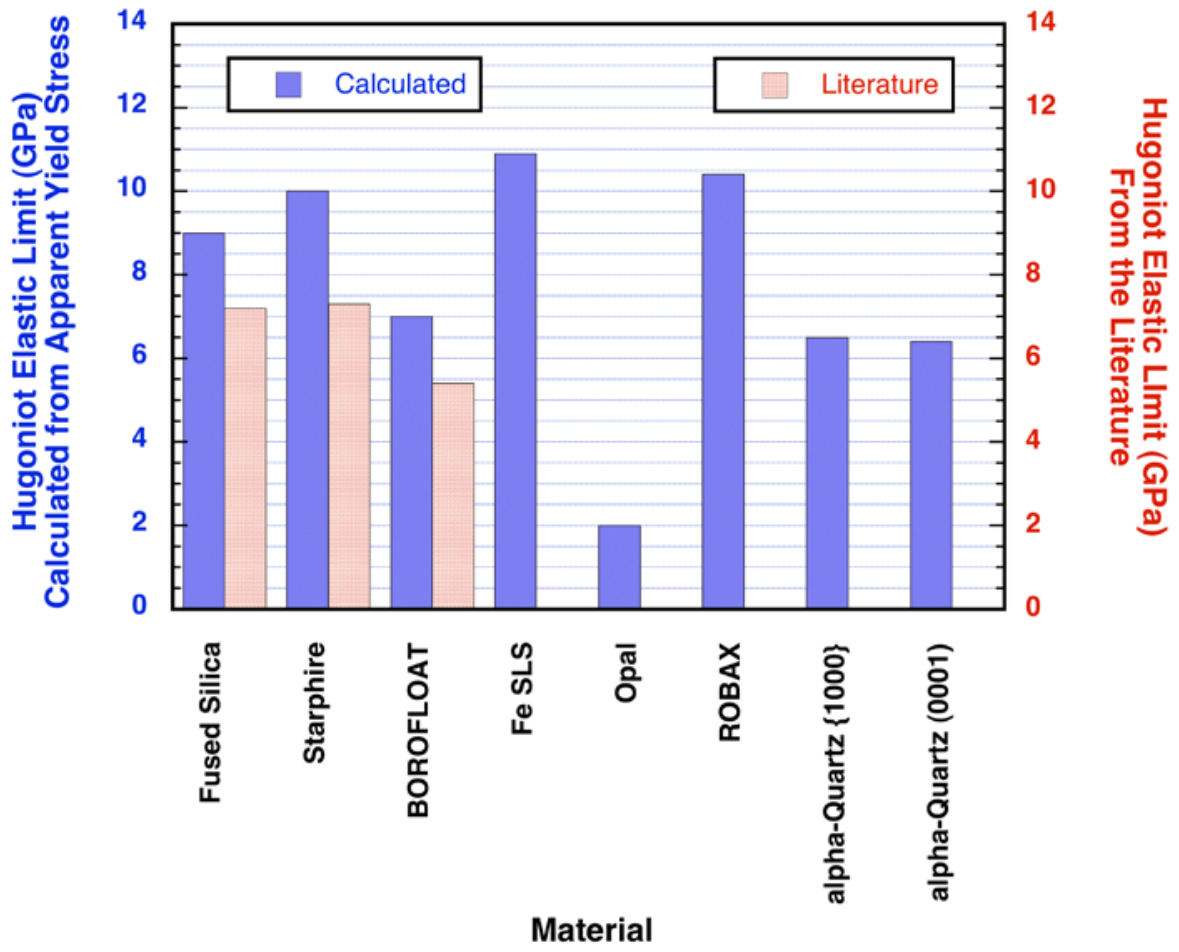

Figure 3.10. Comparison of the calculated Hugoniot Elastic Limit from apparent yield stress values with literature HEL values. 


\section{DIAMOND ANVIL CELL (DAC) TESTING}

\subsection{Features and Advantages}

The diamond anvil cell (DAC) is a tool used to study materials experiencing high hydrostatic pressures and the phase transitions they undergo during pressure loading. It was conducted in this study in parallel to spherical indentation and laser shock testing because DAC testing is the most commonly recognized method to generate high pressure in the laboratory so it served as a reference test. A very nice review of the DAC history can be found in Ref. [19].

The DAC is able to reach very high pressure (100s of GPa) by exerting a large counter imposing force between two very small diamond facets. Rates of phase transitions, recrystallization, birefringence, and other material properties can be measured concurrently using x-ray diffraction, the ruby method, heating apparatus, and Raman and brillouin scattering.

The press consists of four main parts, a force generator, two diamond anvils, a gasket, and a pressure-transmitting medium. A schematic of the DAC is shown Fig. 4.1 and a photo of a piece of test material, ruby, and gasket is shown in Fig. 4.2.

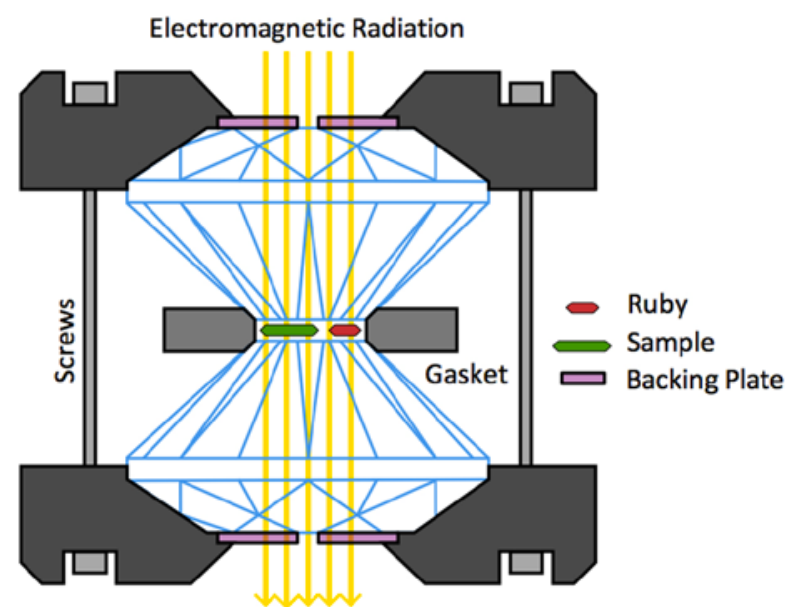

Figure 4.1. Schematic of the diamond anvil cell test. 


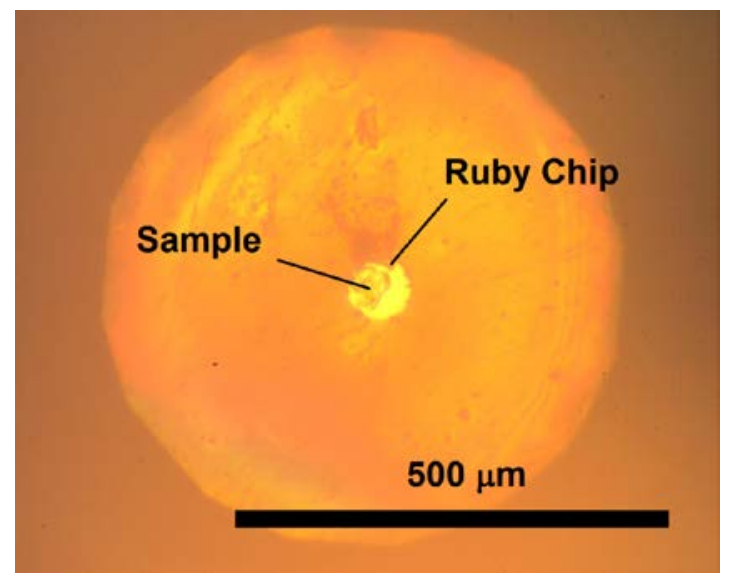

Figure 4.2. Siliceous material and ruby pressure sensor mounted in the diamond anvil cell. The 4:1 methanol:ethanol pressure medium is used to ensure hydrostatic pressure conditions.

The placement and co-pressurization of a ruby crystal enables the hydrostatic pressure to be measured because the peak shift as a function of pressure is calibrated for ruby. An illustration of this functionality is shown in Fig. 4.3.

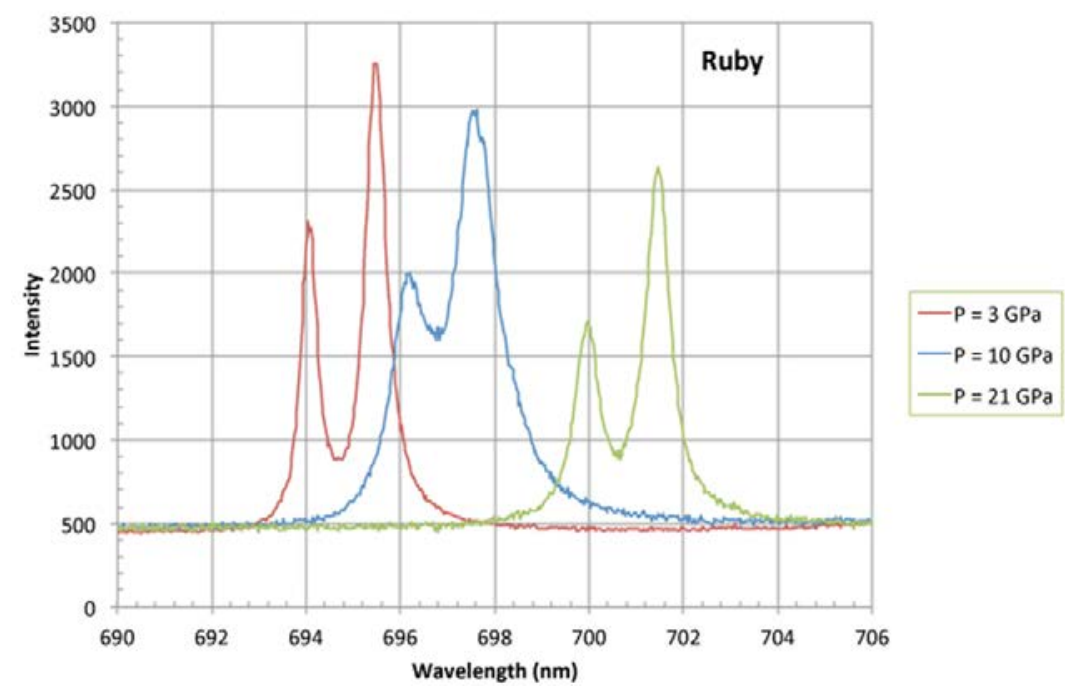

Figure 4.3. Peak-shift of ruby R-1 fluorescence emission is used to measure pressure in the diamond anvil cell. The spectra are presented at a three different pressures in a typical high pressure experiment on siliceous material. 


\subsection{DAC Stress Field}

The DAC produces a hydrostatic stress state on the test material (and the ruby). An illustration of that stress field is shown in Fig. 4.4.

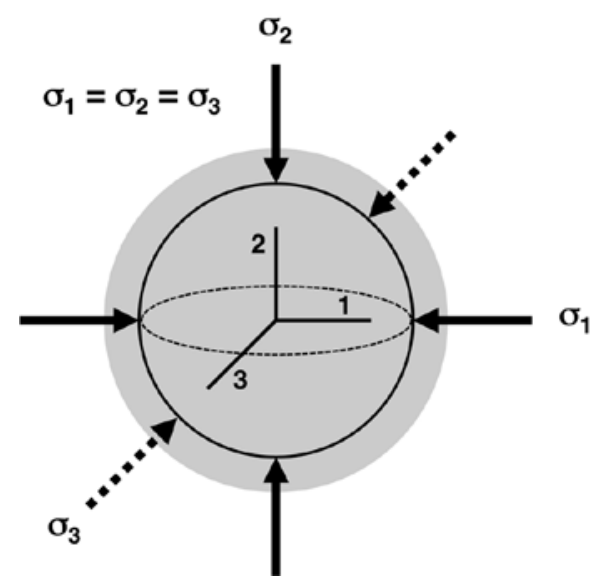

Figure 4.4. Stress state produced by diamond anvil cell testing.

\subsection{Experimental Method}

Diamond anvil cell testing was performed on the materials listed in Table 4.1 up to approximately $20 \mathrm{GPa}$. A 4:1 methanol-ethanol mixture was used for the liquid medium and its Raman spectrum was subtracted from the generated raw spectrum of each test. A Raman spectrum was generated prior to loading, at several stresses up to $20 \mathrm{GPa}$, and then again after unloading. 
Table 4.1. Diamond anvil cell test matrix.

Material
Structure
Glass
Glass
Glass
Glass
Glass
Glass Ceramic
Crystal
Crystal

Brand Name or Type

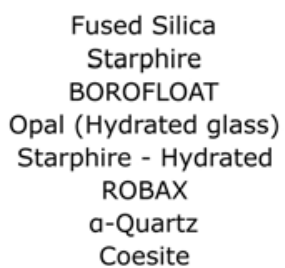

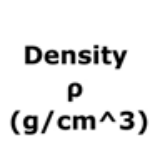

\subsection{8}

2.50

2.22

1.97

2.13

2.51

2.64

3.0

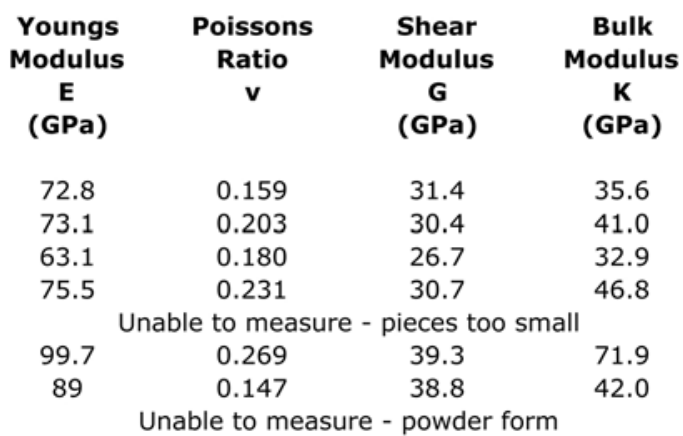

\subsection{Results and Discussion}

The Raman spectra for all the materials listed in Table 4.1 are shown in Figs. 4.5.-4.12 as a function of pressure.

All the glasses showed evidence of permanent densification when they were hydrostatically pressured up to $20 \mathrm{GPa}$. Permanent densification for the glass ceramic was not identified.

Peaks in the Raman spectrum tended to form for all the glasses and glass ceramics by 10 $\mathrm{GPa}$ indicating long-range ordering was being induced while under pressure. They were reversible and were absent after unloading. This suggests the material, while under pressure in a ballistic event, may have a different structure than it does under ambient temperature and pressure. Diffraction (X-Ray or neutron) analysis would need to be concurrently performed to explain what that long-range ordering was.

The amount of peak shifting per unit stress was much greater for the hydrated Starphire soda lime silicate glass than the baseline (unhydrated or as-received) Starphire. This indicates that introduced water into Starphire's amorphous structure decreases stiffness. 
It appears that an additional phase is formed in pressurized Coesite sample at high pressures - perhaps Stishovite. This is evidenced by the appearance of new Raman peaks at pressures above 6.5 GPa (Fig. 4.14). Diffraction analysis and repeat testing would confirm this.

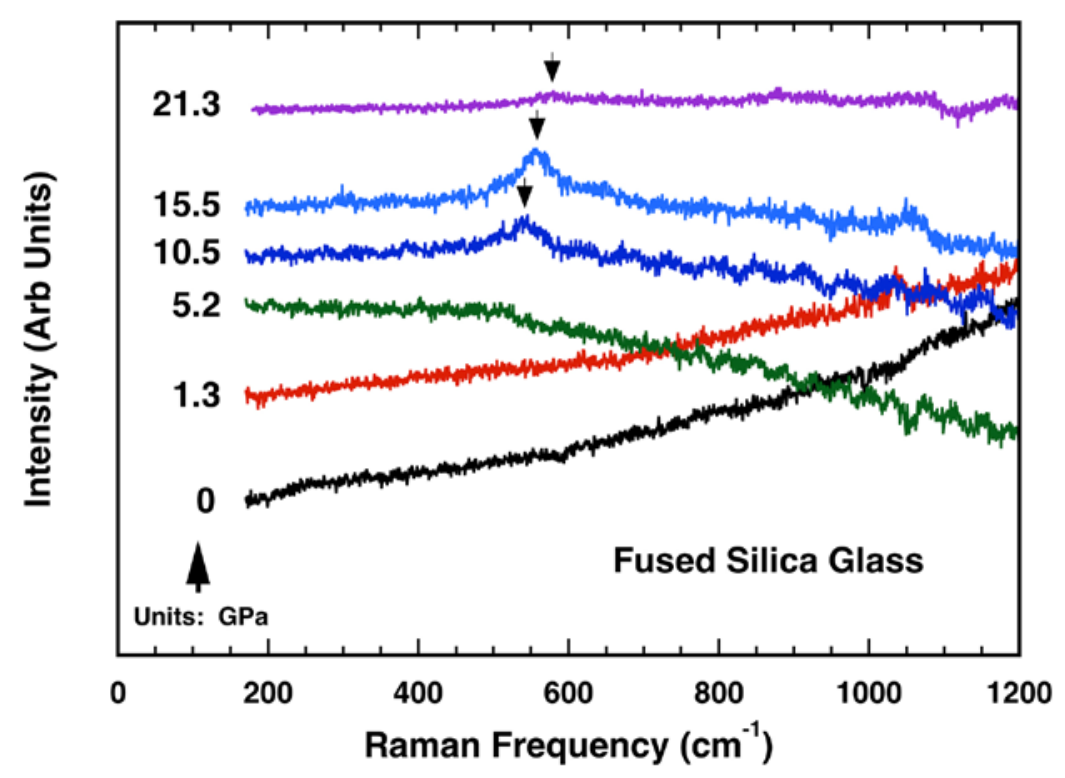

Figure 4.5. Raman spectrum as a function of stress for fused silica.

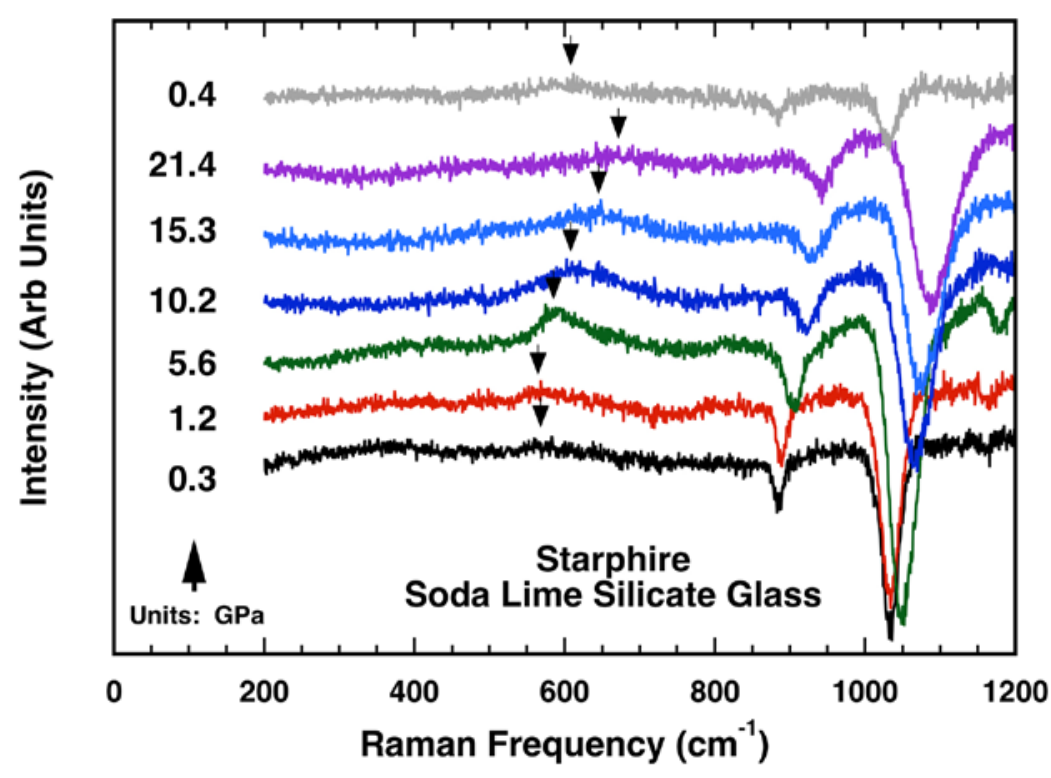

Figure 4.6. Raman spectrum as a function of stress for Starphire soda lime silicate glass. 


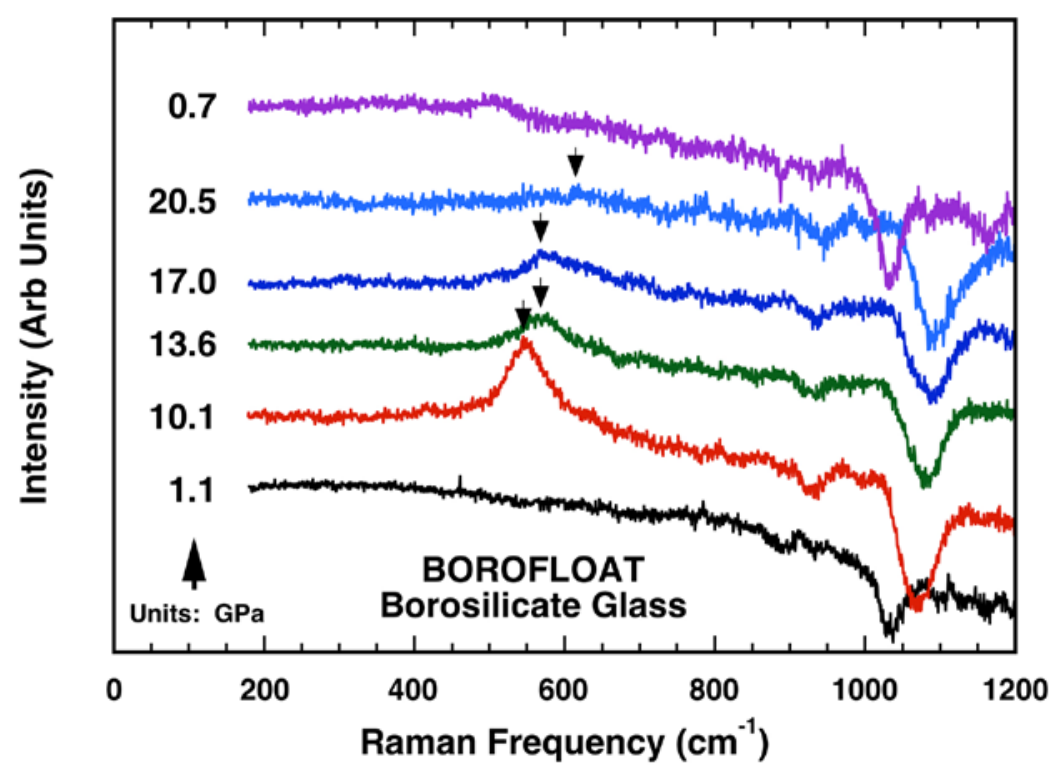

Figure 4.7. Raman spectrum as a function of stress for BOROFLOAT borosilicate glass.

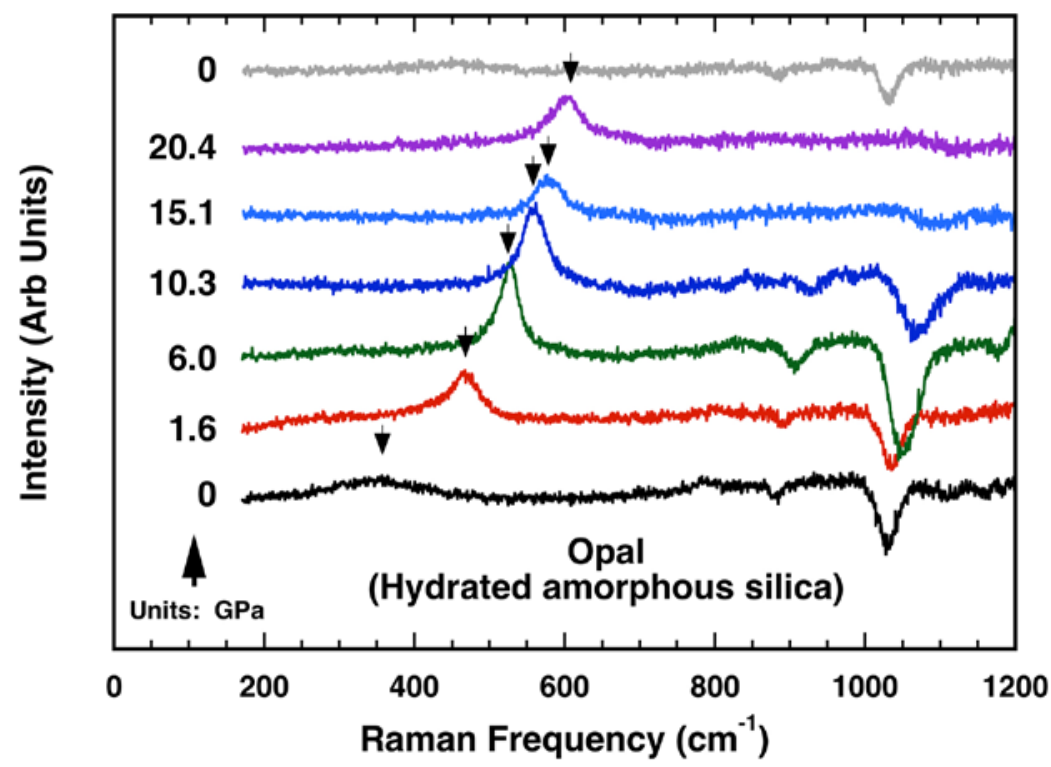

Figure 4.8. Raman spectrum as a function of stress for opal (hydrated silica) glass. 


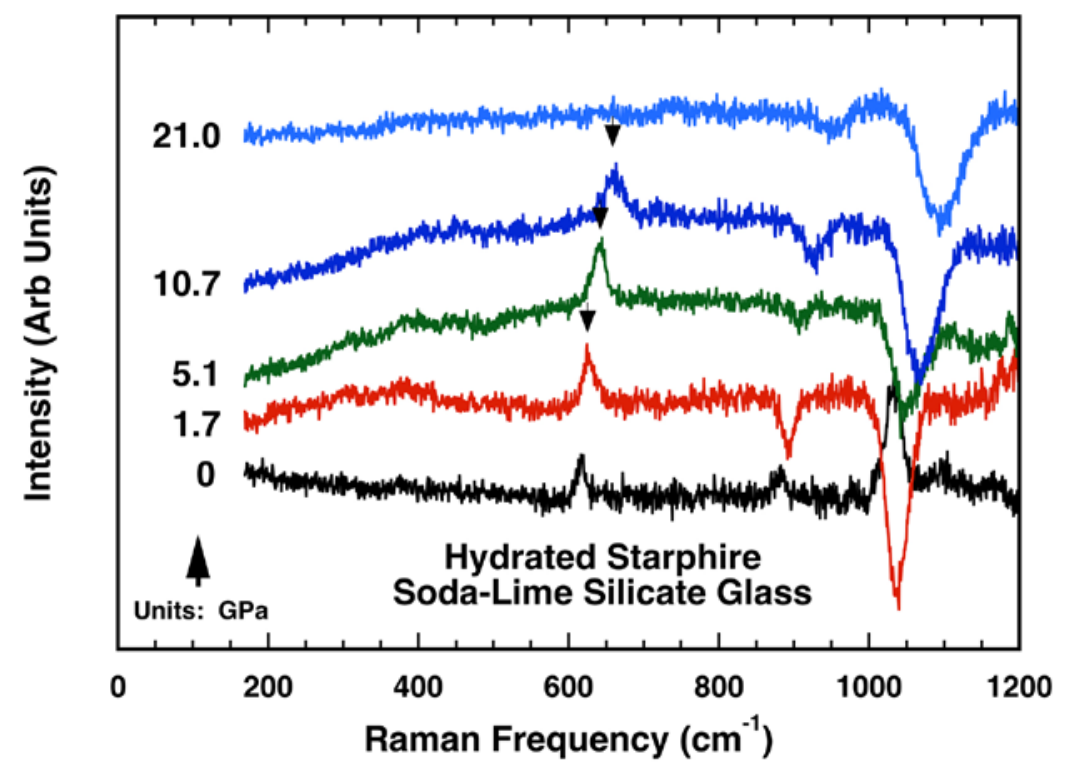

Figure 4.9. Raman spectrum as a function of stress for hydrated Starphire soda lime silicate glass.

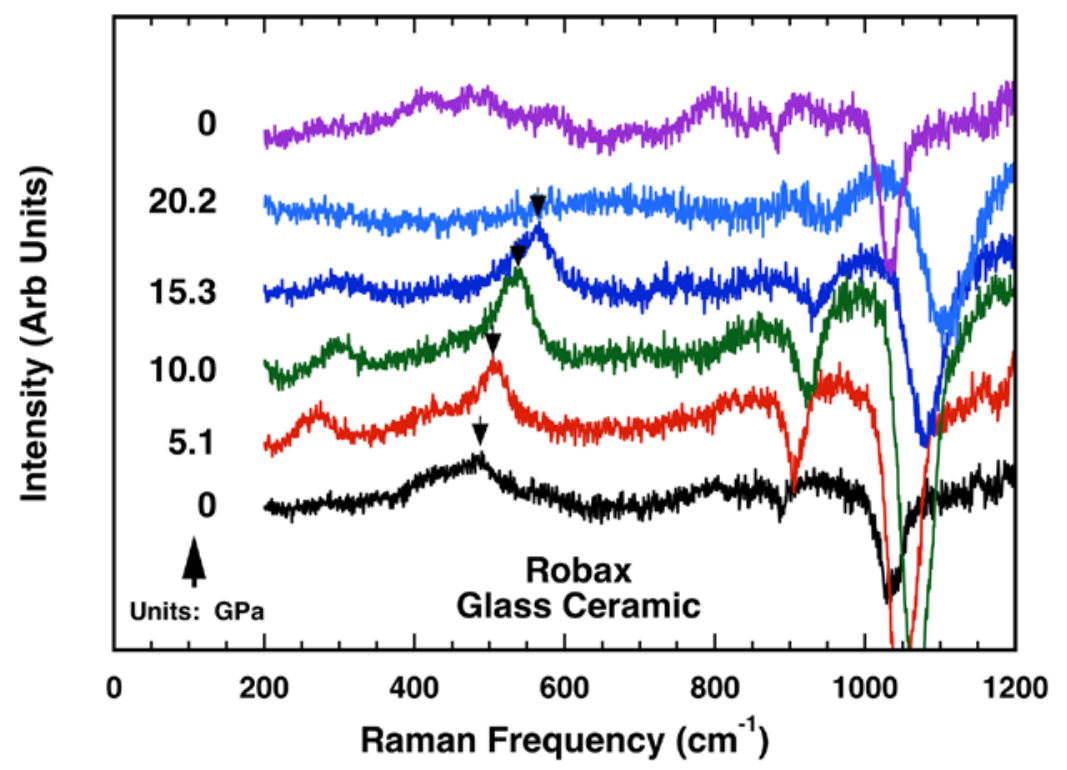

Figure 4.10. Raman spectrum as a function of stress for ROBAX glass ceramic. 


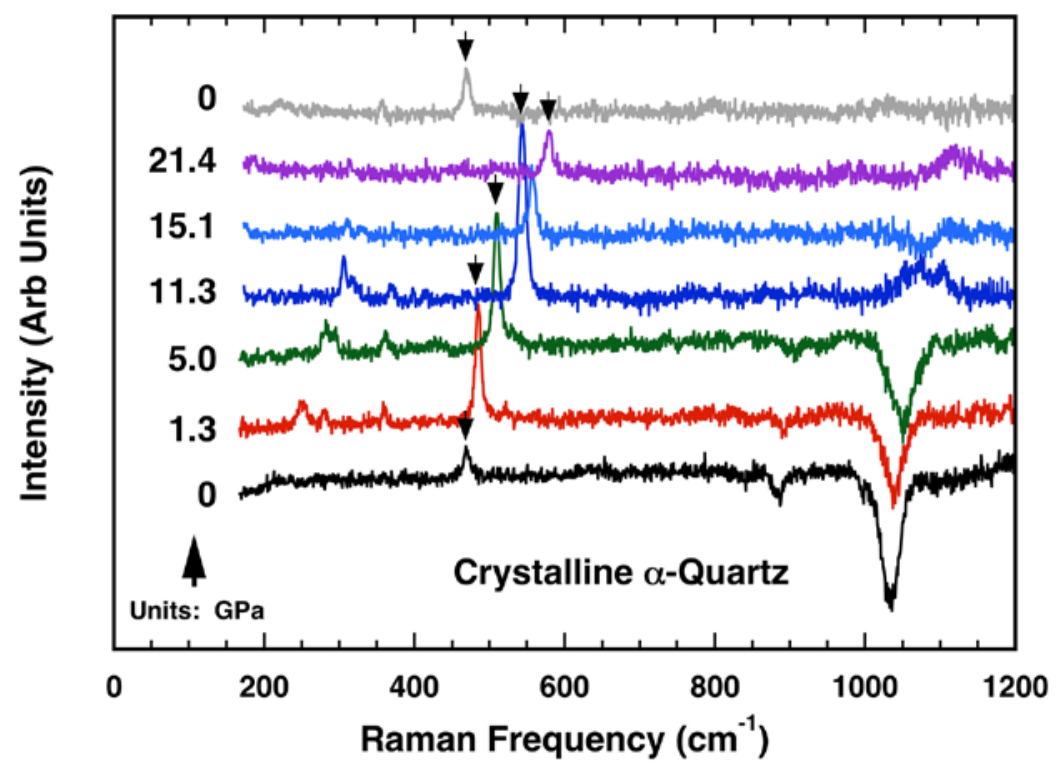

Figure 4.11. Raman spectrum as a function of stress for $\alpha$-Quartz.

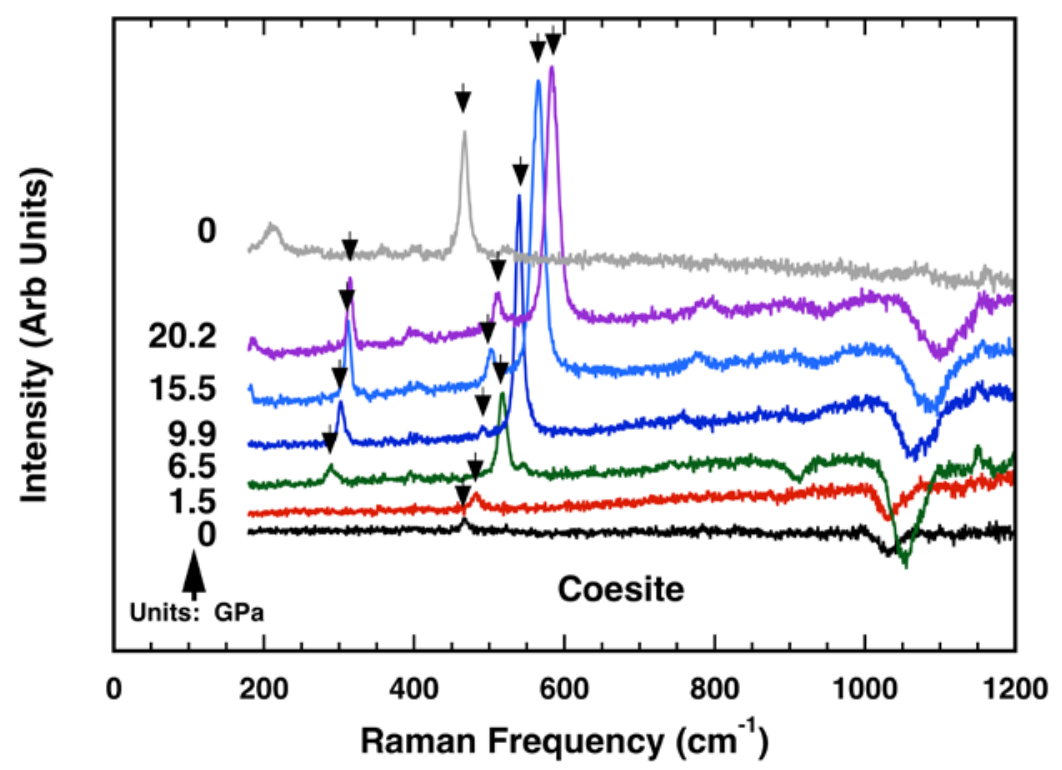

Figure 4.12. Raman spectrum as a function of stress for Coesite. 


\section{LASER SHOCK TESTING}

\subsection{Features and Advantages}

The laser shock process is a surface modification method in which a laser is used to introduce compression in the surfaces of metallic components with minimal cold working. For this testing, its use was adapted to the testing of glass and glass ceramics. As shown in Fig. 5.1, "laser shock testing" utilizes a high powered laser to focus a short duration energy pulse onto the surface of a test coupon. A coating, which is typically black tape, is placed on the surface to facilitate the absorption of the laser beam energy. In order to direct the shock wave into surface of the work, a transparent layer, usually flowing water, is continuously applied to the surface. During a specific pulse, and as schematically shown in Fig. 5.2, the laser passes through the water and explodes the tape, creating a compressive shock wave. The energy and pressure of that shock wave peens metals (i.e., the primary use of this laser shock concept - see Fig. 5.3); however, the authors in the present study, and in past work involving polycrystalline ceramics and the study of spallation [20], sought to explore its effect on siliceous (non-metallic) materials. The peak pressure is calculated from the measured energy versus time curve as shown in Fig. 5.4. The produced energy density is high; the depth of the compressive surface stress induced by laser shock can be as much as four times deeper than that of conventional shot preening. 


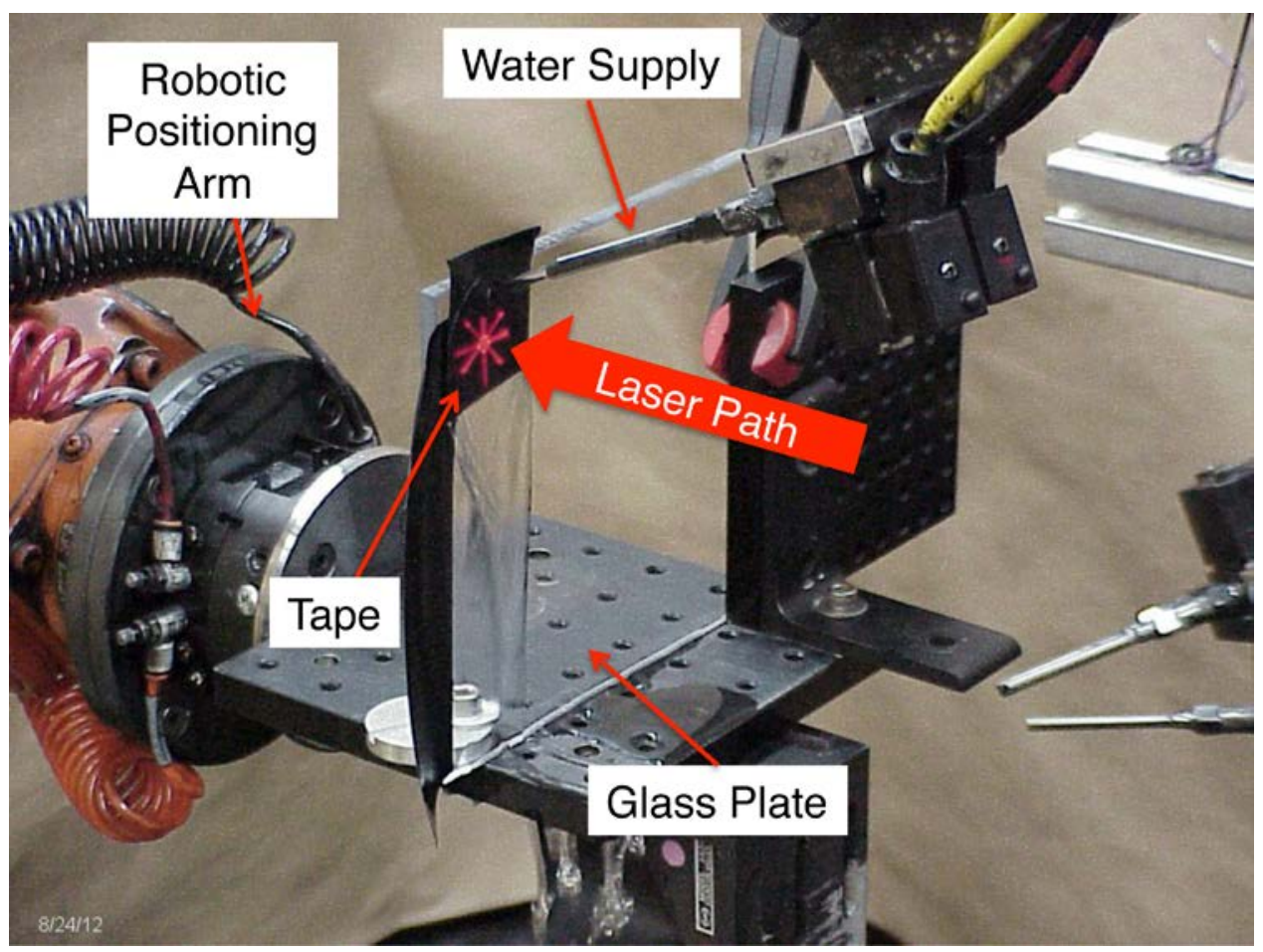

Figure 5.1. Setup of laser shock system.

\section{Laser Shock Principle - Side View}

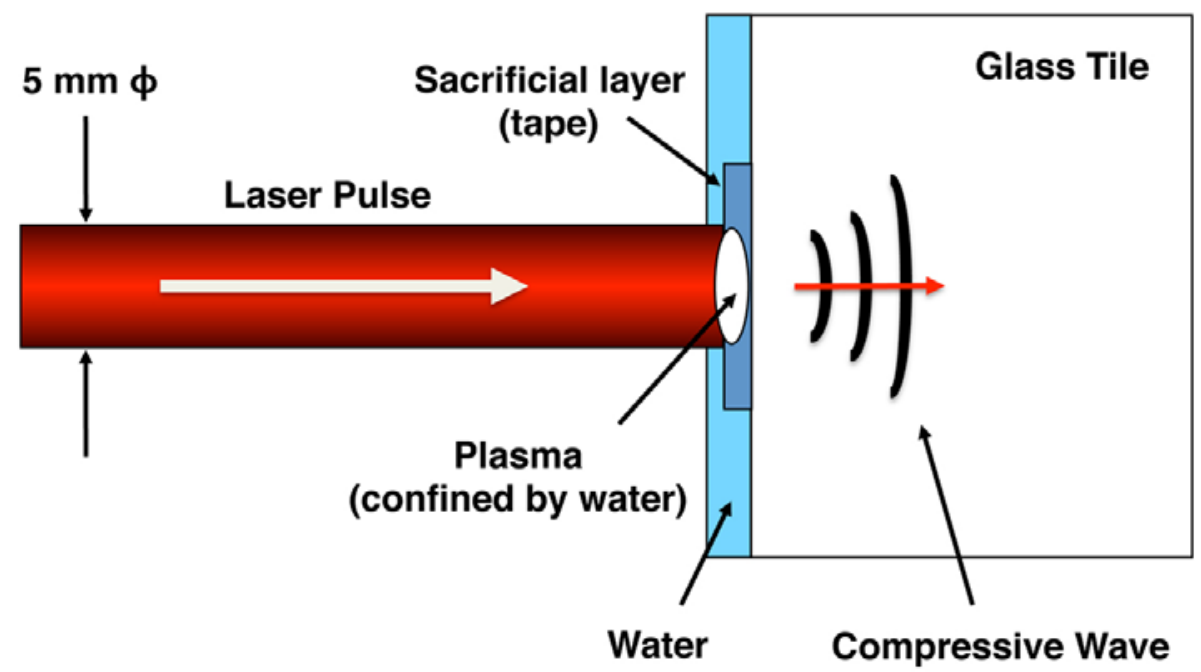

Figure 5.2. Schematic of laser shock process. 


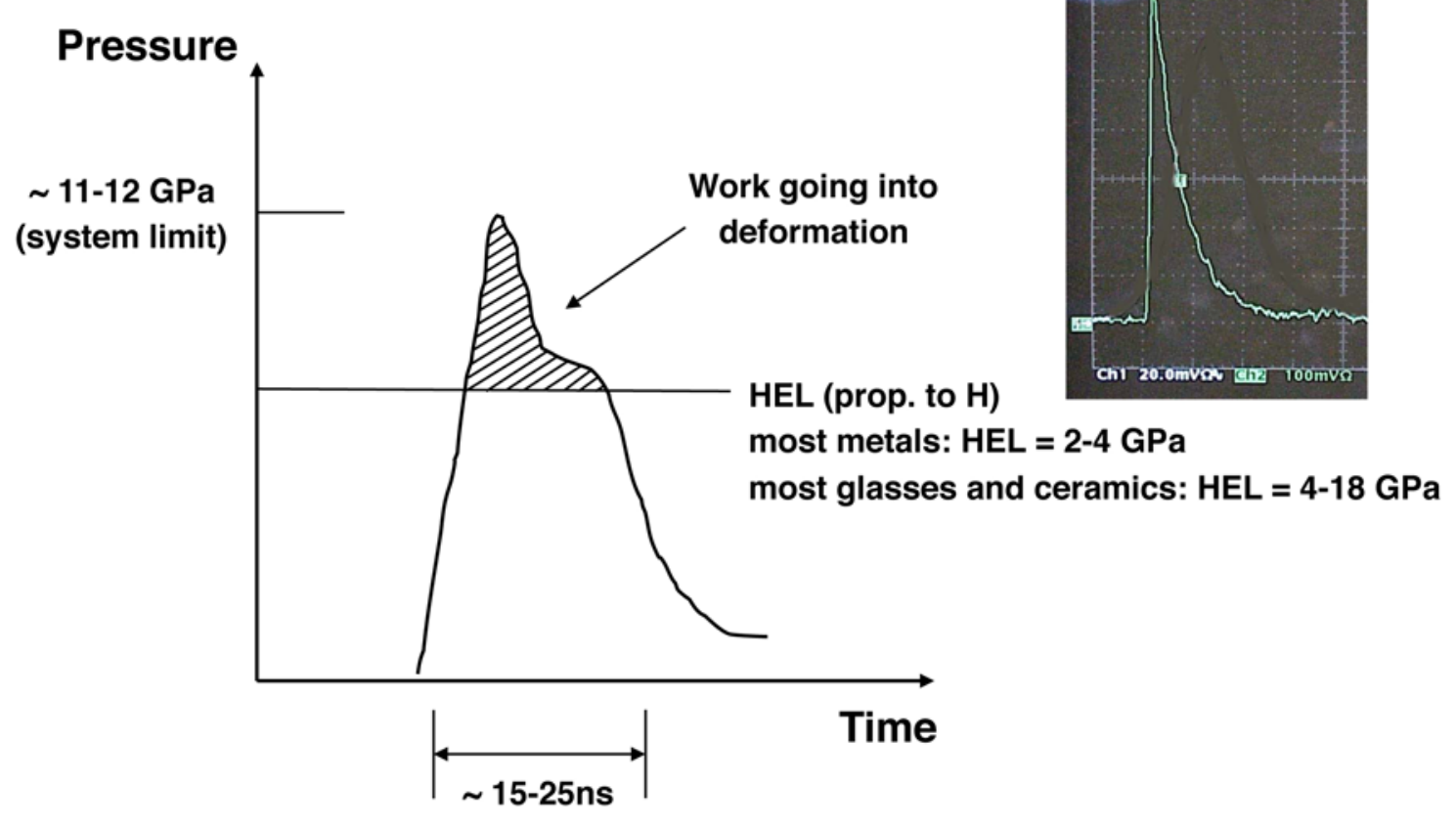

Figure 5.3. Exceeding the Hugoniot elastic limit (HEL) will deform the target material.

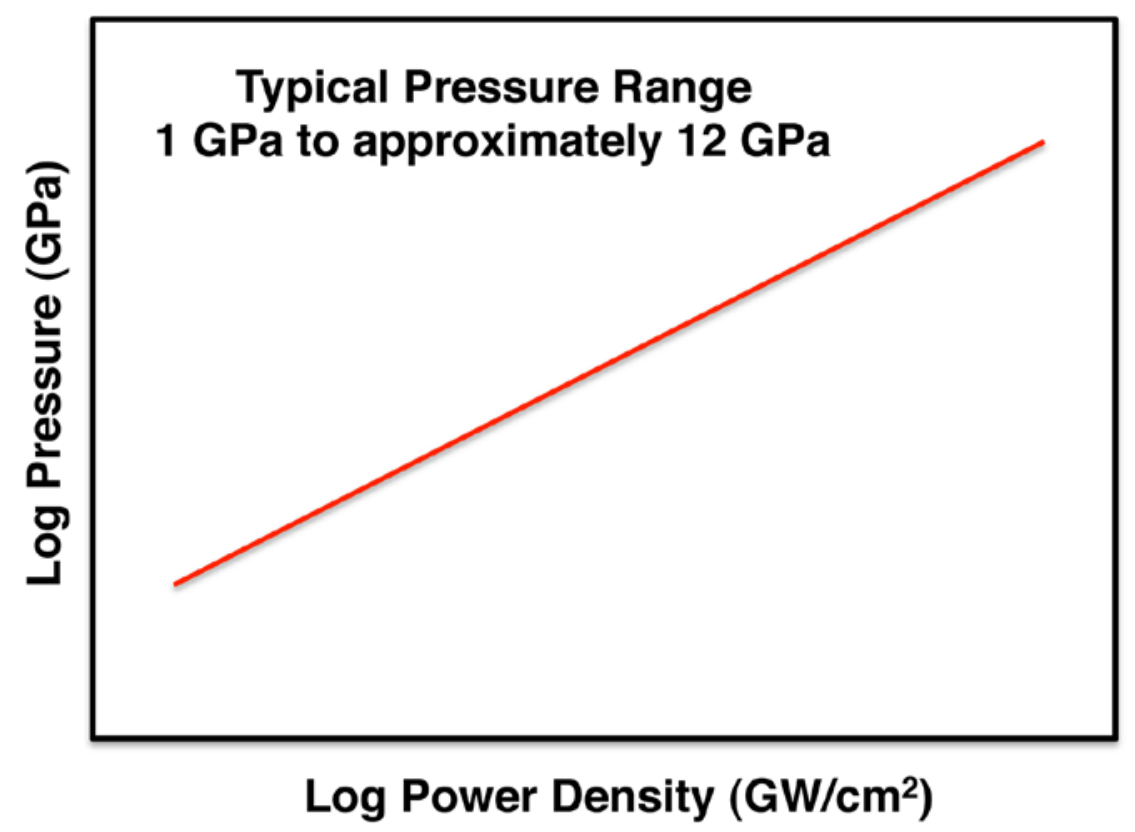

Figure 5.4. Impact pressure is a function of applied power density. 


\subsection{Laser Shock Stress Field}

During the laser shock process, the energy is applied very rapidly, with a rise time of approximately $4 \mathrm{~ns}$, and then gradually decays over a couple tens of ns. The pressure application is nearly constant over a $5 \mathrm{~mm}$ diameter, and this produced "time zero" stress field is represented by the left hand side of Fig. 5.5. The resulting pressure wave mimics the behaviour shown schematically in Figure 5.6. Once this compressive wave (or P-wave) reaches the rear surface, it is reflected as a tensile wave propagating back towards the original impacted surface. During the initial stages of the reflection process, the net wave generated by the combination of the compressive and tensile waves is still primarily compressive in nature. During the mid-stage of the reflection a portion of the net wave is tensile while at the late-stage of the reflection it is predominantly tensile in nature.

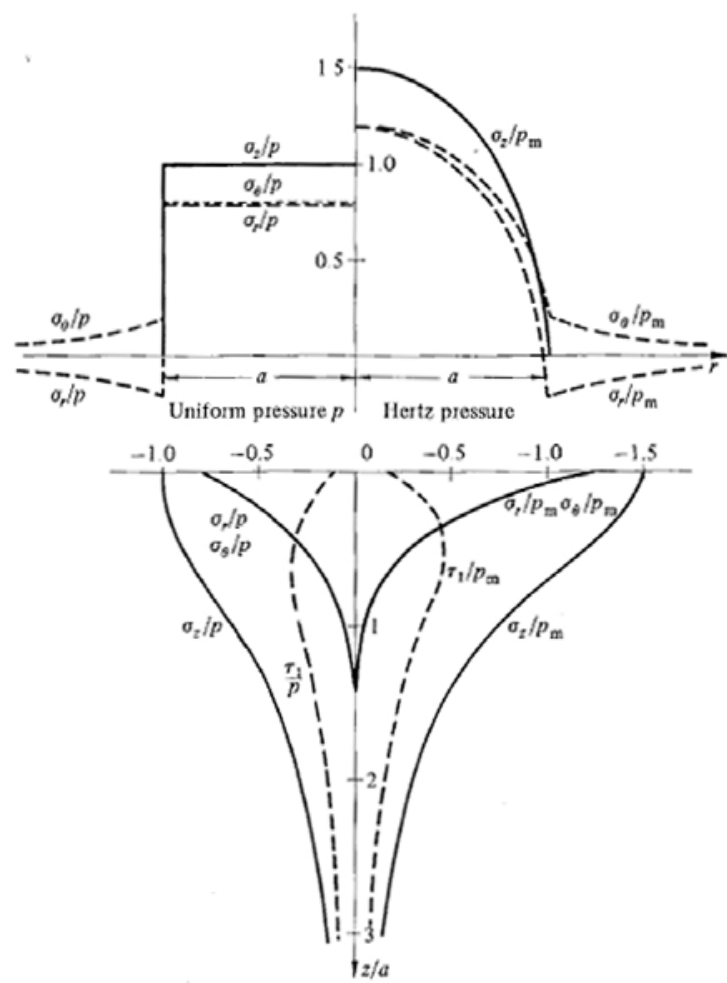

Figure 5.5. Stress fields associated with uniform loading of laser shock (left side of schematic). 


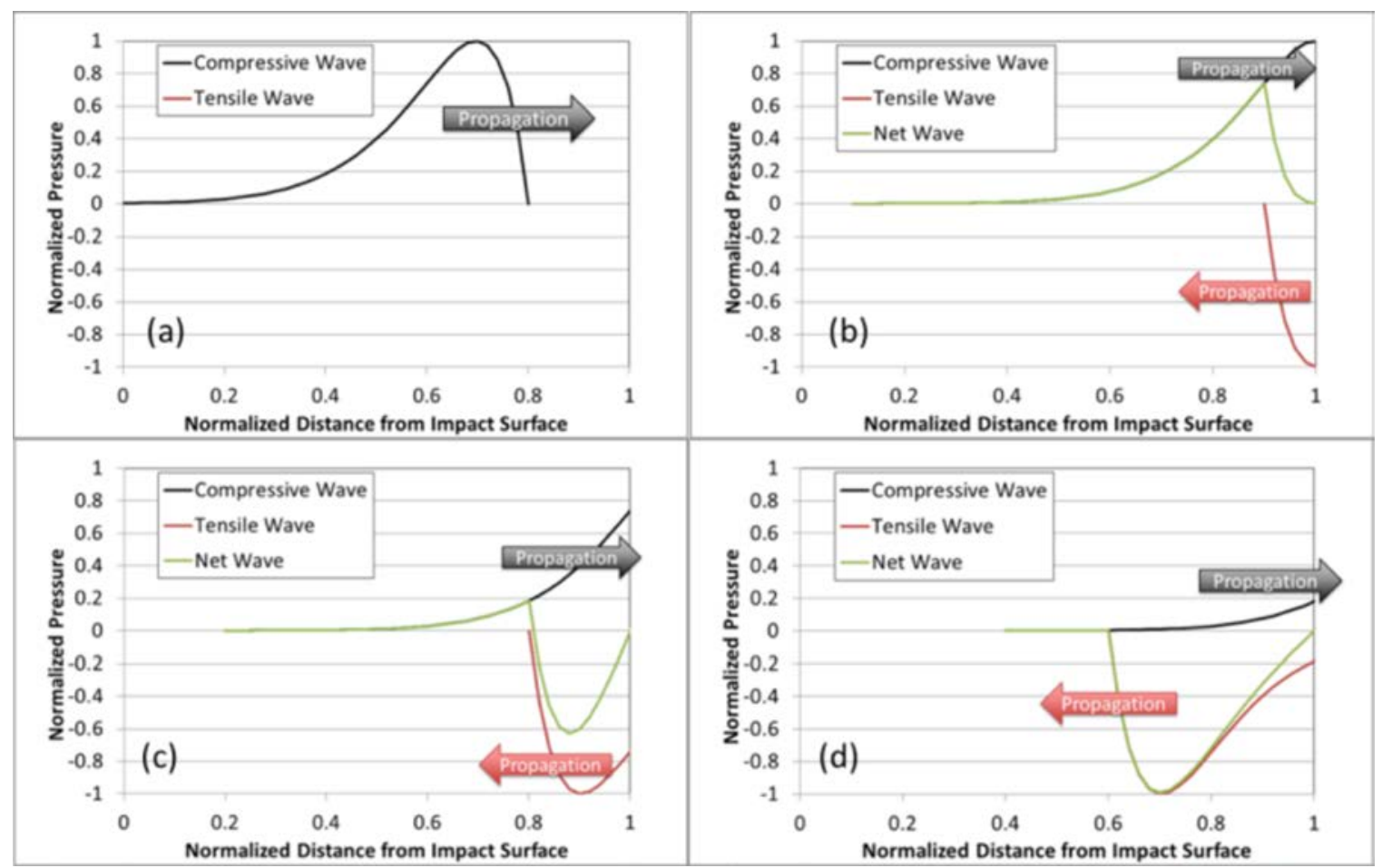

Figure 5.6. One dimensional P-wave propagation curves showing (a) compressive wave just prior to reaching back surface, and the initial interaction of compressive and reflected tensile waves during (b) early, (c) mid, and (d) late stages of reflection. P-wave speeds were $>5500 \mathrm{~m} / \mathrm{s}$ in the tested materials.

\subsection{Experimental Method}

Laser shock testing was used to measure minimum pressures required to induce damage in the glasses and glass ceramics listed in Table 5.1. Each plate was attached to the end of a robotic arm as shown in Fig. 5.1. Individual shots were made in a rectangular pattern consisting of 1 to 5 positions located along 4 parallel rows (schematically shown in Fig. 5.7). The laser intensity versus time profile was measured for each shot. This information was then used to calculate the energy density assuming a laser spot diameter of $5 \mathrm{~mm}$, which remained constant for all shots. The pressure was calculated from existing pressure-energy density curves. The presence of damage on the impacted surface, the back surface, or within the bulk was noted for each shot. 
With the exception of the borosilicate glass, a single shot was made at each position. However, in the case of the last test for Borosilicate plate 3, multiple shots using same laser settings were made for position 4 in row 3 . The laser settings were chosen such that no visible damage occurred during the first shot. Damage evolution was subsequently monitored after successive shots.

Table 5.1. Laser shock test matrix.

\begin{tabular}{|c|c|c|c|c|c|c|}
\hline $\begin{array}{l}\text { Material } \\
\text { Structure }\end{array}$ & Brand Name or Type & $\begin{array}{c}\text { Density } \\
\rho \\
\left(\mathrm{g} / \mathrm{cm}^{\wedge} 3\right)\end{array}$ & $\begin{array}{c}\text { Youngs } \\
\text { Modulus } \\
\text { E } \\
\text { (GPa) }\end{array}$ & $\begin{array}{c}\text { Poissons } \\
\text { Ratio } \\
v\end{array}$ & $\begin{array}{c}\text { Shear } \\
\text { Modulus } \\
\text { G } \\
\text { (GPa) }\end{array}$ & $\begin{array}{c}\text { Bulk } \\
\text { Modulus } \\
\text { K } \\
\text { (GPa) }\end{array}$ \\
\hline Glass & Fused Silica & 2.18 & 72.8 & 0.159 & 31.4 & 35.6 \\
\hline Glass & Starphire (soda-lime silicate) - Air & 2.50 & 73.1 & 0.203 & 30.4 & 41.0 \\
\hline Glass & Starphire (soda-lime silicate) - Tin & 2.50 & 73.1 & 0.203 & 30.4 & 41.0 \\
\hline Glass & BOROFLOAT (borosilicate) - Air & 2.22 & 63.1 & 0.180 & 26.7 & 32.9 \\
\hline Glass & BOROFLOAT (borosilicate) - Tin & 2.22 & 63.1 & 0.180 & 26.7 & 32.9 \\
\hline Glass & Fe-containing soda-lime silicate - Tin & 2.51 & 75.5 & 0.231 & 30.7 & 46.8 \\
\hline Glass & Fe-containing soda-lime silicate - Air & 2.51 & 75.5 & 0.231 & 30.7 & 46.8 \\
\hline Glass Ceramic & ROBAX & 2.51 & 99.7 & 0.269 & 39.3 & 71.9 \\
\hline
\end{tabular}

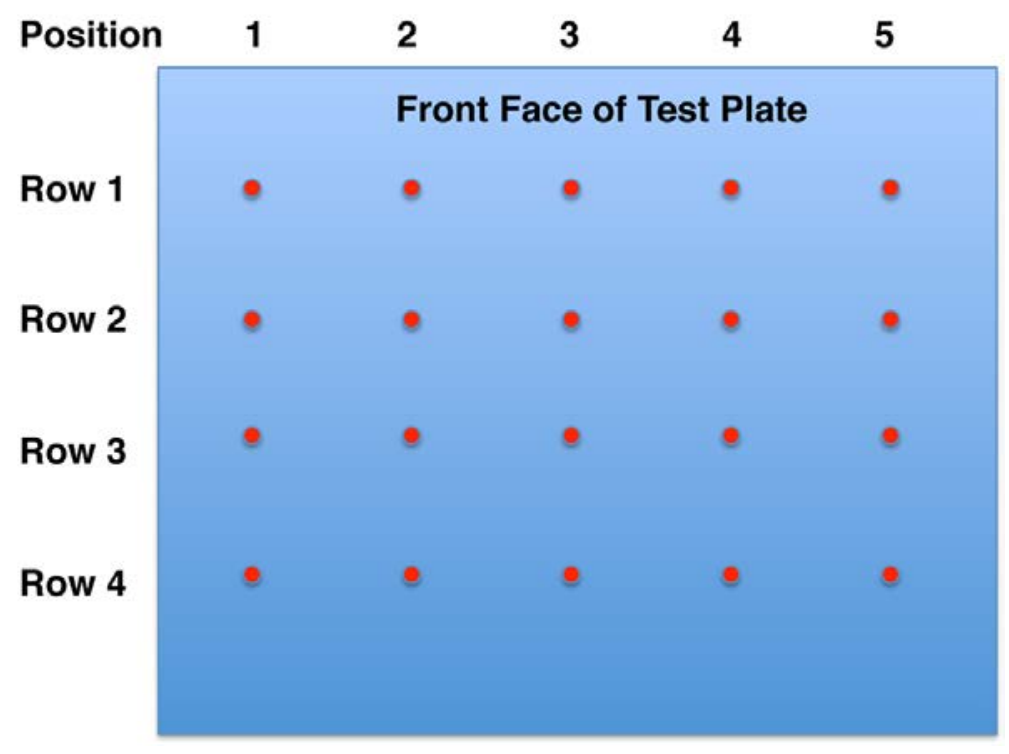

Figure 5.7. Layout of laser shock tests on test tiles. 


\subsection{Results and Discussion}

An example of the pressure - damage initiation response is represented graphically in Fig. 5.8 for one of the materials, and the minimum pressure needed to initiate damage in all the materials is shown in Fig. 5.9. The complete listing of all measured data is included in Appendix II. Of all the materials studied, the fused silica exhibited the lowest damage initiation pressure.

Damage initiated on the tin side at lower impact stresses than the air side for the float glasses (Starphire, BOROFLOAT, and the iron-containing soda lime silicate). Additionally, more failure initiation sites were visible on the tin side than the air side for an equivalent impact pressure. This is consistent with there being a greater size and concentration of surface-located flaws on the tin side than the air side. An artifact of the damage initiation starting at lower impact pressures on the tin side is the conical and secondary cracking spreads out at shallower depths than on the air side for an equivalent impact pressure.

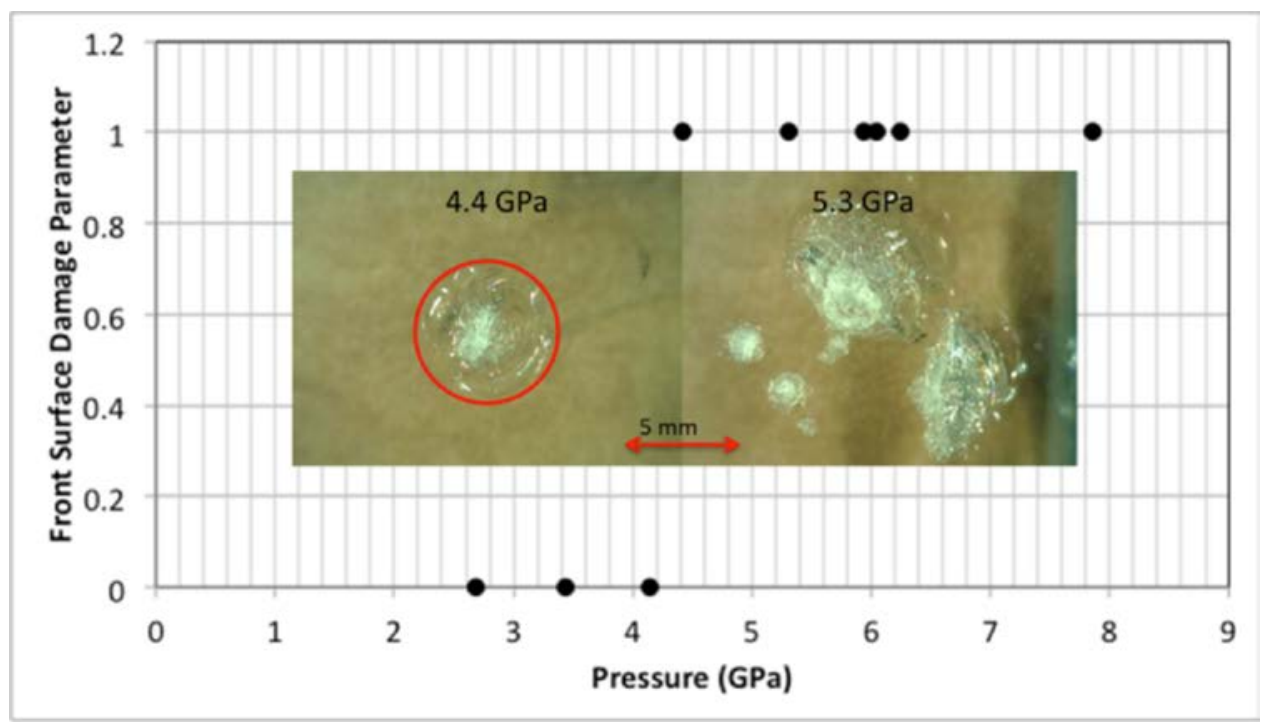

Figure 5.8. Graphical example of onset of impact-side damage as a function of pressure for the tin side of Starphire soda lime silicate glass. Zero represents no damage whereas a value of one means damage occurred. 


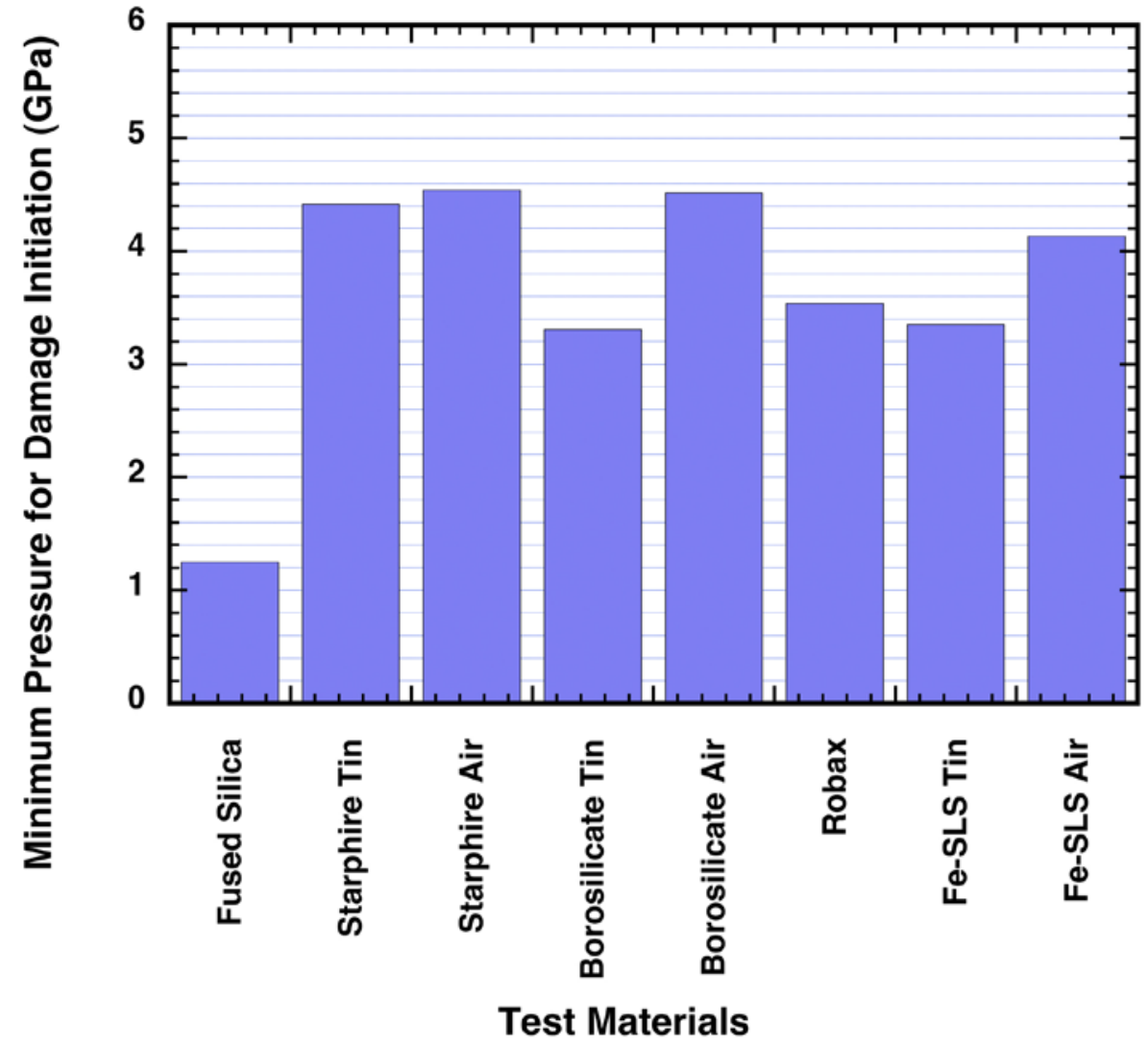

Figure 5.9. Minimum laser shock pressure needed to initiate damage on the contact side.

Comparisons of laser-shock impact are shown in Figs. 5.10-5.12 for fused silica, the tin side of Starphire and the tin side of BOROFLOAT, respectively. Among the glasses, fused silica was damaged at the lowest impact stresses. Damage in Starphire tended to show a spotty, often disconnected damage zone. Damage in BOROFLOAT tended to spread out more radially at shallower depths. 


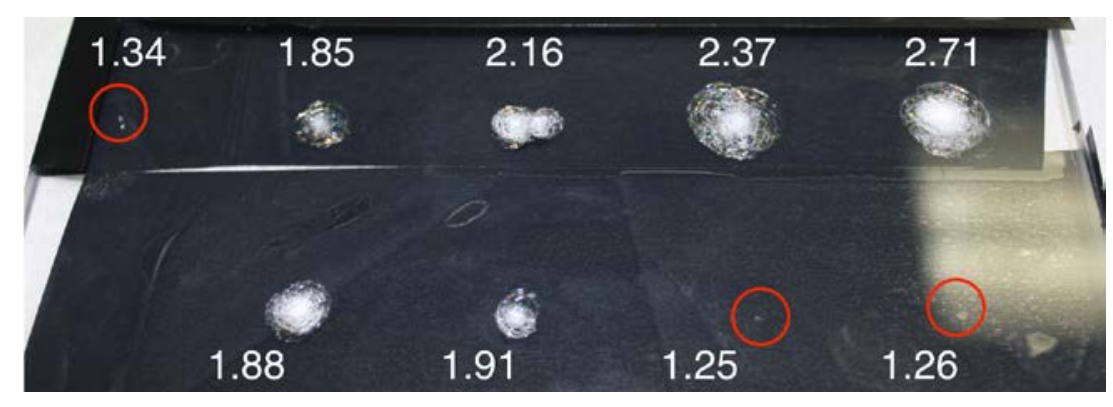

Figure 5.10. Shock damage on fused silica glass. Shown values are the applied pressure in GPa.

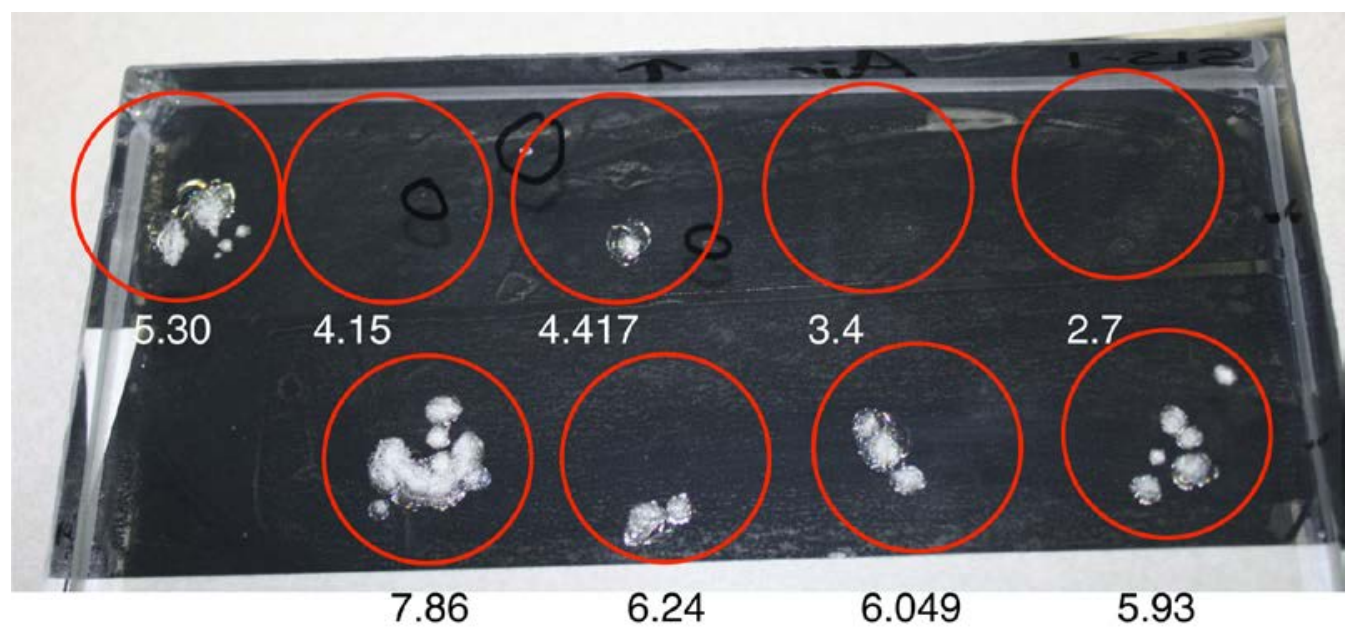

Figure 5.11. Shock damage on the tin side of Starphire soda lime silicate glass. Shown values are the applied pressure in GPa. 


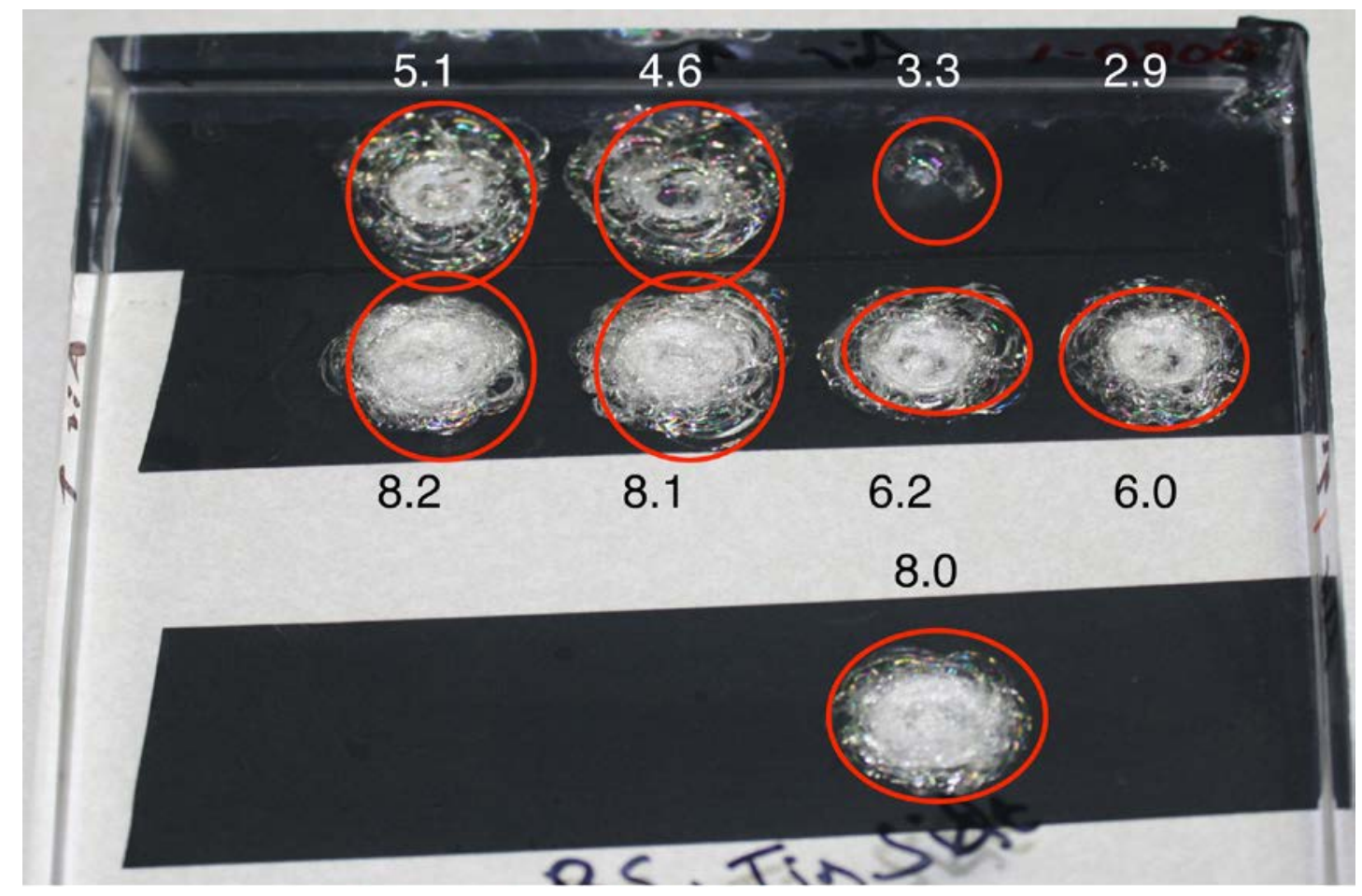

Figure 5.12. Shock damage on the tin side of BOROFLOAT borosilicate glass. Shown values are the applied pressure in $\mathrm{GPa}$.

Multiple failure initiation sites were visible in the impact side damage zone, and their initiations were likely a consequence of the local surface flaw population that existed in a (Hertzian) radial tensile stress annular zone around the $5 \mathrm{~mm}$ diameter impact area. Multiple initiation sites are quite possible owing to the short ( $20 \mathrm{~ns})$ pulse of laser shock event. Examples of this are shown in Figs. 5.13-5.14.

The formation of multiple fracture initiations is possible because the impact pulse is so short (less than $30 \mathrm{~ns}$ ). The terminal crack propagation speed is about one-half the S-wave [21], and that speed is listed in Table 5.2 for the materials that were laser shock tested. It takes approximately $4000 \mathrm{~ns}$ for a crack to propagate $180^{\circ}$ circumferentially around a $5 \mathrm{~mm}$ diameter, so if a pulse is shorter than that, then there is a possibility that two or more cracks could form. The pulse time was about 2 orders of magnitude shorter than that, so the observation of there being multiple failure initiations is consistent with that. 


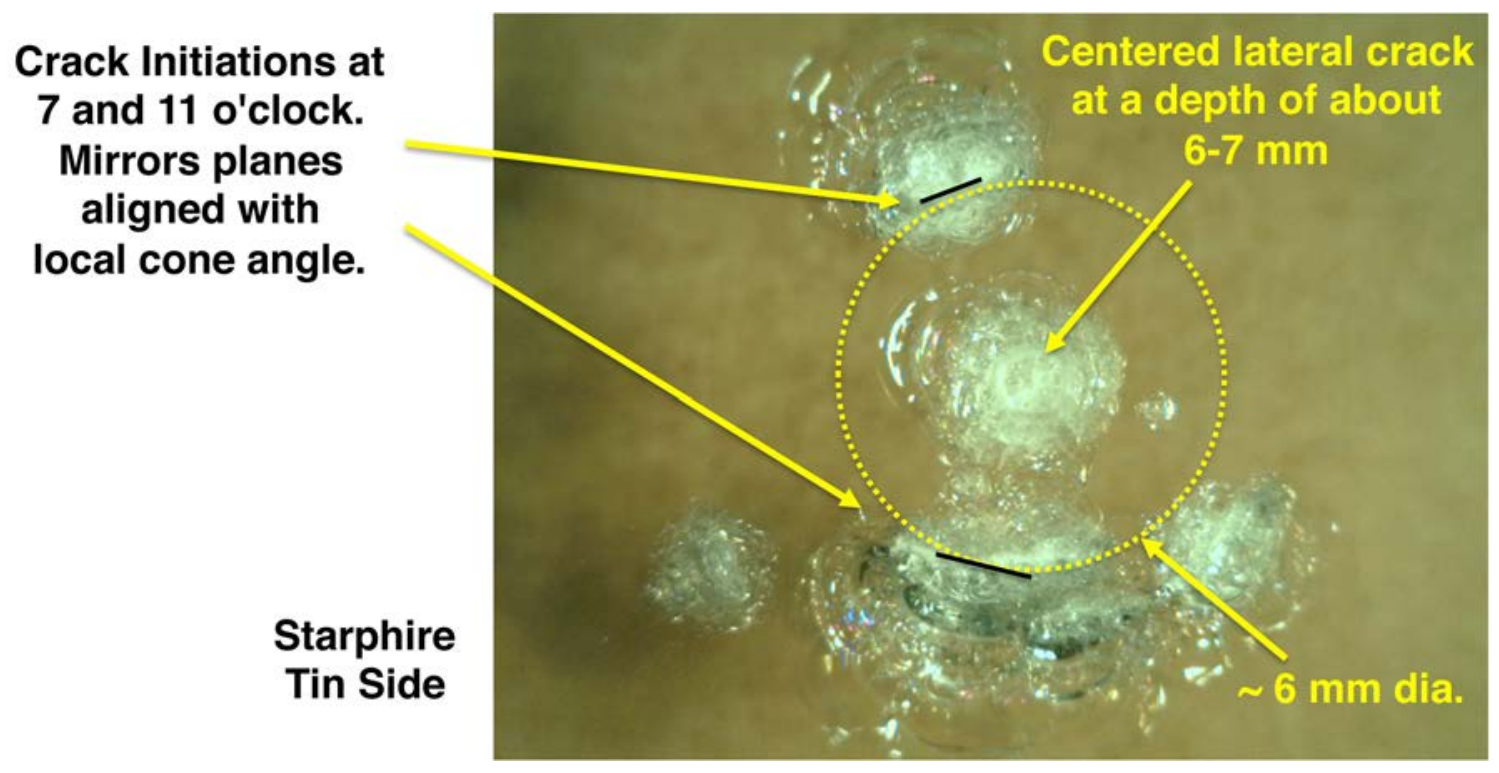

Figure 5.13. Example of multiple failure initiation locations on laser shock impacted Starphire soda lime silicate glass.

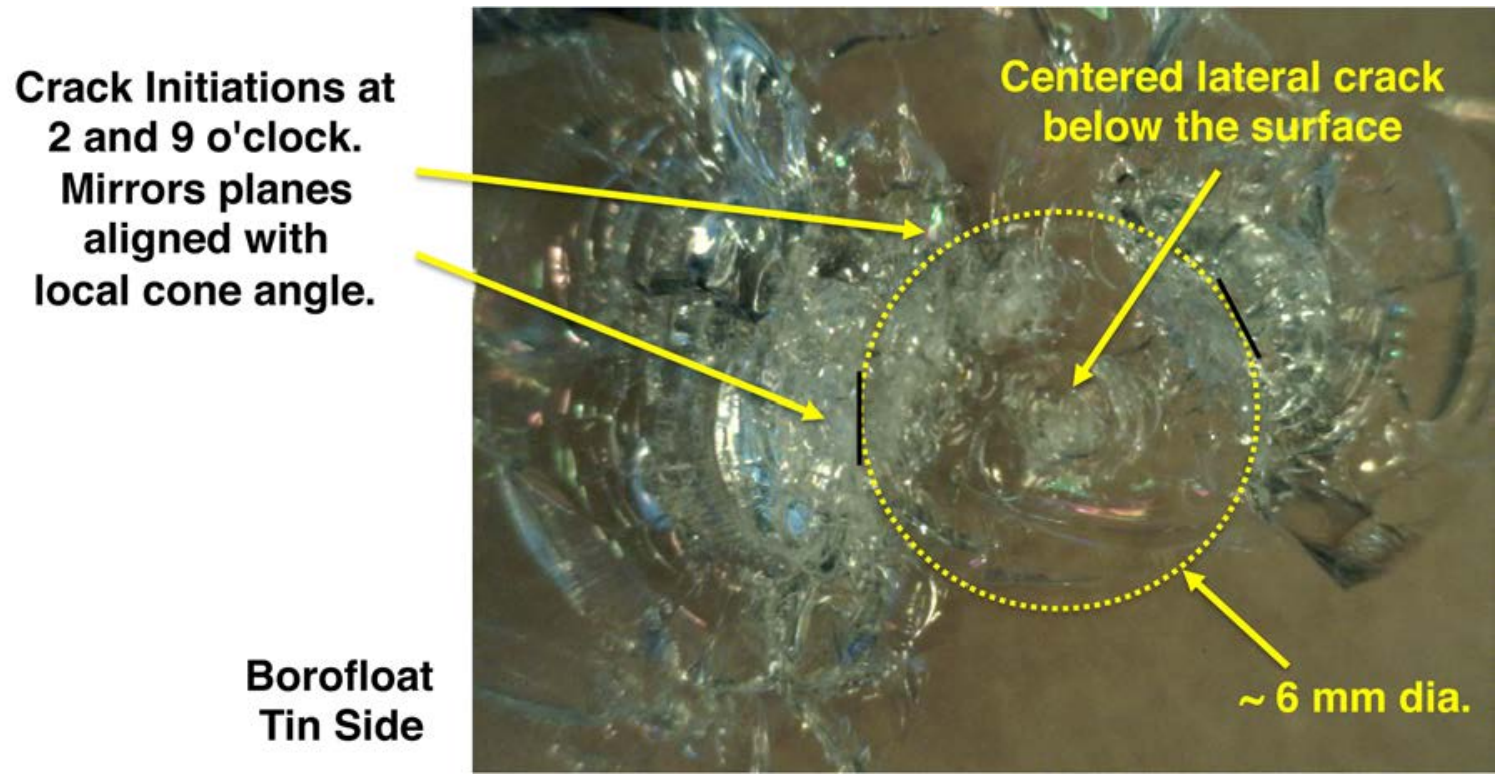

Figure 5.14. Example of multiple failure initiation locations on laser shock impacted BOROFLOAT borosilicate glass. 
Table 5.2. Estimated crack propagation speeds.

\begin{tabular}{|c|c|c|c|c|c|c|c|}
\hline $\begin{array}{c}\text { Material } \\
\text { Structure }\end{array}$ & Brand Name or Type & $\begin{array}{c}\text { P-Wave or } \\
\text { Compressive } \\
\text { Wave } \\
\text { Speed } \\
\text { VL } \\
(\mathrm{m} / \mathrm{s})\end{array}$ & $\begin{array}{c}\text { S-Wave or } \\
\text { Shear } \\
\text { Wave } \\
\text { Speed } \\
\text { vS } \\
(\mathrm{m} / \mathrm{s})\end{array}$ & $\begin{array}{c}\text { Estimated } \\
\text { Maximum or Terminal } \\
\text { Crack Propagation } \\
\text { Speed } \\
\text { VC } \\
(\mathrm{m} / \mathrm{s})\end{array}$ & $\begin{array}{c}\text { Estimated } \\
\text { Time it takes to } \\
\text { go around } 5 \mathrm{~mm} \\
\text { circumference } \\
(\mu \mathrm{s})\end{array}$ & $\begin{array}{c}\text { Estimated } \\
\text { Maximum pulse } \\
\text { time to get more } \\
\text { than } 1 \text { initiation } \\
\text { on } 5 \mathrm{~mm} \text { circle } \\
(\mu \mathrm{s})\end{array}$ & $\begin{array}{c}\text { Estimated } \\
\text { Maximum pulse } \\
\text { time to get more } \\
\text { than } 1 \text { initiation } \\
\text { on } 5 \mathrm{~mm} \text { circle } \\
(\mathrm{ns})\end{array}$ \\
\hline Glass & Fused Silica & 5957 & 3793 & 1896 & 8.3 & 4.1 & 4100 \\
\hline Glass & Starphire (soda-lime silicate) - Air & 5714 & 3488 & 1744 & 9.0 & 4.5 & 4500 \\
\hline Glass & Starphire (soda-lime silicate) - Tin & 5714 & 3488 & 1744 & 9.0 & 4.5 & 4500 \\
\hline Glass & BOROFLOAT (borosilicate) - Air & 5560 & 3474 & 1737 & 9.0 & 4.5 & 4500 \\
\hline Glass & BOROFLOAT (borosilicate) - Tin & 5560 & 3474 & 1737 & 9.0 & 4.5 & 4500 \\
\hline Glass & Fe-containing soda-lime silicate - Tin & 5910 & 3495 & 1748 & 9.0 & 4.5 & 4500 \\
\hline Glass & Fe-containing soda-lime silicate - Air & 5910 & 3495 & 1748 & 9.0 & 4.5 & 4500 \\
\hline Glass Ceramic & ROBAX & 7043 & 3959 & 1980 & 7.9 & 4.0 & 4000 \\
\hline
\end{tabular}

A representative example of the commonly observed impact side damage zone is shown in Fig. 5.15. This impact side damage zone typically had a conical shaped habit and propagated several millimeters in from the surface.

Additionally, a subsurface damage zone sometimes formed in the (thick) Starphire and BOROFLOAT glasses whose formation was not influenced by surface-located flaws and any crack propagation associated with that impact side damage. The zone tended to form with higher impact stresses. It was not observed in the iron-containing soda lime silicate; however, that could be a consequence of that material not being tested to as high an impact stress as the Starphire and BOROFLOAT were. It was co-present with impact-initiated surface damage in almost all tests; however, failure analysis indicates this subsurface damage zone perhaps formed first, and then the crack propagation from the impact-side surface damage intersected it or was perturbed by its already-existing presence. The fact that the speed of the p-wave (compressive wave) is more than 3 times faster than the estimated terminal crack propagation speed in these materials is consistent with this interior damage zone forming first. In one test case (BOROFLOAT and 5.1 GPa), see Fig. 5.16, this subsurface damage zone formed in the absence of impact-side surface damage supporting the assertion their damage type is completely independent of impact-side surface damage. This internal damage zone was not evident in any of the laser shock tests in the glass ceramic material. 


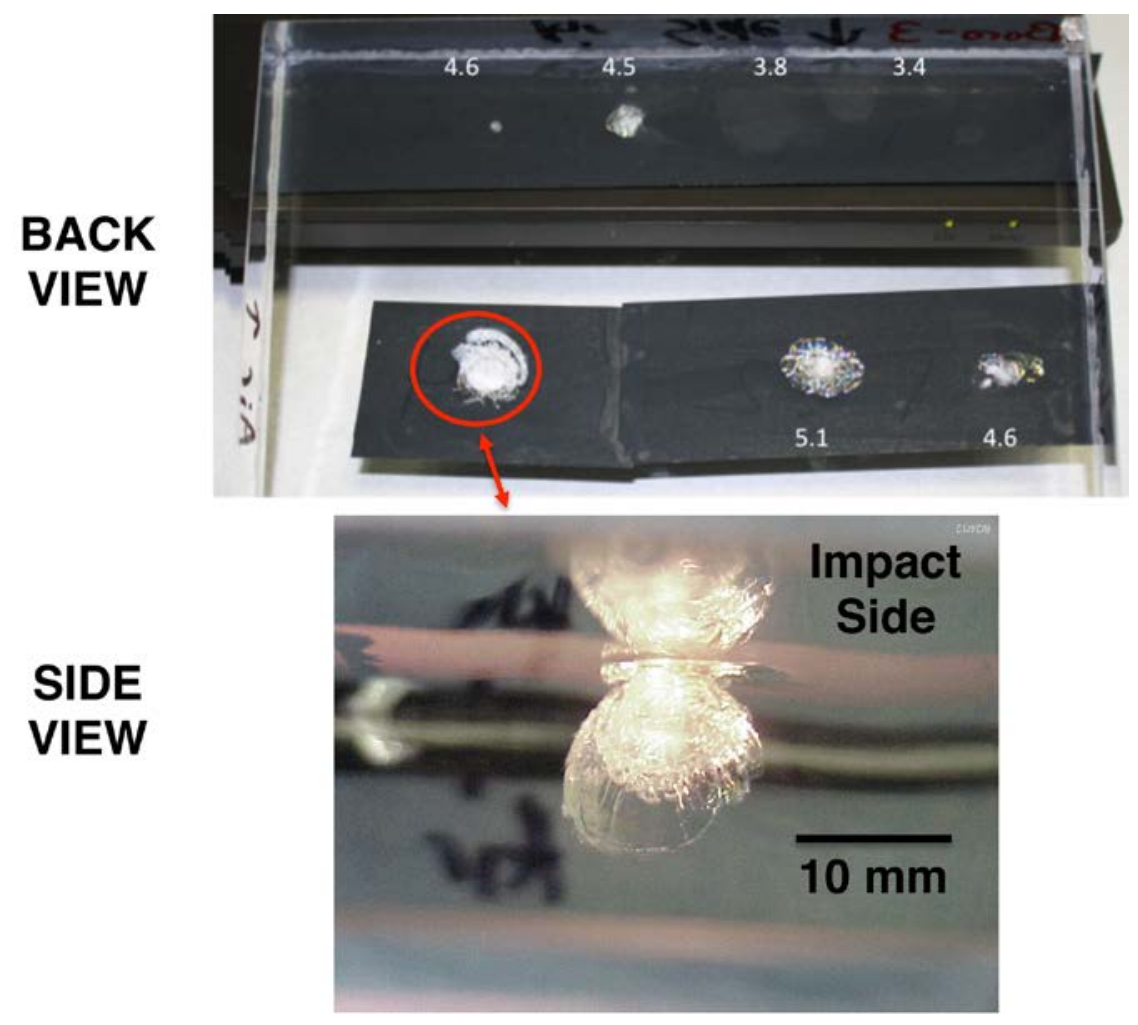

Figure 5.15. Side view of a surface-located damage zone caused by laser shock. 


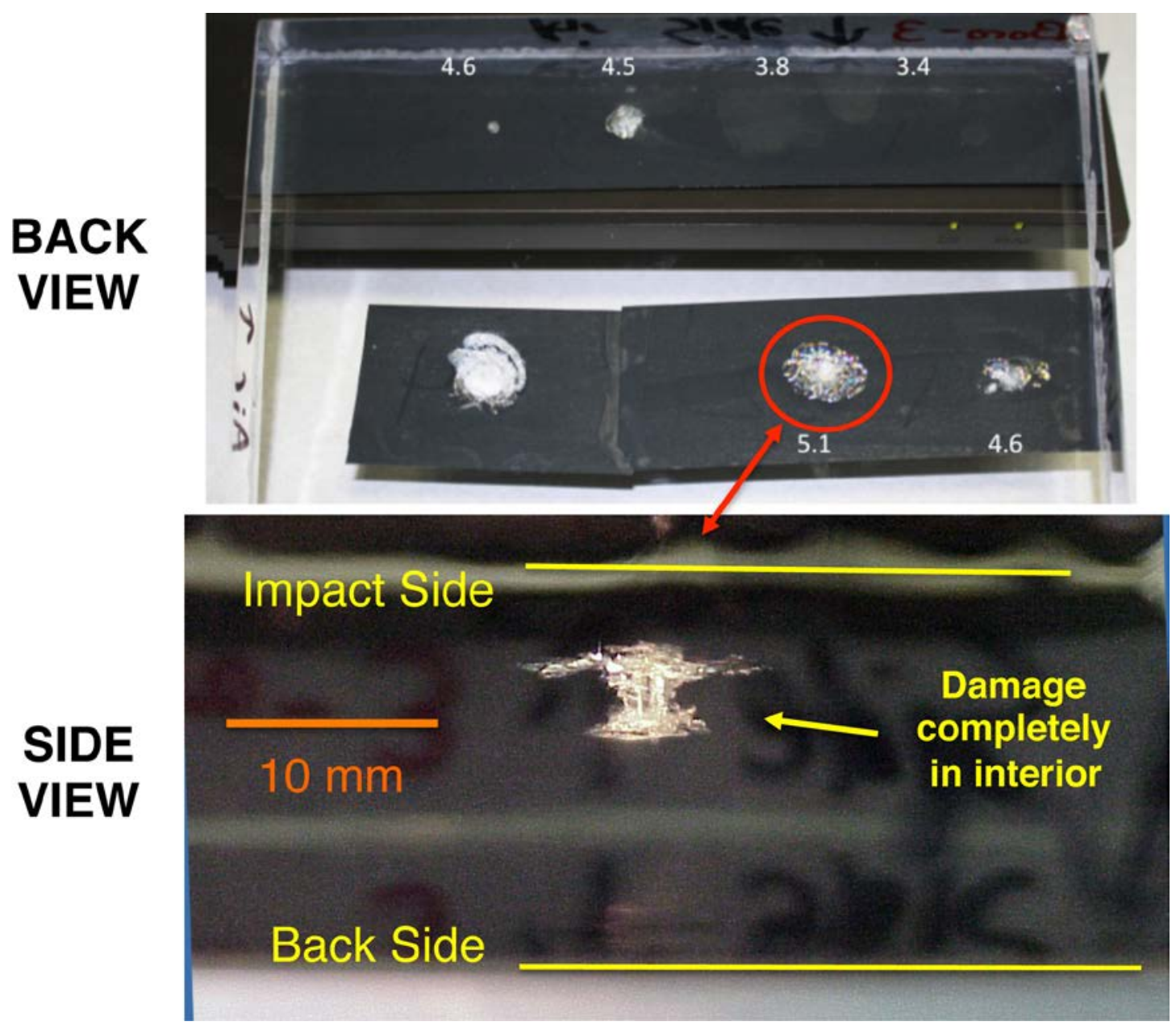

Figure 5.16. Side view of an interior damage zone caused by laser shock.

The impact side damage, and its ease to initiate, is most likely limited by the surface-flaw population that exists on the glasses and glass ceramics. Surface flaws are a characteristic of the material's handling history and are not necessarily characteristic of the material itself. A smaller flaw size should result in greater impact damage resistance. The trend of impact side damage initiation stress tracked (Figs 5.17-5.18) with previous work of the authors on ball impact crack initiation force and spherical indentation ring crack initiation force [22-24]; this is consistent with impact side damage initiation being associated with surface-located flaws. Impact side damage initiation stress did not track with apparent yield stress (Fig. 5.19). 


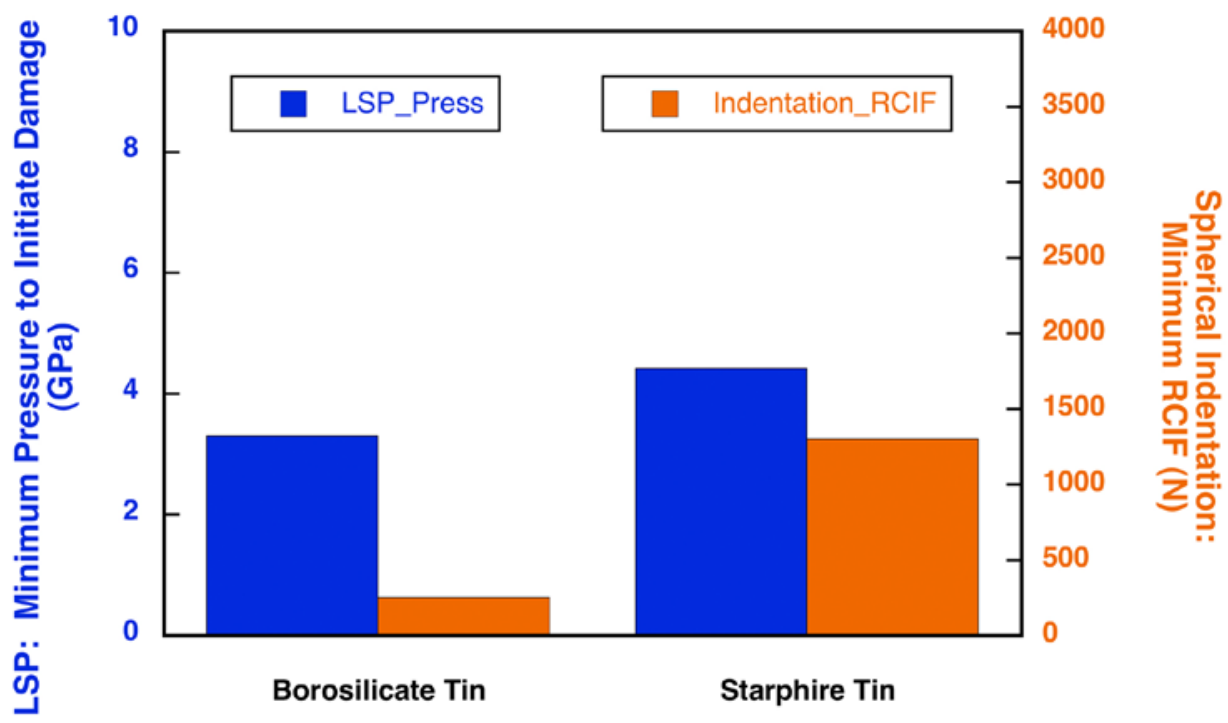

Figure 5.17. Minimum pressure to initiative shock damage increased with ring crack initiation force measured using spherical indentation in previous studies by the authors [22-24].

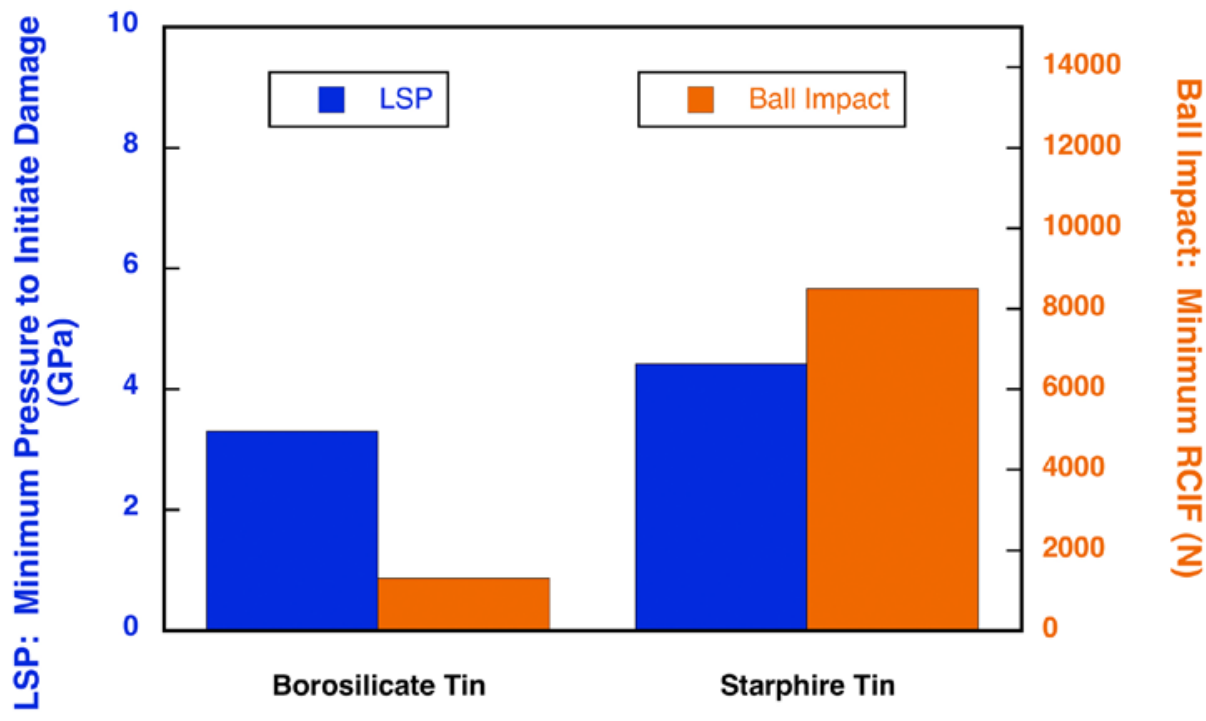

Figure 5.18. Minimum pressure to initiative shock damage increased with ball impact ring crack initiation force measured in a previous studies by the authors [22-24]. 


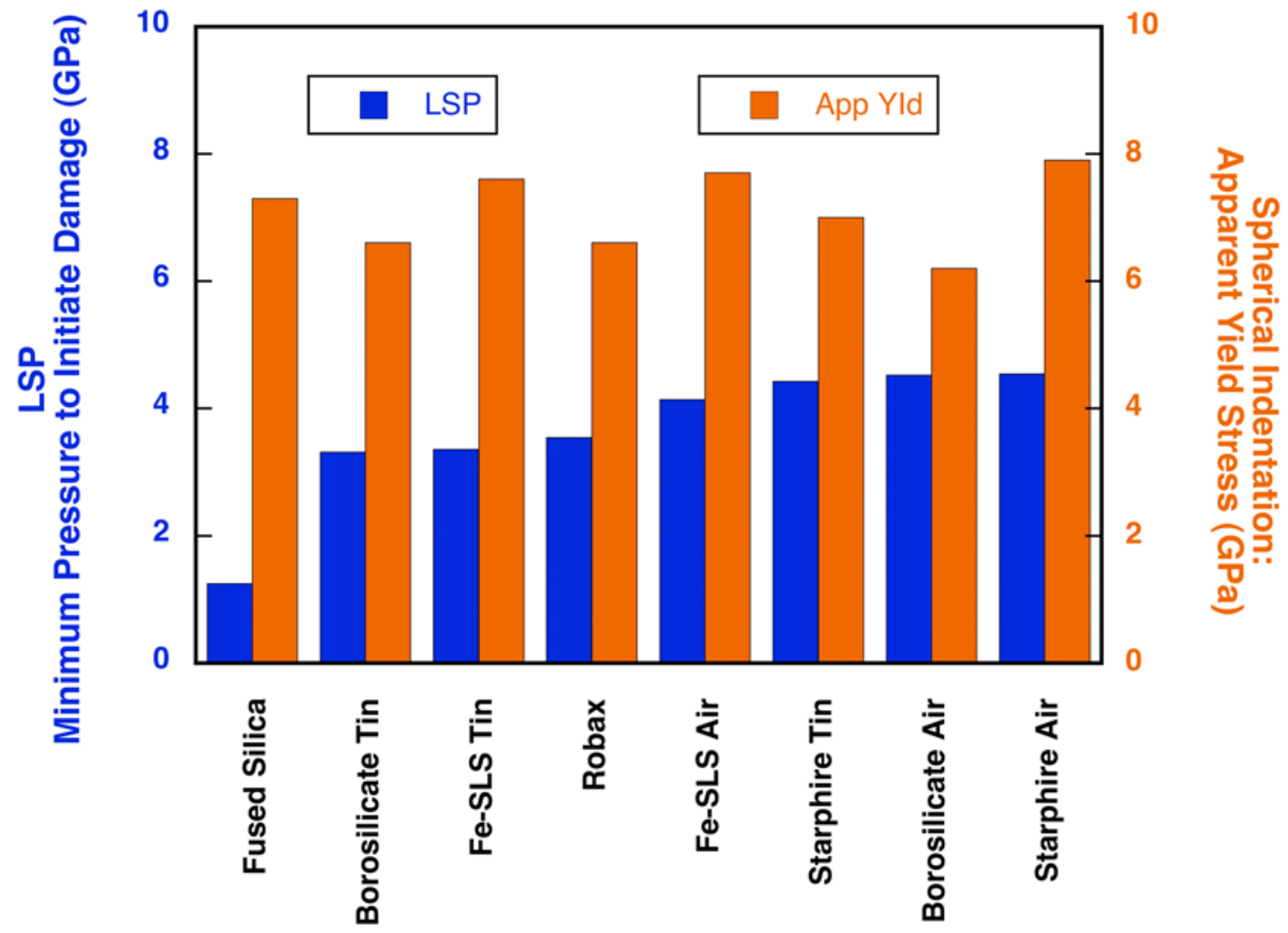

Figure 5.19. There was no correlation between onset of laser-shock-induced damage on the impact surface and apparent yield stress.

The amount of microcracking within the $5 \mathrm{~mm}$ diameter impact of the ROBAX glass ceramic was more extensive (finer sized) than in the glasses. This could be a consequence of potential differences in surface flaw populations among these materials and the fact that the glass ceramic has nano crystallites in it.

If available, then a larger tile thickness of test material is desired to avoid tile fracture. A suggested thickness of 8-9 $\mathrm{mm}$ or greater is recommended for laser shock testing. Therefore, a fractured tile is an indicator of a "specimen size effect" and may inhibit the ability to examine bulk damage otherwise produced in a thicker tile of the same material. 


\section{SUMMARY}

Several siliceous based materials were examined in this study. Some were glasses (fused silica or fused quartz, Starphire soda lime silicate glass, hydrated Starphire, BOROFLOAT borosilicate glass, an iron-containing soda lime silicate glass, opal (a hydrated silicate glass), a glass ceramic (ROBAX), and others were single crystal (quartz) and polycrystalline (Coesite) ceramics. Some of these materials are presently used in transparent armor systems or are under consideration for such. The testing of these materials allowed for comparisons of glass types, glass versus a glass ceramic, effect of water content, and comparison of amorphous versus crystalline materials of the same composition.

The responses of these materials to high pressure loading were studied using spherical indentation testing, diamond anvil cell testing, and laser shock testing. Each test is different and enables the study of different aspects of high pressure response. Spherical indentation, when using small indenter diameters, produces both high pressure and shear, and the loading and unloading histories enable estimations of yield stress and hysteresis. Diamond anvil cell testing produces a hydrostatic stress, and when concurrently used with Raman Spectroscopy, enables the identification of changes of state of material as a function of pressure. Laser shock testing produces high pressures but under dynamic conditions (impact event less than $30 \mathrm{~ns}$ ), so this enables the study of the effect of rate on high pressure.

From these three tests, the following observations were made:

Spherical indentation testing

- Always confirm indenter diameter. The diameter of a commercial spherical indenter should be independently confirmed by the user because the manufacturer's reported value of it should not be trusted. For example, the diameter of the indenter used in this study was $\sim 27 \%$ smaller than what the manufacturer reported, and this difference was confirmed using two different measurement methods. This is noteworthy because once a 
correct value of diameter was used in the Hertzian stress analysis, the measured elastic responses of the test materials behaved as expected.

- The use of the adjective "apparent" in apparent yield stress. A yield-like response is being detected in spherical indentation by the use of a indent depth of penetration sensor. But in a Hertzian indent, when a yield-like response occurs, it occurs at a location under the indenter at a depth of approximately one-fourth the contact diameter. The indenter depth of penetration sensor will not detect (permanent) penetration until that yielding manifests itself to the surface. Therefore, the "actual" yielding in spherical indentation occurs at a compressive load slightly lower than what it experimentally determined here at an estimated, but unconfirmed, stress difference of $5-10 \%$. For that reason, our reporting of a value here is not the material's actual yield stress but rather an "apparent yield stress."

- Estimating apparent yielding. The onset of apparent yielding (i.e., an apparent yield stress) could be estimated by (1) using an indent tester capable of concurrently measuring applied load and indenter depth of penetration, and (2) identifying the indentation load where the idealized (elastic) Hertzian loading curve diverged from the experimentally generated loading curve.

- Comparison of apparent yield stresses. The BOROFLOAT's apparent yield stress $(\sim 5.5 \mathrm{GPa})$ was about $25 \%$ lower than that of Starphire ( $7.5 \mathrm{GPa})$. The apparent yield stress of the iron-containing soda lime silicate was equivalent to that of the Starphire. The apparent yield stress of ROBAX was about 10\% lower. The apparent yield stress of opal was about $80 \%$ lower than that of Starphire. Two different directions of loading on alpha quartz had anisotropy and their apparent yield stresses were about 15\% lower than that of Starphire.

- Hardness, spherical indentation, yield stress, and material properties. Estimating the yield stress (or an apparent yield stress) of a material is determining an intrinsic material property. Hardness, on the other hand, is not a material property but rather is a material 
characteristic because it depends on the indenter shape being used. If spherical indentation can be employed to estimate apparent yield stress, then it is a superior measurement.

- Hysteresis and elastic modulus. While BOROFLOAT had a lower apparent yield stress than both Starphire and the iron-containing soda lime silicate glass, its total amount of hysteresis was $\sim 35 \%$ lower when indented to the same maximum load. However, the amount of applied stress is higher in the Starphire and iron-containing soda lime silicate than the BOROFLOAT (for the same indentation force) because the elastic modulus of both of them is about $15 \%$ higher than that of BOROFLOAT. The glass ceramic had an equivalent amount of hysteresis as BOROFLOAT, but its elastic modulus is $\sim 50 \%$ higher than that of BOROFLOAT. If the product of the amount of hysteresis and elastic modulus is related to total absorbed energy, then the glass ceramic absorbs more energy than the BOROFLOAT.

Diamond anvil cell testing

- Permanent densification. All the glasses showed evidence of permanent densification when they were hydrostatically pressured up to $20 \mathrm{GPa}$. The identification of permanent densification for the glass ceramics could not be made.

- Long-range ordering. While under pressure, peaks in the Raman spectrum tended to form for all the glasses and glass ceramics by $10 \mathrm{GPa}$ indicating long-range ordering. They were reversible and were absent after unloading. Diffraction (X-Ray or neutron) analysis would need to be concurrently performed to explain what that long-range ordering was.

- Effect of water in glass. The amount of peak shifting per unit stress was much greater for the hydrated Starphire soda lime silicate glass than the baseline (unhydrated or asreceived) Starphire. This indicates that introduced water into Starphire's amorphous structure decreases stiffness. 
- Coesite and Stishovite. It appears that an additional phase is formed in pressurized Coesite sample at high pressures - perhaps Stishovite. This is evidenced by the appearance of new Raman peaks at pressures above 6.5 GPa. Diffraction analysis and repeat testing would confirm this.

\section{Laser shock testing}

- Surface flaws. The impact side damage, and its ease to initiate, is most likely limited by the surface-flaw population that exists on the glasses and glass ceramics. Surface flaws are a characteristic of the material's handling history and not necessarily characteristic of the material itself. A smaller flaw size should result in greater impact damage resistance. Impact side damage initiation stress tracked with previous work of the authors on ball impact crack initiation force and spherical indentation ring crack initiation force; this is consistent with impact side damage initiation being associated with surface-located flaws. Impact side damage initiation stress did not track with apparent yield stress.

- Multiple failure initiations. Multiple failure initiation sites were visible in the impact side damage zone, and their initiations were likely a consequence of the local surface flaw population that existed in a (Hertzian) radial tensile stress annular zone around the $5 \mathrm{~mm}$ diameter impact area. Multiple initiation sites are quite possible owing to the short $(\sim 20$ ns) pulse of laser shock event.

- Tin side damages easier in float glass. Damage initiated on the tin side at lower impact stresses than the air side for the float glasses (Starphire, BOROFLOAT, and the ironcontaining soda lime silicate). Additionally, more failure initiation sites were visible on the tin side than the air side for an equivalent impact pressure. This is consistent with there being a greater size and concentration of surface-located flaws on the tin side than the air side. An artifact of the damage initiation starting at lower impact pressures on the tin side is the conical and secondary cracking spreads out at shallow depths than on the air side for an equivalent impact pressure. 
- Glass ceramic damaged differently. The amount of microcracking within the $5 \mathrm{~mm}$ diameter impact of the ROBAX glass ceramic was more extensive (finer sized) than the glasses. This could be a consequence of potential differences in surface flaw populations among between them.

- Interior damage zone. A subsurface damage zone sometimes formed in the (thick) Starphire and BOROFLOAT glasses whose formation was not influenced by surfacelocated flaws and any crack propagation associated with that impact side damage. The interior damage zone tended to form with higher impact stresses. It was not observed in the iron-containing soda lime silicate; however, that could be a consequence of that material not being tested to as high an impact stress as the Starphire and BOROFLOAT were. The interior damage zone was co-present with impact-initiated surface damage in almost all tests; however, failure analysis indicates this subsurface damage zone perhaps formed first, and then the crack propagation from the impact-side surface damage intersected it or was perturbed by its already-existing presence. The fact that the speed of the p-wave (compressive wave) is more than 3 times faster than the estimated terminal crack propagation speed in these materials is consistent with this interior damage zone forming first. In one test case (BOROFLOAT and 5. $1 \mathrm{GPa}$ ), this subsurface damage zone formed in the absence of impact-side surface damage supporting the assertion the damage type is completely independent of impact-side surface damage. This internal damage zone was not evident in any of the laser shock tests in the glass ceramic material.

- Minimum tile thickness. If available, then a larger tile thickness of a test material is desired to avoid tile fracture. A suggested thickness of $8-9 \mathrm{~mm}$ or greater is recommended for laser shock testing. A fractured tile is a "specimen size effect" and may inhibit the ability to examine bulk damage that may otherwise be observed in a thicker tile of the same material. 


\section{REFERENCES}

[1] R. B. Sosman, The Phases of Silica, Rutgers University Press, New Brunswick, NJ, 1965.

[2] R. B. Sosman, "New and Old Phases of Silica," Transactions of the British Ceramic Society," 54:655-670 (1977).

[3] P. W. Bridgman, "The Compression of 39 Substances to $100,000 \mathrm{~kg} / \mathrm{cm}^{2}$," Proceedings of the American Academy of Arts and Sciences, 76:55-70 (1948).

[4] P. W. Bridgman and I. Simon, "Effects of Very High Pressure on Glass," Journal of Applied Physics, 24:405-413 (1953).

[5] R. Roy and H. M. Cohen, "Effects of High Pressure on Glass: a Possible Piezometer for the 100-Kilobar Region," Nature, 190:798-799 (1961).

[6] S. Sakka and J. D. Mackenzie, "High Pressure Effects on Glass," Journal of NonCrystalline Solids, 1:107-142 (1969).

[7] D. R. Uhlmann, "Densification of Alkali Silicate Glasses at High Pressure," Journal of Non-Crystalline Solids, 13:89-99 (1973/74).

[8] R. B. Heimann, "High-Temperature and High-Pressure Polymorphs of Silica: A Review," Materials Science and Engineering, 9:57-67 (1977).

[9] S. Susman, K. J. Volin, D. L. Price, M. Grimsditch, J. P. Rino, R. K. Kalia, P. Vashishta, G. Gwanmesia, Y. Wang, and R. C. Liebermann, "Intermediate-range order in permanently densified vitreous $\mathrm{SiO} 2$ : a neutron-diffraction and molecular-dynamics study," Physical Review B, 43:1194-97 (1991).

[10] T. Rouxel, H. Ji, T. Hammouda, and A. Moreac, "Poisson's Ratio and the Densification of Glass under High Pressure," Physical Review Letters, 100:225501 (2008).

[11] M. Takata, M. Tomozawa, and E. B. Watson, "Effect of Water Content on Mechanical Properties of $\mathrm{Na}_{2} \mathrm{O}-\mathrm{SiO}_{2}$ Glasses, Journal of the American Ceramic Society, 65:C156C157 (1982).

[12] T. J. Holmquist and G. R. Johnson, "Model for Glass Subjected to Large Strains, High Strain Rates, and High Pressures," Journal of Applied Mechanics, 78:051003 (2011).

[13] K. L. Johnson, Contact Mechanics, Cambridge University Press, Cambridge, 1985. 
[14] A. A. Wereszczak, R. H. Kraft, and J. J. Swab, "Flexural and Torsional Resonances of Ceramic Tiles via Impulse Excitation of Vibration," Ceramic Engineering and Science Proceedings, 24:207-13 (2003).

[15] A. A. Wereszczak, "Elastic Property Determination of WC Spheres and Estimation of Compressive Loads and Impact Velocities That Initiate Their Yielding and Cracking," Ceramic Engineering and Science Proceedings, [7], 27:211-223 (2006).

[16] L. M. Barker and R. E. Hollenbach, "Shock-Wave Studies of PMMA, Fused Silica, and Sapphire," Journal of Applied Physics, 41:4208-4226 (1970).

[17] C. S. Alexander, L. C. Chhabildas, W. D. Reinhart, and D. W. Templeton, "Changes to the Shock Response of Fused Quartz Due to Glass Modification," International Journal of Impact Engineering, 35:1376-1385 (2008).

[18] N. Bourne, J. Millett, Z. Rosenberg, and N. Murray, "On the Shock Induced Failure of Brittle Solids," Journal of the Mechanics and Physics of Solids, 46:1887-1908 (1998).

[19] W. A. Bassett, "Diamond Anvil Cell, 50th Birthday," High Pressure Research, 29:163186 (2009).

[20] T. J. Holmquist and A. A. Wereszczak, "Laser Induced Spall in Silicon Carbide," $23^{\text {rd }}$ International Symposium on Ballistics, Tarragona, Spain, 16-20 April, 2007.

[21] G. D. Quinn, "Fractography of Ceramics and Glasses," NIST Special Publication 960-16, 2006, US Government Printing Office, Washington, DC.

[22] A. A. Wereszczak, E. E. Fox, T. G. Morrissey, and D. J. Vuono, "Low Velocity Sphere Impact of a Soda Lime Silicate Glass," ORNL/TM-2011/259, October, 2011.

[23] T. G. Morrissey, M. K. Ferber, A. A. Wereszczak, and E. E. Fox, "Low Velocity Sphere Impact of a Borosilicate Glass," ORNL/TM-2012/60, May 2012.

[24] A. A. Wereszczak, E. E. Fox, T. G. Morrissey, and D. J. Vuono, "Initial Examination of Low Velocity Sphere Impact of Glass Ceramics,” ORNL/TM-2012/139, June, 2012. 


\section{ACKNOWLEDGEMENTS}

Research performed under Work For Others funded by U.S. Army Tank-Automotive Research, Development and Engineering Center, under contract DE-AC-00OR22725 with UT-Battelle, LLC.

The authors express sincere appreciation to A. Dolan of the U.S. Army Research, Development and Engineering Command - Tank-Automotive and Armaments Command for sponsoring this work, ORNL's J. Hemrick and R. Wiles for their review of this report and T. Holmquist for their helpful comments.

This submission was produced by a contractor of the United States Government under contract DE-AC05-00OR22725 with the United States Department of Energy. The United States Government retains, and the publisher, by accepting this submission for publication, acknowledges that the United States Government retains, a nonexclusive, paid-up, irrevocable, worldwide license to publish or reproduce the published form of this submission, or allow others to do so, for United States Government purposes. 


\section{APPENDIX I: List of Spherical Indentation Results}

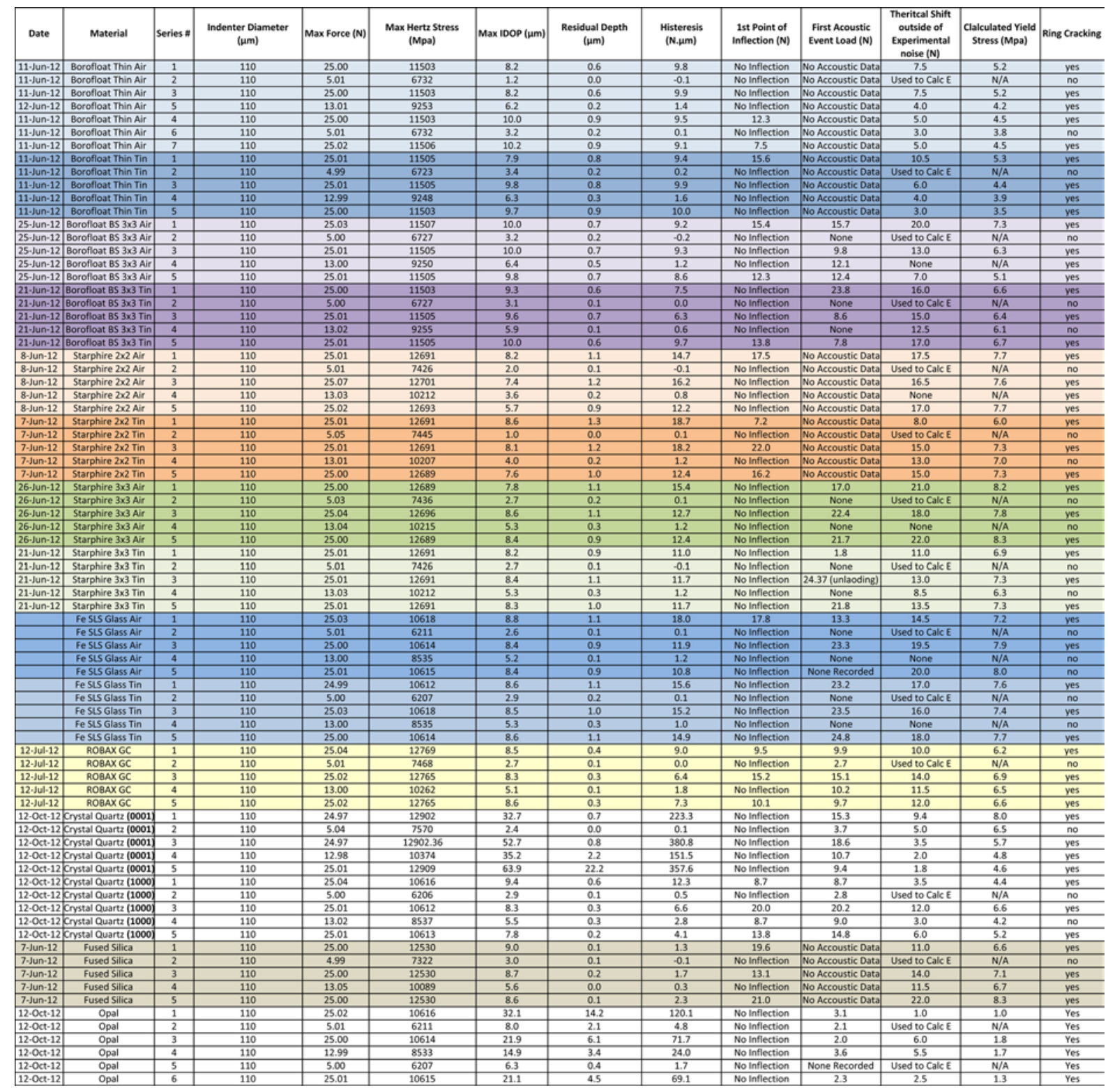




\section{APPENDIX II: List of Laser Shock Results}

Fused Silica or Fused Quartz Glass

\begin{tabular}{|c|c|c|c|c|c|c|c|c|c|c|c|c|}
\hline & & & & & & & & & & \multirow{4}{*}{$\begin{array}{c}\text { Visible } \\
\text { Contact Side } \\
\text { Damage? }\end{array}$} & \multirow{4}{*}{$\begin{array}{c}\text { Visible } \\
\text { Spall or Back Side } \\
\text { Damage? }\end{array}$} & \multirow[b]{3}{*}{ Comments } \\
\hline \multirow[b]{3}{*}{ Row } & \multirow[b]{3}{*}{ Sample No } & \multirow[b]{3}{*}{ Material } & \multirow[b]{3}{*}{ ORNL ID } & \multirow[b]{3}{*}{ Shot \# } & & \multirow{3}{*}{$\begin{array}{l}\text { Pulse Width } \\
\text { (ns) }\end{array}$} & \multirow{3}{*}{$\begin{array}{l}\text { hSpot Diameter } \\
(\mathrm{mm})\end{array}$} & \multirow{3}{*}{$\begin{array}{c}\text { Power Density } \\
\mathrm{GW} / \mathrm{cm}^{\wedge} \mathbf{2} \\
\end{array}$} & \multirow{3}{*}{$\begin{array}{c}\text { Pressure } \\
\text { GPa }\end{array}$} & & & \\
\hline & & & & & Energy & & & & & & & \\
\hline & & & & & (J) & & & & & & & \\
\hline 1 & $212304-1$ & Fused Silica & $6 \times 6 \times 0.25 "$ thk & 1 & 20.1 & 25.4 & 5.0 & 4.030 & 5.094 & $Y$ & $Y$ & \\
\hline 1 & $212304-1$ & Fused Silica & $6 \times 6 \times 0.25 "$ thk & 2 & 20.2 & 20.4 & 5.0 & 5.043 & 5.736 & $Y$ & $\mathrm{Y}$ & \\
\hline 1 & $212304-1$ & Fused Silica & $6 \times 6 \times 0.25^{\prime \prime}$ thk & 3 & 19.9 & 20.5 & 5.0 & 4.944 & 5.676 & $Y$ & $Y$ & \\
\hline 1 & $212304-1$ & Fused Silica & $6 \times 6 \times 0.25^{\prime \prime}$ thk & 4 & 20.1 & 20.0 & 5.0 & 5.118 & 5.781 & $Y$ & $Y$ & \\
\hline 1 & $212304-1$ & Fused Silica & $6 \times 6 \times 0.25^{\prime \prime}$ thk & 5 & 20.2 & 19.6 & 5.0 & 5.249 & 5.859 & $Y$ & $Y$ & \\
\hline 1 & $212304-1$ & Fused Silica & $6 \times 6 \times 0.25$ "thk & 6 & 20.6 & 20.0 & 5.0 & 5.246 & 5.857 & $Y$ & $Y$ & \\
\hline 1 & 212 304-2 & Fused Silica & $6 \times 6 \times 0.25^{\prime \prime}$ thk & 1 & 5.2 & 21.6 & 5.0 & 1.226 & 2.713 & $Y$ & $Y$ & \\
\hline 1 & $212304-2$ & Fused Silica & $6 \times 6 \times 0.25^{\prime \prime}$ thk & 2 & 4.1 & 22.0 & 5.0 & 0.949 & 2.369 & $\mathrm{Y}$ & $\mathrm{N}$ & \\
\hline 1 & $212304-2$ & Fused Silica & $6 \times 6 \times 0.25^{\prime \prime}$ thk & 3 & 3.2 & 20.4 & 5.0 & 0.794 & 2.155 & $Y$ & $Y$ & \\
\hline 1 & $212304-2$ & Fused Silica & $6 \times 6 \times 0.25^{\prime \prime}$ thk & 4 & 2.7 & 22.8 & 5.0 & 0.596 & 1.853 & $\mathrm{Y}$ & $\mathrm{N}$ & \\
\hline 1 & $212304-2$ & Fused Silica & $6 \times 6 \times 0.25 "$ thk & 5 & 1.4 & 21.6 & 5.0 & 0.323 & 1.339 & $Y(v s)$ & $\mathrm{N}$ & \\
\hline 2 & $212304-2$ & Fused Silica & $6 \times 6 \times 0.25 "$ thk & 1 & 1.3 & 22.4 & 5.0 & 0.286 & 1.257 & $Y(v s)$ & $\mathrm{N}$ & \\
\hline 2 & $212304-2$ & Fused Silica & $6 \times 6 \times 0.25^{\prime \prime}$ thk & 2 & 1.3 & 22.8 & 5.0 & 0.284 & 1.250 & $Y(v s)$ & $\mathrm{N}$ & \\
\hline 2 & $212304-2$ & Fused Silica & $6 \times 6 \times 0.25^{\prime \prime}$ thk & 3 & 2.6 & 21.2 & 5.0 & 0.629 & 1.906 & $Y$ & $\mathrm{Y}$ & \\
\hline 2 & $212304-2$ & Fused Silica & $6 \times 6 \times 0.25^{\prime \prime}$ thk & 4 & 2.7 & 22.4 & 5.0 & 0.612 & 1.877 & $Y$ & $Y$ & \\
\hline 1 & $212304-3$ & Fused Silica & $6 \times 6 \times 0.25^{\prime \prime}$ thk & 1 & 3.5 & 21.6 & 5.0 & 0.825 & 2.200 & $Y$ & $Y$ & \\
\hline 1 & $212304-3$ & Fused Silica & $6 \times 6 \times 0.25^{\prime \prime}$ thk & 2 & 0.9 & 22.4 & 5.0 & 0.205 & 1.052 & $\mathrm{~N}$ & $\mathrm{~N}$ & \\
\hline 1 & $212304-3$ & Fused Silica & $6 \times 6 \times 0.25 "$ thk & 3 & 0.9 & 22.8 & 5.0 & 0.201 & 1.042 & $\mathrm{~N}$ & $\mathrm{~N}$ & \\
\hline 1 & $212304-3$ & Fused Silica & $6 \times 6 \times 0.25 \mathrm{In}$ thk & 4 & 1.3 & 19.6 & 5.0 & 0.330 & 1.354 & N & $\mathrm{N}$ & \\
\hline 3 & $212304-3$ & Fused Silica & $6 \times 6 \times 0.25 "$ thk & 1 & 1.2 & 20.4 & 5.0 & 0.287 & 1.258 & $\mathrm{~N}$ & $\mathrm{~N}$ & \\
\hline 3 & $212304-3$ & Fused Silica & $6 \times 6 \times 0.25^{\prime \prime}$ thk & 2 & 2.0 & 21.6 & 5.0 & 0.460 & 1.614 & $Y$ & $Y$ & \\
\hline 3 & $212304-3$ & Fused Silica & $6 \times 6 \times 0.25^{\prime \prime}$ thk & 3 & 1.9 & 21.6 & 5.0 & 0.446 & 1.588 & $Y$ & $Y$ & \\
\hline 3 & $212304-3$ & Fused Silica & $6 \times 6 \times 0.25 "$ thk & 4 & 1.6 & 22.0 & 5.0 & 0.359 & 1.416 & $\mathrm{~N}$ & Y & Possible internal c \\
\hline
\end{tabular}

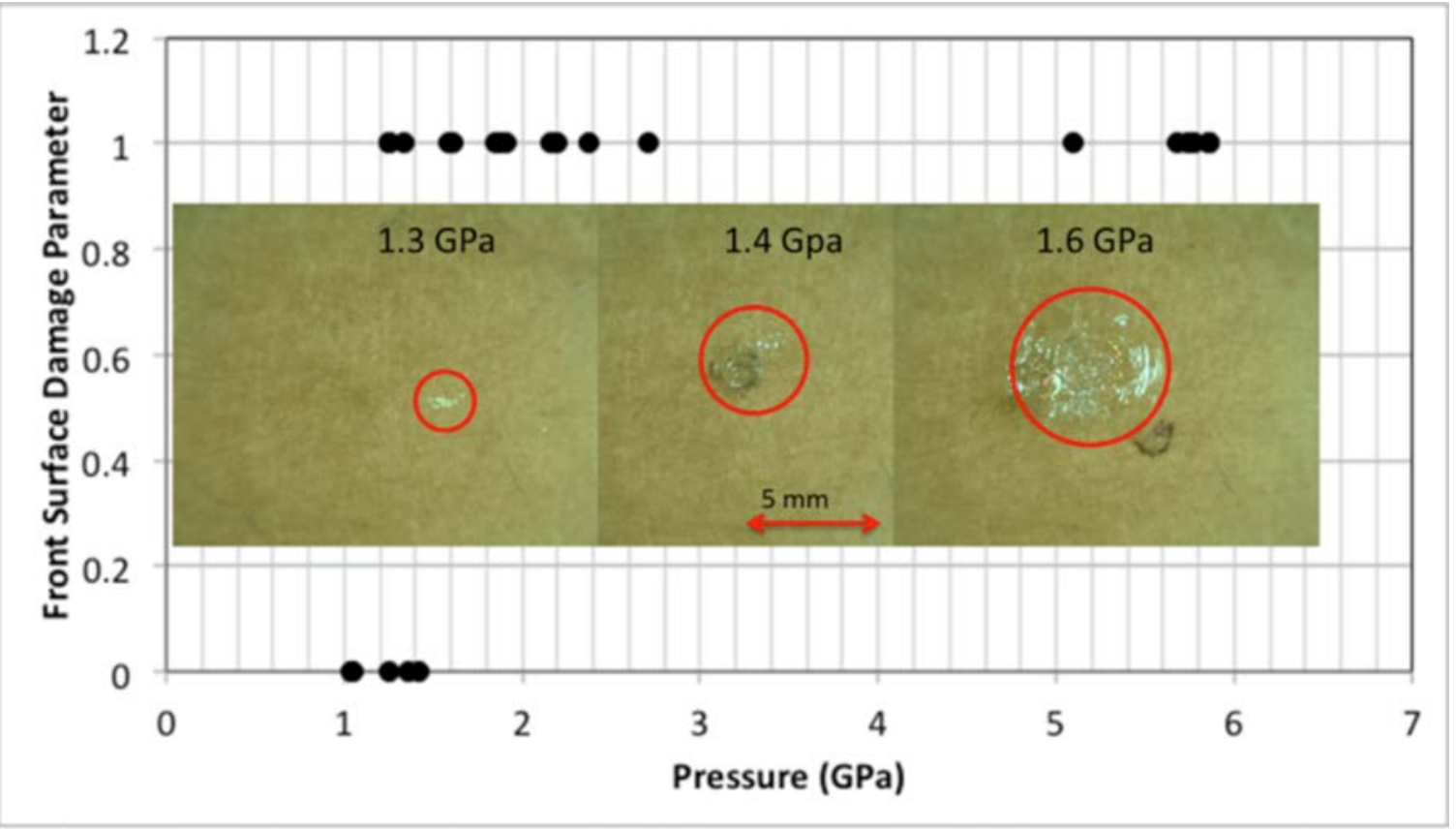


Starphire Soda Lime Silicate Glass Air Side
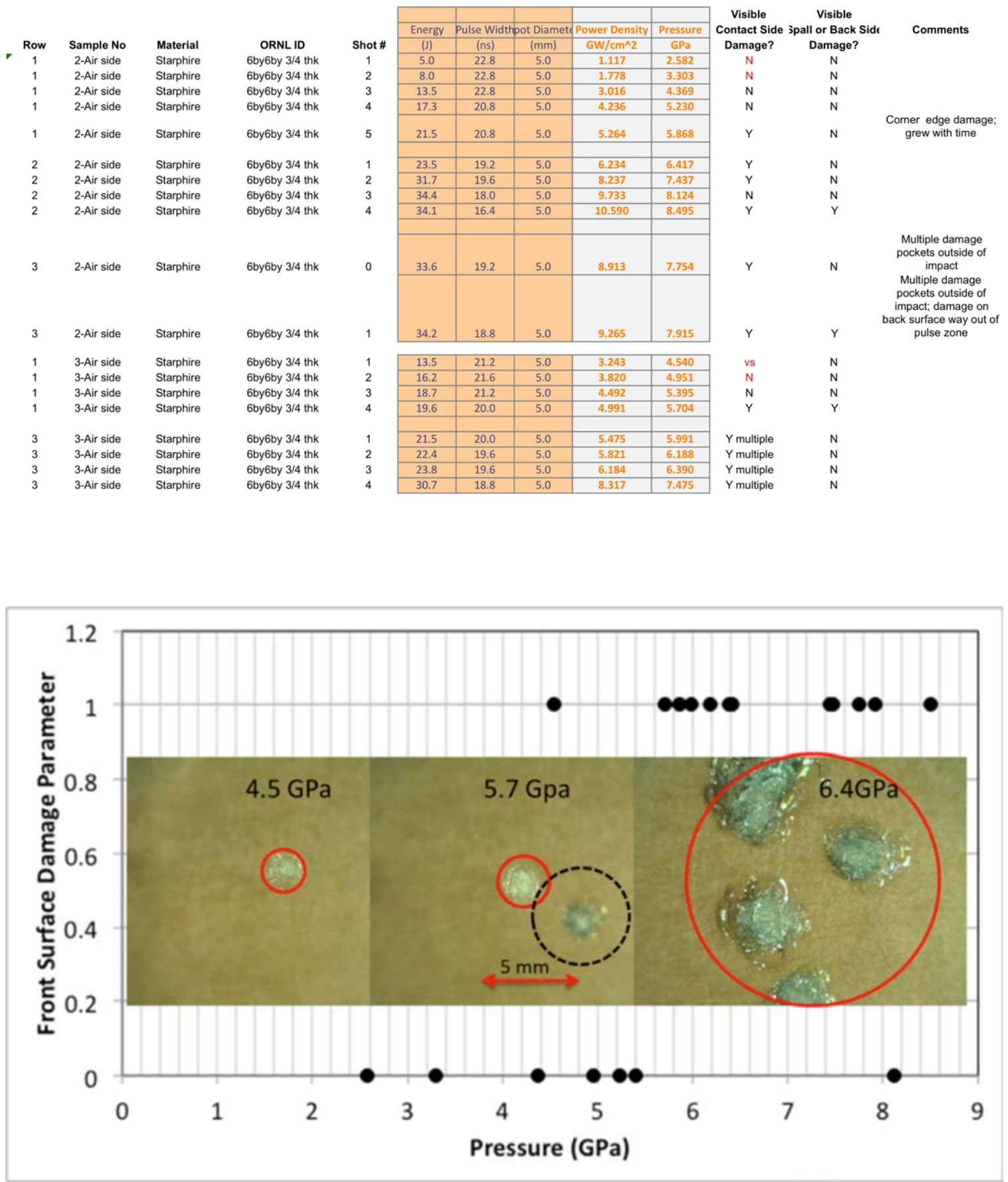
Starphire Soda Lime Silicate Glass Tin Side

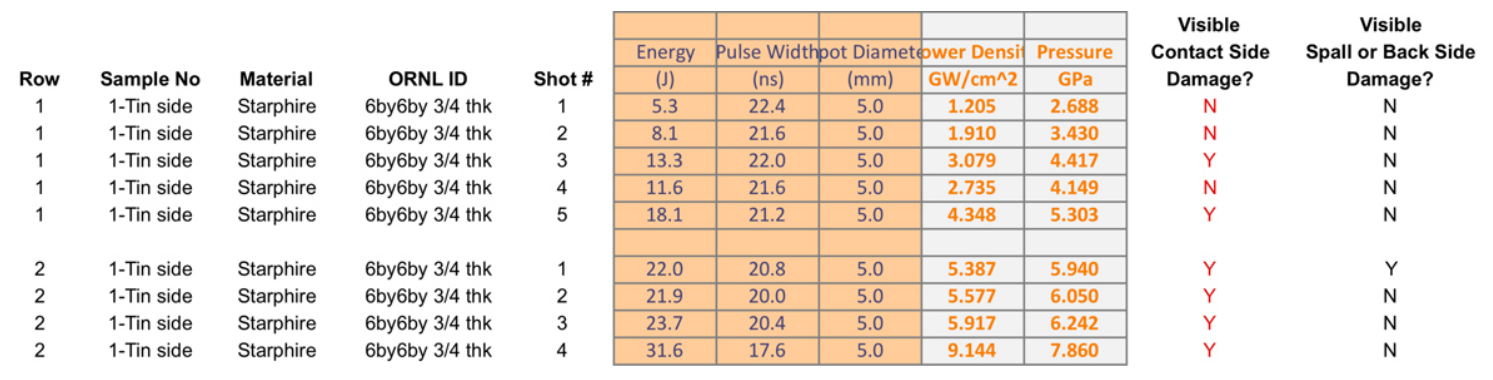

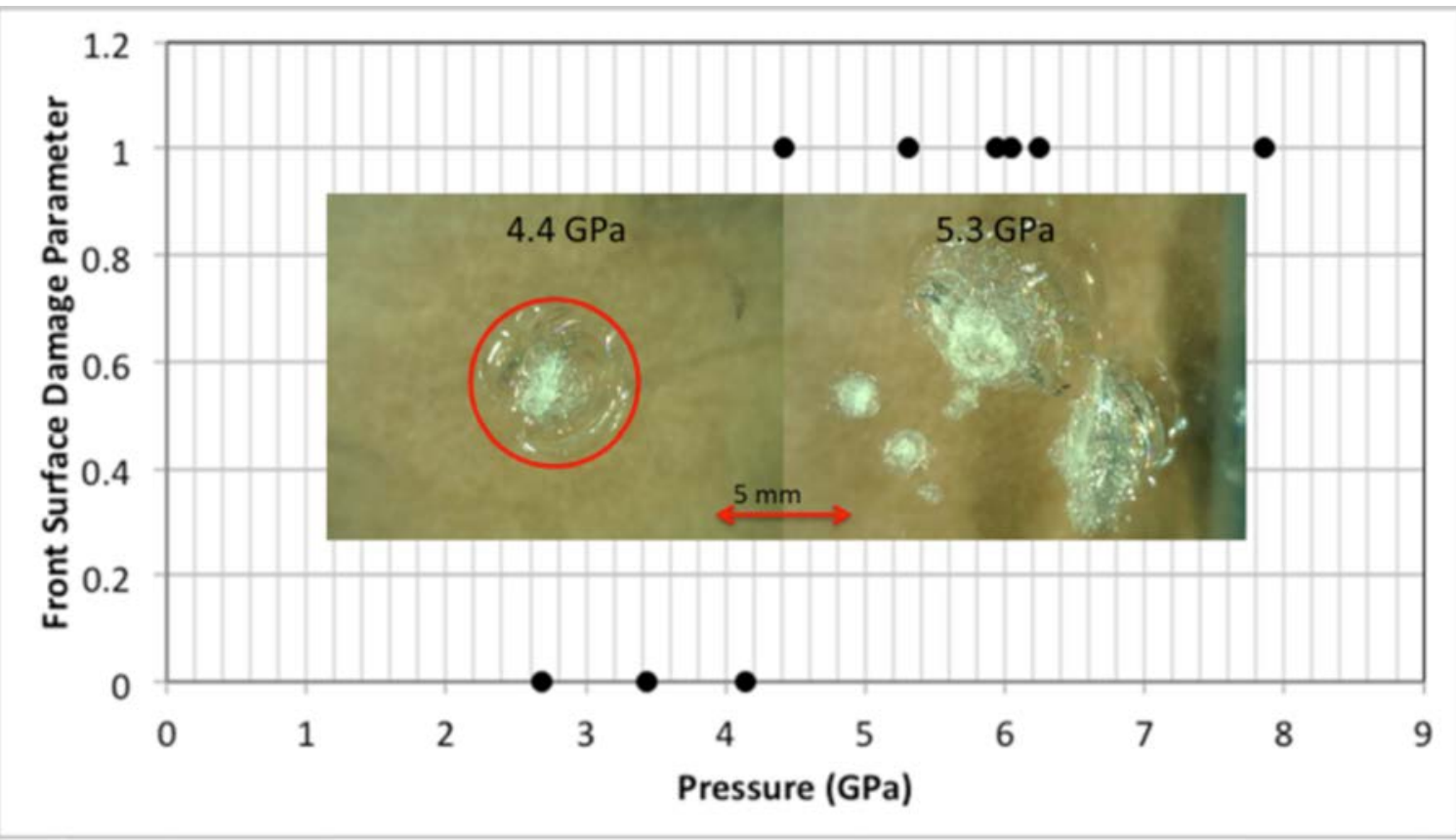


Borofloat Borosilicate Glass Air Side

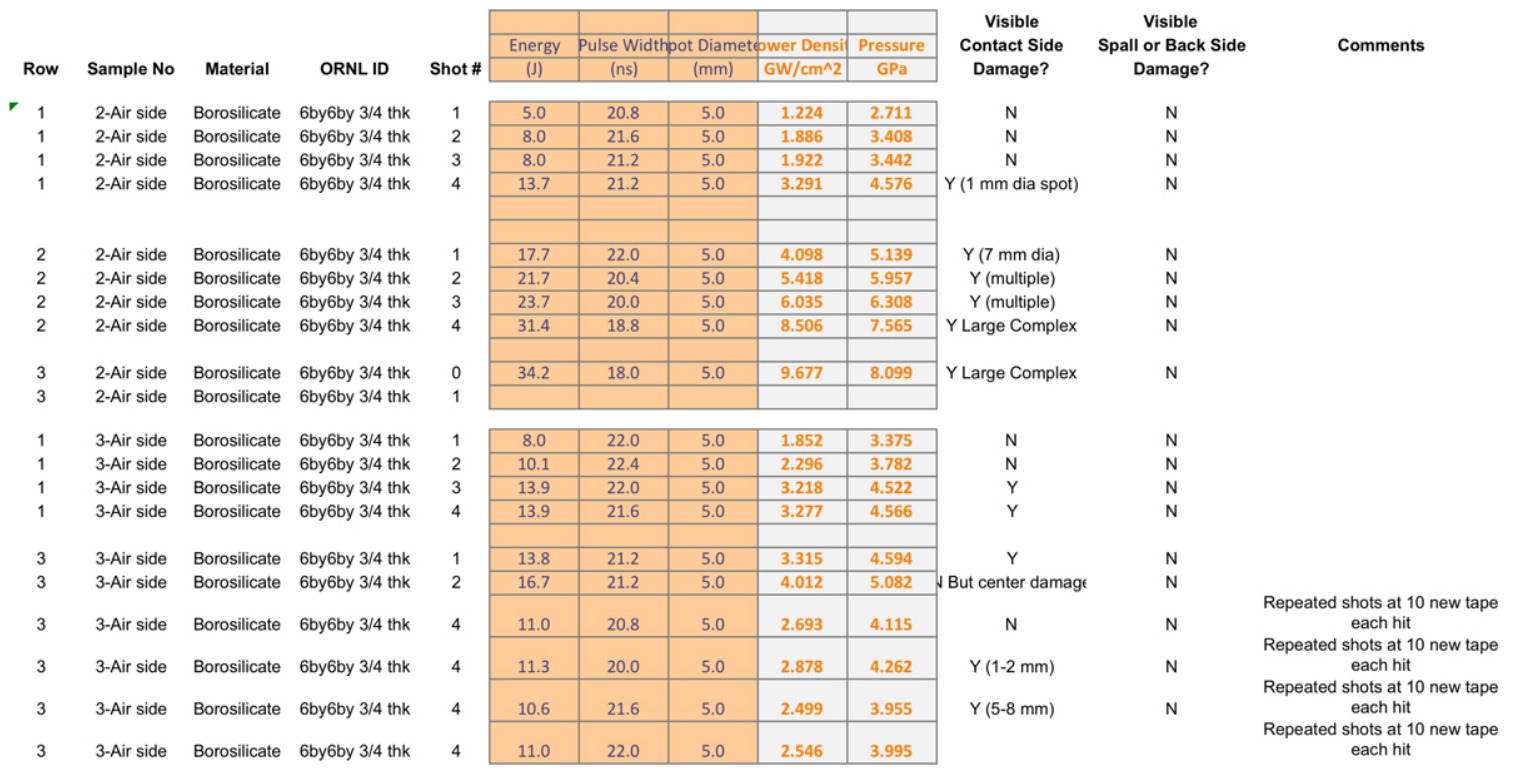

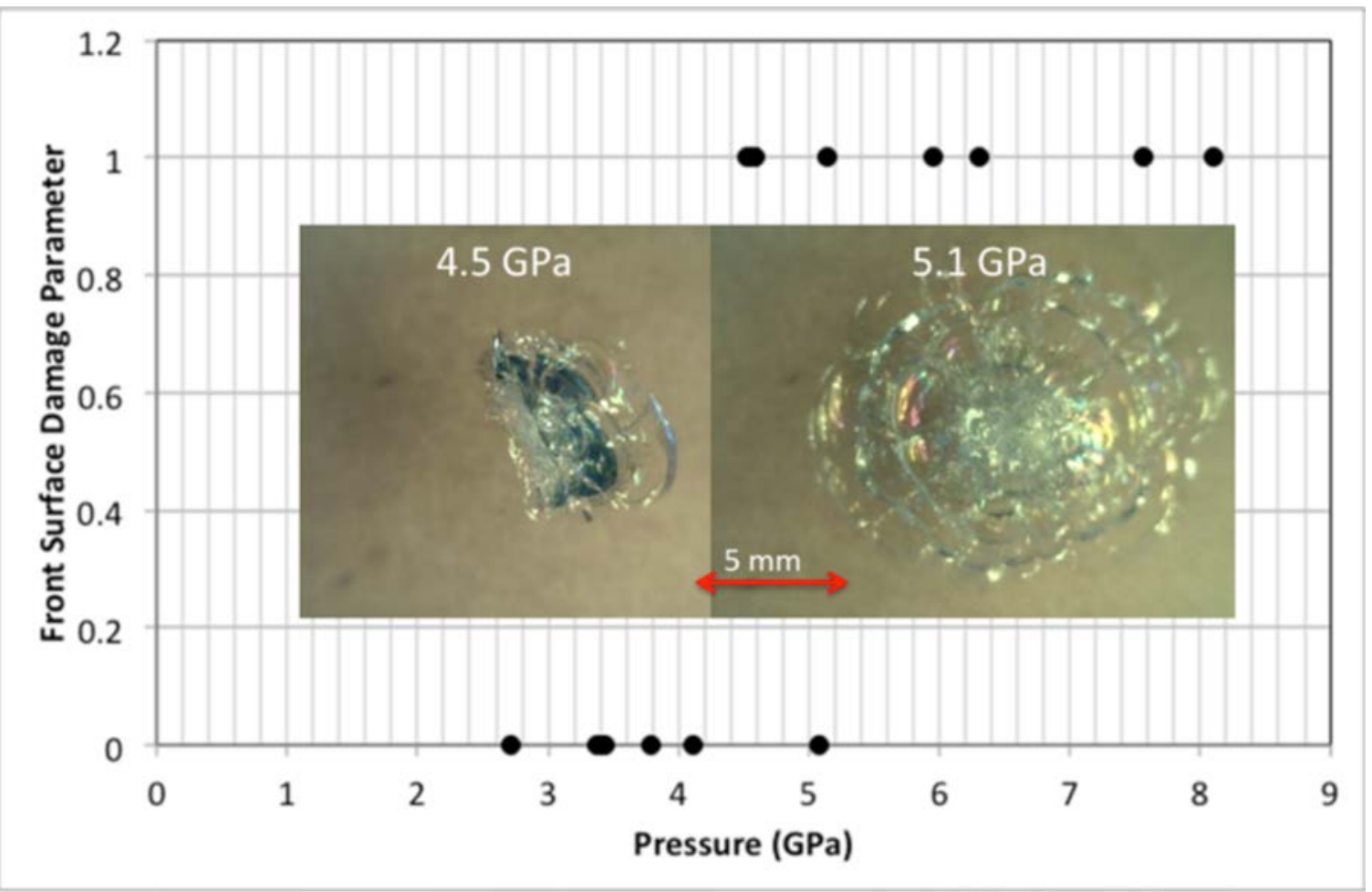


Borofloat Borosilicate Glass Tin Side
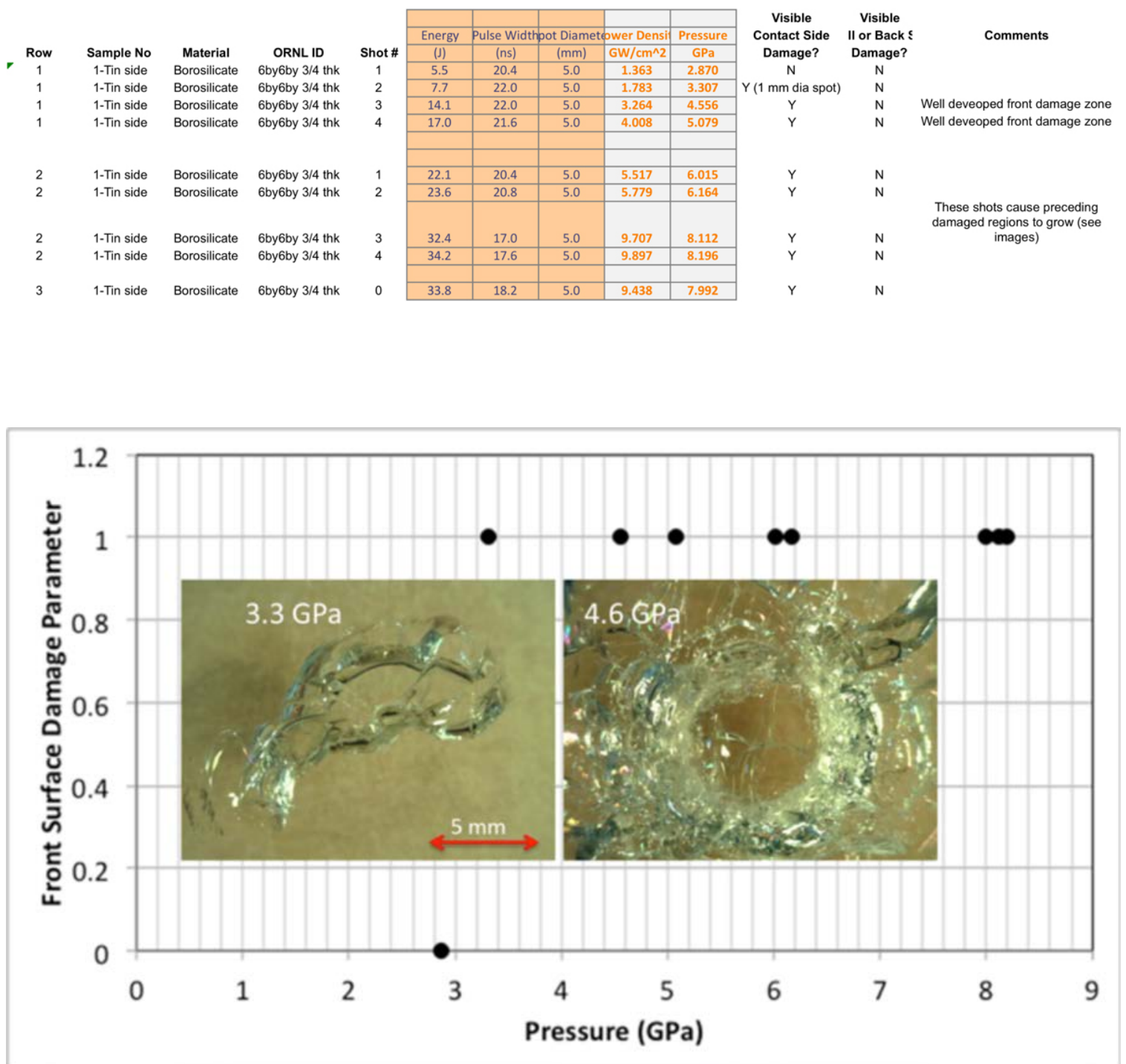
Fe-Containing Soda Lime Silicate Glass Air Side

\begin{tabular}{|c|c|c|c|c|c|c|c|c|c|c|c|}
\hline & & & & & & & & \multirow{3}{*}{$\begin{array}{c}\text { Visible } \\
\text { Contact Side } \\
\text { Damage? }\end{array}$} & \multirow{3}{*}{$\begin{array}{l}\text { Visible } \\
\text { Il or Back } \text { @Comments } \\
\text { Damage? }\end{array}$} \\
\hline \multirow[b]{2}{*}{ Row } & \multirow[b]{2}{*}{ Sample No } & \multirow[b]{2}{*}{ Material } & \multirow[b]{2}{*}{ ORNL ID } & \multirow[b]{2}{*}{ Shot \# } & Energy & Pulse Width & pot Diamete & ower Densi & Pressure & & \\
\hline & & & & & (J) & (ns) & $(\mathrm{mm})$ & $\mathrm{GW} / \mathrm{cm}^{\wedge} 2$ & $\mathrm{GPa}$ & & \\
\hline 1 & 2 Air Side & Shelf Glass & 6 by 6 by $3 / 4$ thk & 1 & 5.0 & 21.6 & 5.0 & \begin{tabular}{|l|}
1.167 \\
\end{tabular} & 2.643 & $\mathrm{~N}$ & $\mathrm{~N}$ \\
\hline 1 & 2 Air Side & Shelf Glass & 6 by 6 by $3 / 4$ thk & 2 & 7.3 & 22.0 & 5.0 & 1.697 & 3.222 & $\mathrm{~N}$ & $\mathrm{~N}$ \\
\hline 1 & 2 Air Side & Shelf Glass & 6 by 6 by $3 / 4$ thk & 3 & 13.4 & 22.0 & 5.0 & 3.102 & 4.435 & Small spot & $\mathrm{N}$ \\
\hline 1 & 2 Air Side & Shelf Glass & 6 by 6 by $3 / 4$ thk & 4 & 11.2 & 21.6 & 5.0 & 2.641 & 4.072 & $\mathrm{~N}$ & $\mathrm{~N}$ \\
\hline 1 & 2 Air Side & Shelf Glass & 6 by 6 by $3 / 4$ thk & 5 & 11.3 & 21.2 & 5.0 & 2.715 & 4.132 & Small spot & $\mathrm{N}$ \\
\hline 3 & 2 Air Side & Shelf Glass & 6 by 6 by $3 / 4$ thk & 1 & 10.3 & 21.6 & 5.0 & 2.429 & 3.896 & $\mathrm{~N}$ & $\mathrm{~N}$ \\
\hline 3 & 2 Air Side & Shelf Glass & 6 by 6 by $3 / 4$ thk & 2 & 13.6 & 21.6 & 5.0 & 3.207 & 4.513 & $\mathrm{~N}$ & $\mathrm{~N}$ \\
\hline 3 & 2 Air Side & Shelf Glass & 6 by 6 by $3 / 4$ thk & 3 & 13.6 & 21.6 & 5.0 & 3.207 & 4.513 & Y small & $\mathrm{N}$ \\
\hline 3 & 2 Air Side & Shelf Glass & 6 by 6 by $3 / 4$ thk & 4 & 16.4 & 21.2 & 5.0 & 3.940 & 5.033 & $\mathrm{~N}$ & $\mathrm{~N}$ \\
\hline 4 & 2 Air Side & Shelf Glass & 6 by 6 by $3 / 4$ thk & 1 & 17.0 & 21.6 & 5.0 & 4.008 & 5.079 & $\mathrm{~N}$ & $\mathrm{~N}$ \\
\hline 4 & 2 Air Side & Shelf Glass & 6 by 6 by $3 / 4$ thk & 2 & 21.5 & 20.4 & 5.0 & 5.368 & 5.928 & Medium spot & $\mathrm{N}$ \\
\hline 4 & 2 Air Side & Shelf Glass & 6 by 6 by $3 / 4$ thk & 3 & 18.4 & 21.6 & 5.0 & 4.338 & 5.297 & Medium small spot & $\mathrm{N}$ \\
\hline 4 & 2 Air Side & Shelf Glass & 6 by 6 by $3 / 4$ thk & 4 & 18.7 & 20.4 & 5.0 & 4.669 & 5.506 & Medium small spot & $\mathrm{N}$ \\
\hline
\end{tabular}

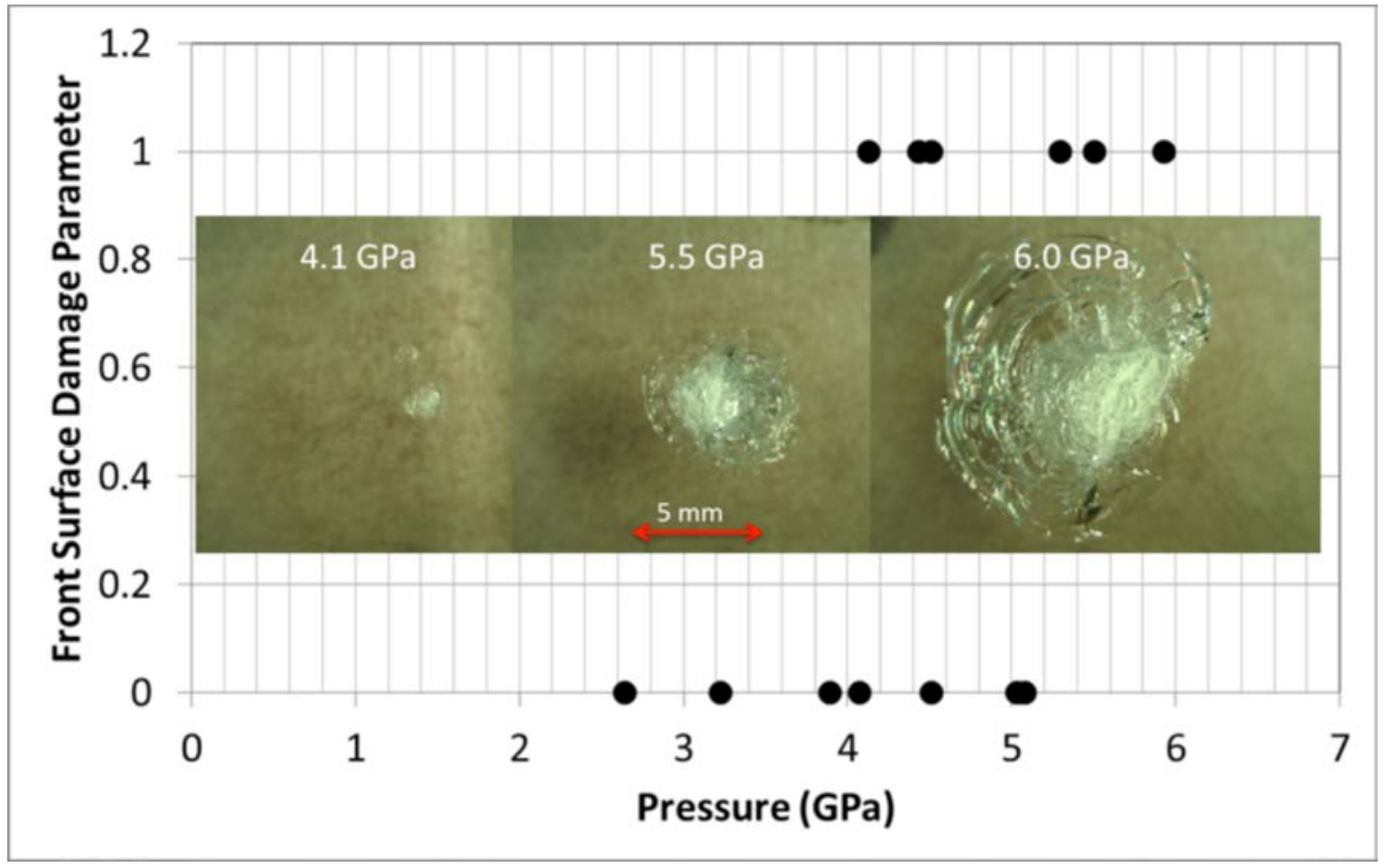


Fe-Containing Soda Lime Silicate Glass Tin Side
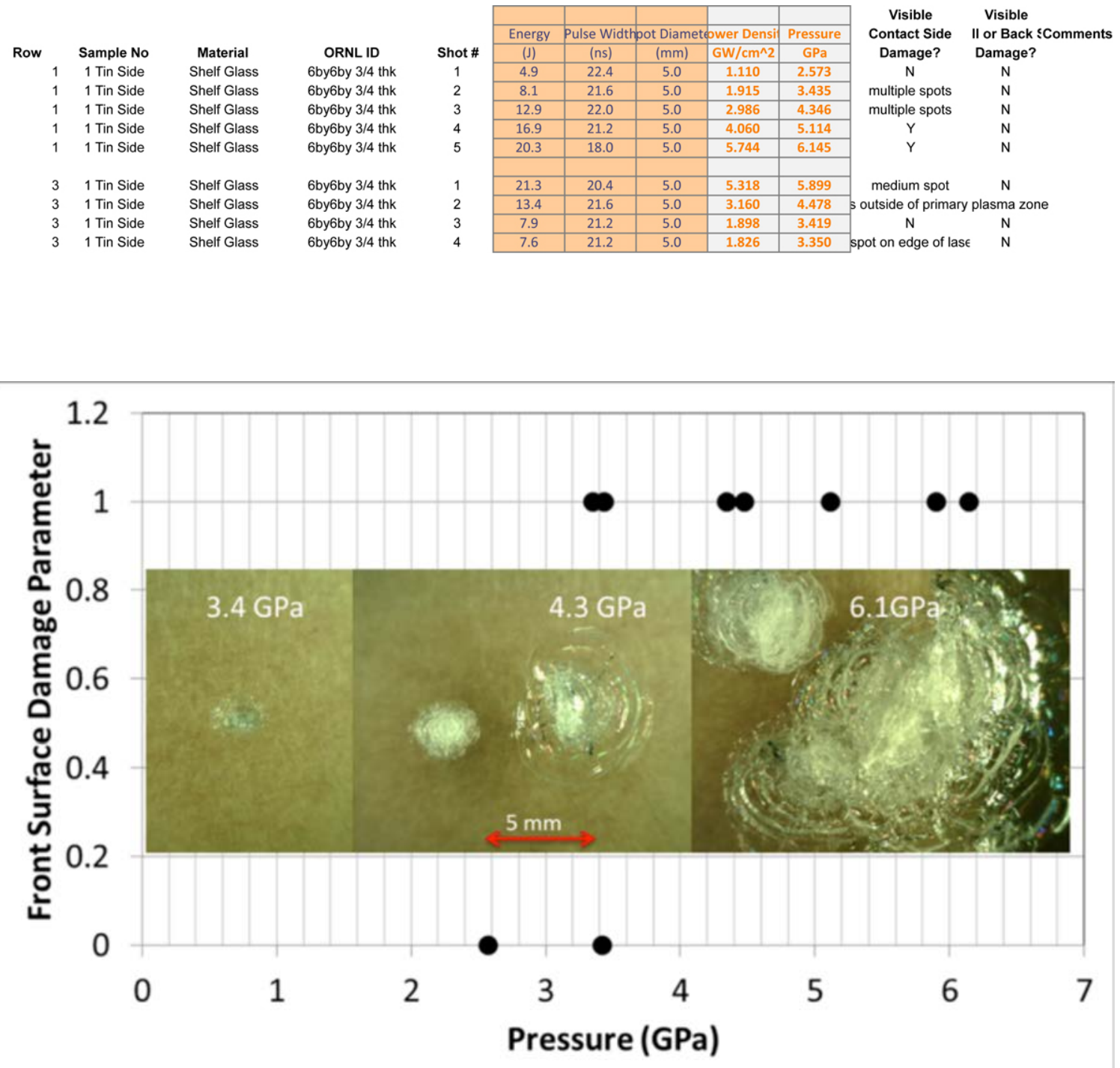
ROBAX Glass Ceramic
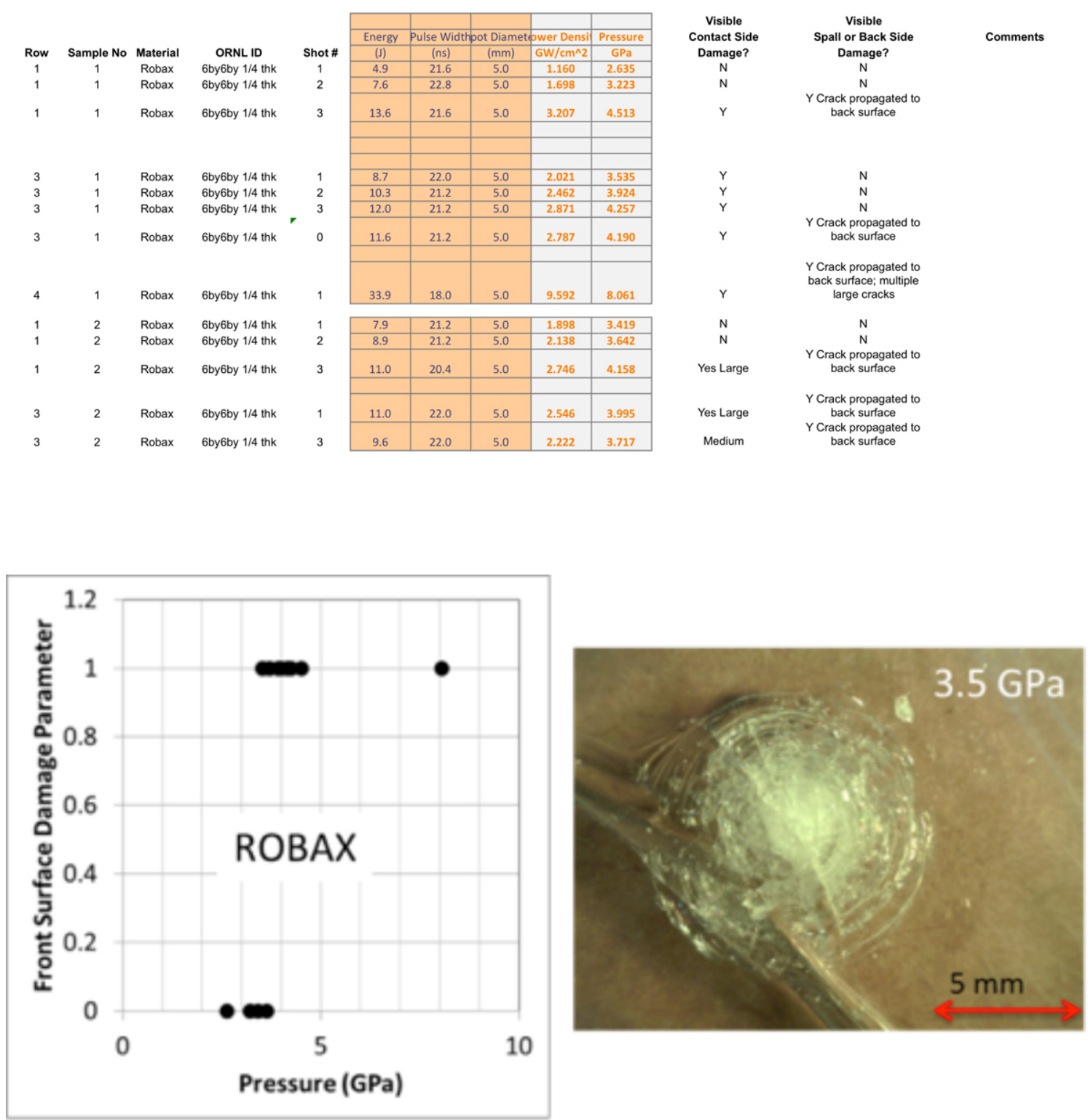